COLORECTAL CANCER IN ULCERATIVE COLITIS

A PROSPECTIVE STUDY OF CLINICAL AND BIOLOGICAL MARKERS IN POPULATION BASED COHORTS

Doctoral thesis by Pasquale Klepp, MD.

Department of Gastroenterology, Lovisenberg Diaconal Hospital, Oslo

And

Institute of Clinical Medicine

Faculty of Medicine

University of Oslo

Oslo, 2021 
(C) Pasquale Klepp, 2021

Series of dissertations submitted to the Faculty of Medicine, University of Oslo

ISBN 978-82-8377-891-5

All rights reserved. No part of this publication may be reproduced or transmitted, in any form or by any means, without permission.

Cover: Hanne Baadsgaard Utigard.

Print production: Reprosentralen, University of Oslo. 
To my dearest Sophie and Philip 


\section{Table of Contents}

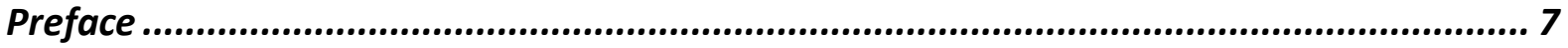

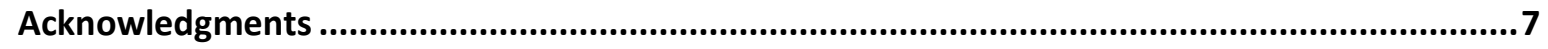

List of articles

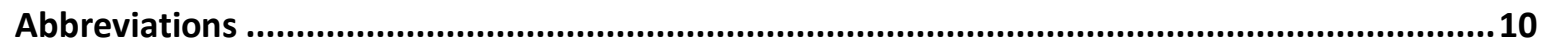

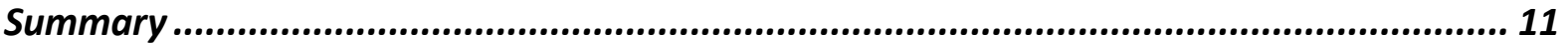

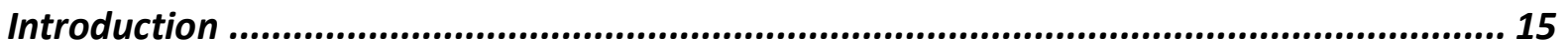

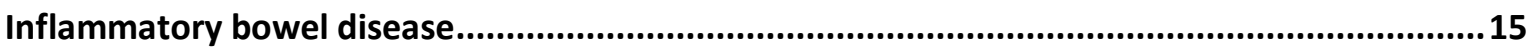

Colorectal Cancer in inflammatory bowel disease .......................................................................16

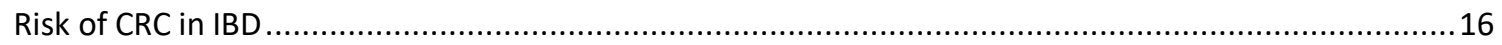

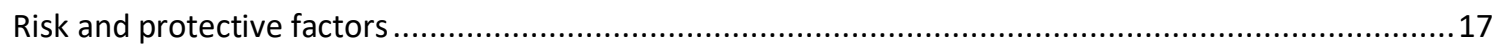

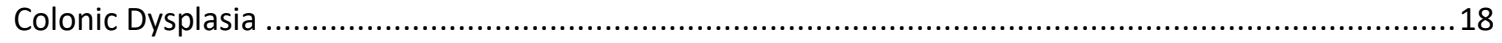

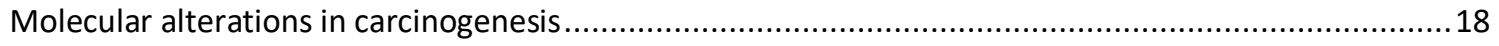

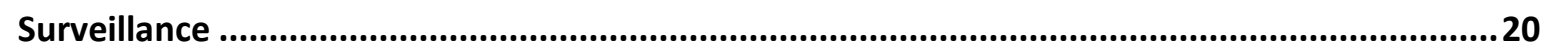

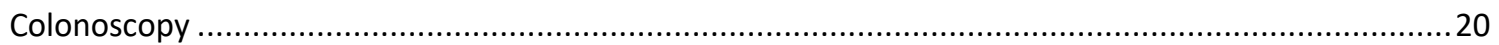

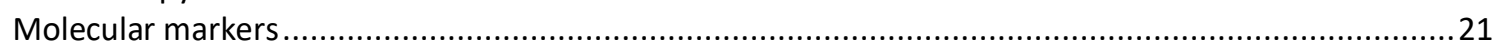

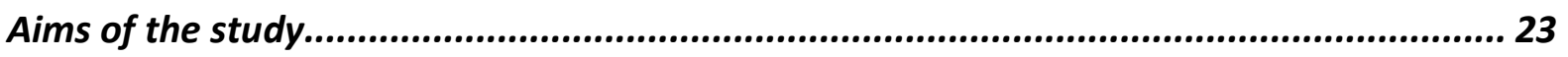

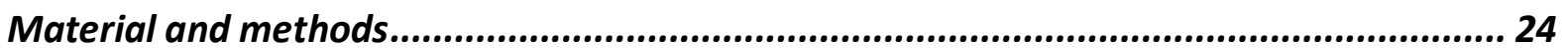

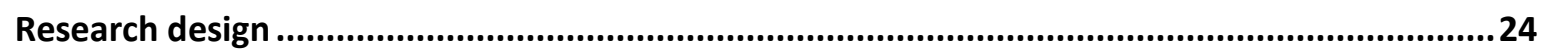

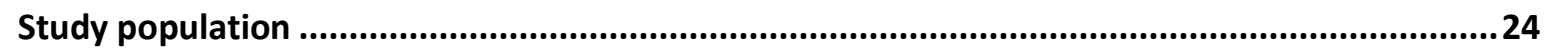

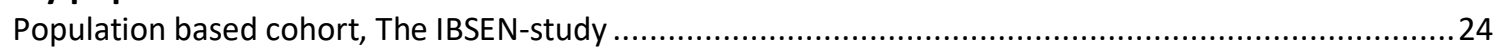

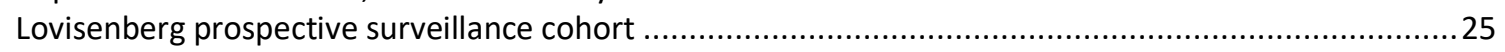

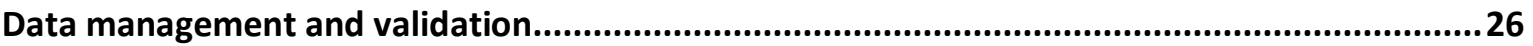

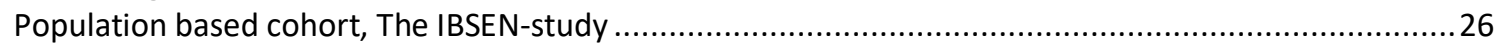

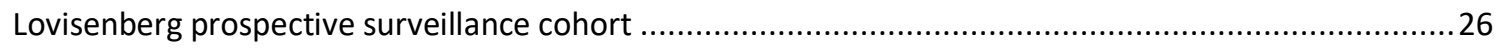

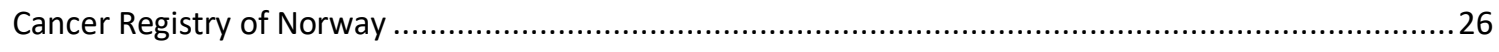

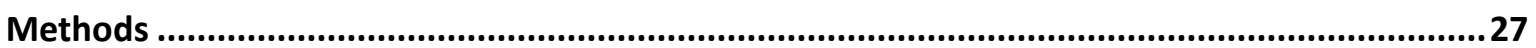

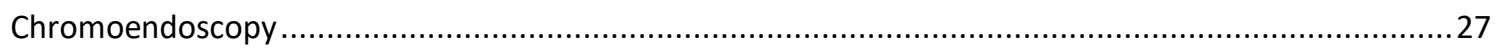

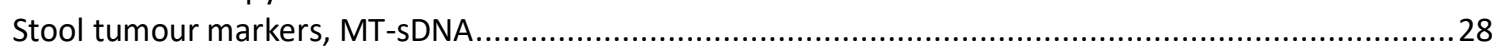

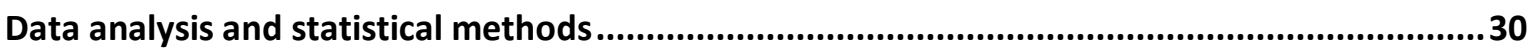

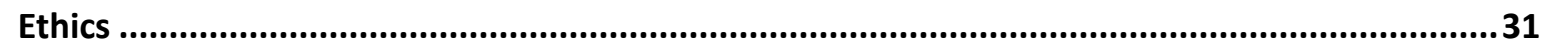

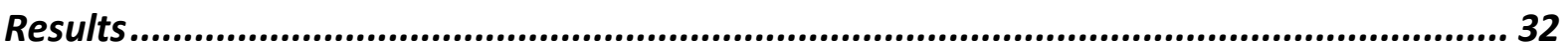

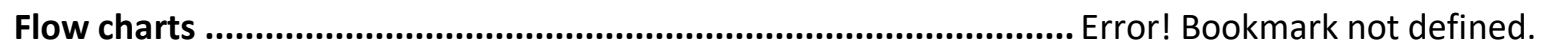

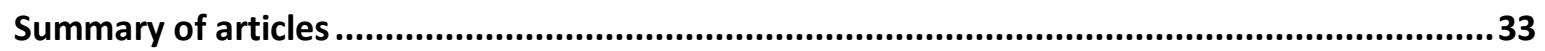

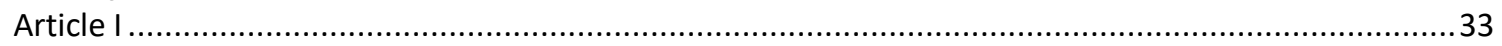

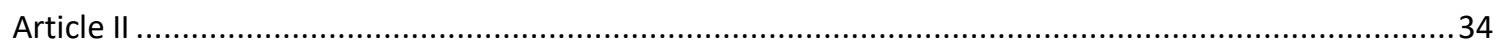

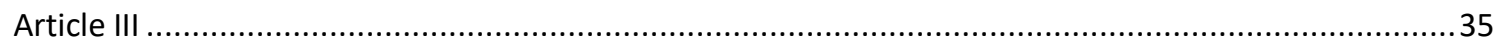

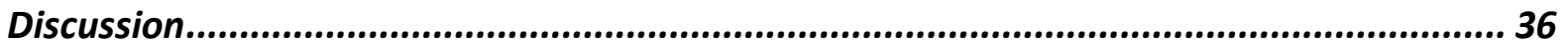




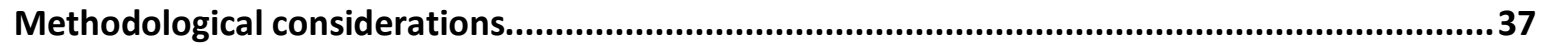

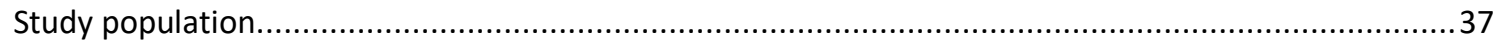

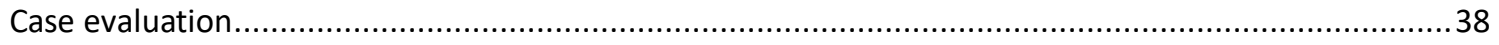

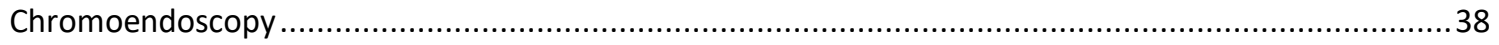

Risk of CRC

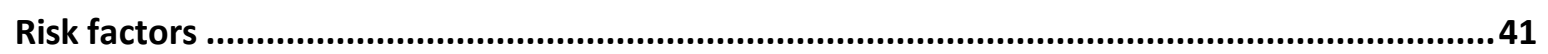

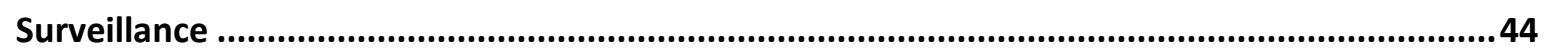

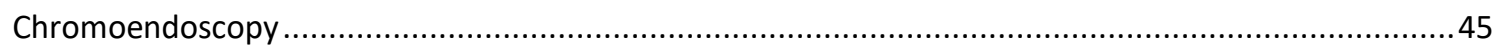

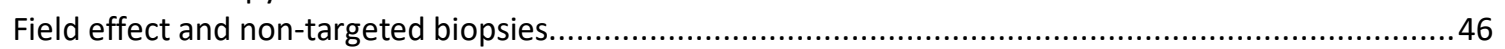

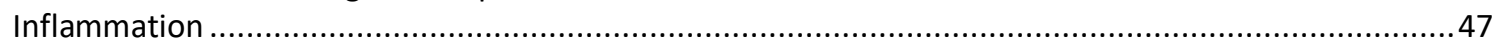

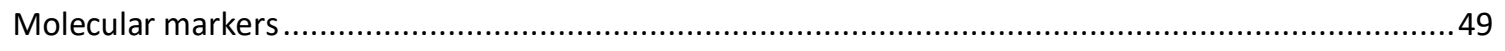

Strengths and limitations of the present study ........................................................... 51

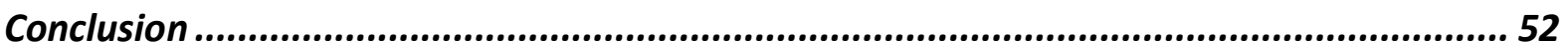

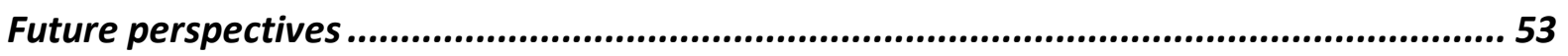

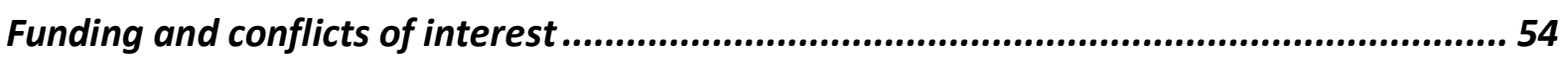

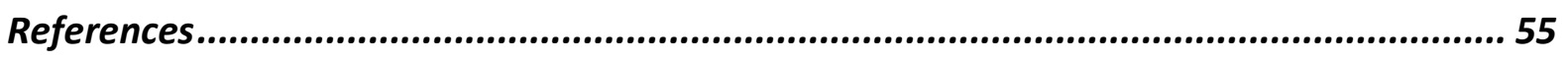

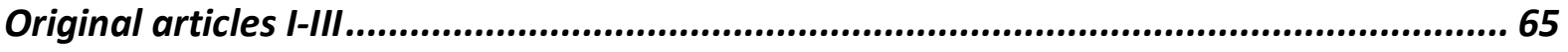




\section{Preface}

\section{Acknowledgments}

First of all, I would like to thank all the patients who willingly participated in this study. The work presented in this thesis was kindly funded by The Lovisenberg Hospital Research Fund, the Unger-Vetlesen Research Institute, The Norwegian Gastroenterology Association's Research Fund and MSD Norway AS.

Special thanks to Dr Bjørn Holm, Mrs Anne Marit Tangen and Dr Hallvard Fanebust for allowing the initiation and completion of this study.

I would like to express my gratitude to my advisors, Ass.Prof Stephan Brackmann, Prof. Bjørn Moum and Prof. Morten Vatn who have willingly helped me throughout the study. Your knowledge has been inspirational and your support invaluable. My gratitude to members of the IBSEN group who have been extremely helpful I also wish to thank the late Prof. Dave Ahlquist and Ass. Prof. John Kisiel at the Mayo Clinic, Rochester. My time at the Molecular Cancer Diagnostics Laboratory in Rochester provided me with hands-on experience with assay of fecal tumour markers. Also, I will always remember Prof. Ahlquist and his wife for their generous hospitability. Dave's advice both scientific and on life in general were highly stimulating.

This study could not have been undertaken without Dr. Viggo Skar, founder of the Unger Vetlesen Research Institute. Dr Arne Røseth's dedication, enthusiasm and adventurous spirit were essential to this project.

I would like to thank the staff at Unger Vetlesen Institute, Dr Jørgen Valeur, Dr Vendel Kristensen, Mrs Ana Urzua, Mrs Anita Tollisen, Mrs Gunn Helen Malmstrøm and Miss Jennifer Fiennes who have provided both research and technical support. Thank you, Prof. Milada Cvancarova, biomedical statistician at the University of Oslo, for your patience, time and sharing of knowledge on statistical analyses and interpretation of results. Your opinions, also philosophical and sense of humour will always be dear to me.

I thank my fellow gastroenterologists and nurses at the section of Gastroenterology at Lovisenberg Hospital previously directed by Dr Finn Strøm and now Dr Hans Lannerstedt. My gratitude to Gjermund for his vital coaching. To my mother, my brother and my very good friends who have encouraged me all along. And finally, dearest Sophie and Philip for all that you are. 


\section{List of articles}

1. Klepp P, Brackmann S, Småstuen MC, Høivik ML, Hovde Ø, Henriksen M, Huppertz-Hauss G, Bernklev T, Høie O, Kempski-Monstad I, Solberg IC, Stray N, Jahnsen J, Vatn MH, Moum BA Risk of colorectal cancer in a population-based study 20 years after diagnosis of ulcerative colitis: results from The IBSEN study. BMJ Open Gastroenterol. 2020 Mar 26;7(1): e000361.

2. Klepp P, Tollisen A, Røseth A, Småstuen MC, Andersen SN, Vatn MH, Moum B, Brackmann S Real-life chromoendoscopy for dysplasia surveillance in ulcerative colitis. World J Gastroenterol. 2018 Sep 21;24(35):4069-4076.

3. Klepp P, Kisiel JB, Småstuen MC, Røseth A, Andersen SN, Vatn MH, Ahlquist DA, Moum BA, Brackmann S. Multi-target stool DNA test in the surveillance of inflammatory bowel disease: a cross-sectional cohort study. Scand J Gastroenterol. 2018 Mar;53(3):273-278. 


\section{Abbreviations}

BMP3 bone morphogenetic protein 3

CA-CRC Colitis associated colorectal cancer

CD Crohn's Disease

CE Chromoendoscopy

CRC Colorectal Cancer

CRN Colorectal neoplasia

FIT fecal immunochemical test

HGD high-grade dysplasia

HR Hazard ratio

IBD Inflammatory Bowel Disease

LGD low-grade dysplasia

MT-sDNA Multitarget stool DNA

$N D R G 4$ N-Myc downstream-regulated gene 4

NPV Negative Predictive Value

PPV Positive Predictive Value

PSC Primary sclerosing cholangitis

UC Ulcerative Colitis

WLE white-light endoscopy 


\section{Summary}

\section{Background}

Although decreasing in incidence, a significant number of IBD patients still develop colitis associated colorectal cancer (CA-CRC). Guidelines, therefore, recommend colonoscopic surveillance at intervals based on a patient's individual risk determined by clinical risk factors. To improve the detection of lesions, high definition (HD) colonoscopy or dyeenhanced colonoscopy, chromoendoscopy (CE) are advised. However, the current risk of CA-CRC in Norway is unknown. Moreover, colonoscopic surveillance is not systematically implemented, and CE is not widely applied for the surveillance of IBD patients in Norway. The purpose of the study was to examine the overall risk of CA-CRC and the association to clinical risk factors in a Norwegian population-based inception cohort of ulcerative colitis (UC) patients. Furthermore, the implementation of CE in everyday practice in a community hospital, and the efficacy of non-invasive multitarget stool DNA tumour markers (MTsDNA), were assessed. Updated knowledge of the risk of CRC in Norwegian UC patients as well as screening methods for CRN, would allow us to further refine neoplasia surveillance in UC.

\section{Methods}

Clinical Risk factors

Clinical risk factors associated with CA-CRC were prospectively evaluated in a populationbased inception cohort of UC patients $(n=517)$ during a prescheduled follow up 20 years after diagnosis of IBD, the IBSEN cohort. The patients were diagnosed with IBD from January 1, 1990, until December 31, 1993, and prospectively followed at one, five, 10 and 20 years after diagnosis.

\section{Chromoendoscopy}

Patients with extensive UC and disease duration of more than 8 years $(n=67)$ were included in a prospective single centre surveillance cohort, the Lovisenberg cohort. Following standard bowel preparation, two expert endoscopists, novice to chromoendoscopy, evaluated each segment of the colon with standard-definition colonoscopes. Targeted biopsies of lesions, as well as non-targeted biopsies for the evaluation of inflammation, were harvested after spray application of indigo carmine. 


\section{Mt-sDNA}

IBD patients $(n=192)$ enrolled from the Lovisenberg cohort and the IBSEN cohort were subjected to either chromo- or white light colonoscopy. EDTA buffered stool samples were assayed for methylated $B M P 3 \& N D R G 4$, mutant $K R A S$ and $\beta$-actin by a laboratory blinded to clinical data.

Results

Risk factors

The overall incidence of CA-CRC was $1.6 \%(8 / 517)$ at 20 years-follow up. The total lifetime risk of CRC prior to or after UC diagnosis was 2.3\%. (12/517). Patients older than 70 at diagnosis had a 15-fold higher risk of CRC compared to those diagnosed when younger than 40 years, Hazard ratio 15.68 (95\% CI 1.31-187.92). Neither sex, first degree relative with CRC, extent of colitis nor primary sclerosing cholangitis affected the risk of CRC.

Chromoendoscopy

The dysplasia detection rate was $10.5 \%$ (7/67 patients). The dysplasia detection yield was $20.8 \%(10 / 48)$ for targeted biopsies and 3.5\% (11/318) for nontargeted biopsies. The sensitivity and specificity for the correct classification of lesions by the endoscopists using chromoendoscopy, were $48 \%$ (95\% confidence interval (CI): $26-70 \%$ ) and 96\% (95\%CI: $93-$ $98 \%)$, respectively. The positive predictive and negative predictive values were $42 \%(95 \% \mathrm{CI}$ : 27-59\%) and 97\% (95\%CI: 95-98\%), respectively.

\section{MT-sDNA}

Sensitivities for the MT-sDNA panel were 100\% (95\% CI 16-100\%) for CRC and 33\% (95\% CI $13-61 \%$ ) for LGD lesions $<1 \mathrm{~cm}$, with specificities of $87 \%$ (95\% CI $81-91 \%$ ) and $93 \%$ (95\% CI 88-96\%), respectively. The estimated number of patients needed to screen to detect a single CRC was 96 (95\% CI 93-99\%) and was 28 (95\% CI 22-34\%) to detect any colorectal neoplasia $(\mathrm{CRN})$.

Conclusion

Although surveillance colonoscopy was not systematically performed, the risk of CA-CRC in $\mathrm{UC}$ was low and comparable to the risk of $\mathrm{CRC}$ in the background population of Norway. Chromoendoscopy appeared to be of value for dysplasia surveillance of UC in a community hospital setting. The yield of non-targeted biopsies was negligible.

The MT-sDNA panel detected CA-CRC. Sensitivity for sub-centimeter colorectal neoplasms in IBD patients, appeared similar to that observed in the non-IBD population. 


\section{Sammendrag}

Bakgrunn

Pasienter med inflammatorisk tarmsykdommer, ulcerøs kolitt og Crohn's sykdom, har økt risiko for å utvikle kolittassossiert kolorektalkreft. Kliniske retningslinjer anbefaler derfor regelmessig koloskopi for å avdekke forstadiene til kolorektalkreft. Lengden på intervallene bestemmes av pasientens individuelle risiko som avhenger av etablerte kliniske faktorer. Gullstandarden for surveillance er koloskopi med høy oppløsning (High Definition) eller med applikasjon av fargestoff (kromoskopi) på slimhinnene. Den aktuelle risikoen for å utvikle kolittassosiert kolorektalkreft i Norge er ukjent. Surveillance med koloskopi utføres ikke systematisk, og kromoskopi er ikke i utstrakt bruk i Norge. I tillegg er kolorektalkreft diagnostisert før neste planlagt koloskopi i inntil $30 \%$ av pasienter med kronisk tarmbetennelse.

Målet med denne studien var å estimere risikoen for kolittassosiert kolorektalkreft og assosiasjonen til kliniske risikofaktorer i en norsk populasjonskohort med ulcerøs kolitt. Videre vurderte vi implementering av kromoskopi i klinisk hverdag på et lokalt sykehus. Til slutt undersøkte vi ikke invasive DNA markører i feces. Oppdatert kunnskap om risikoen for kolittassosiert kolorektalkreft i pasienter med ulcerøs kolitt samt screening metoder vil kunne bidra til å forbedre neoplasisurveillance i denne pasientgruppen.

Metoder

Kliniske risikofaktorer

Kliniske faktorer assosiert med kolittassosiert kolorektalkreft ble undersøkt i en prospektiv populasjon kohort med pasienter med ulcerøs kolitt $(n=517)$, ved planlagt oppfølging 20 år etter ulcerøs kolitt diagnosen, IBSEN kohorten. Pasientene ble diagnostisert med ulcerøs kolitt mellom 1.januar 1990 og 31.desember 1993. De ble fulgt prospektivt 1, 5, 10 og 20 år etter diagnosen.

Kromoskopi

Pasienter med utstrakt ulcerøs kolitt og sykdomsvarighet på mer enn 8 år $(n=67)$ ble inkludert i en prospektiv singelsenter surveillance kohort, Lovisenberg kohorten. Pasientene gjennomgikk standard tarmtømming før koloskopi. Dermed ble kromoskopi utført av to erfarne endoskopører. Det ble tatt både målrettede biopsier av lesjoner samt ikke-målrettede biopsier for undersøkelse av betennelsesgrad etter påføring av indigokarmin med spray. 


\section{Mt-sDNA}

Pasienter med kronisk tarmbetennelse $(n=192)$ fra Lovisenberg kohorten og IBSEN kohorten gjennomgikk enten kromoskopi eller standard kolonoskopi med hvitt lys.

Metylert BMP3 \& NDRG4, mutert KRAS og $\beta$-actin ble analysert i fecesprøver i EDTA buffer. Laboranter var blindet for kliniske data.

Resultater

Risikofaktorer

Den totale insidensen for kolitt-assosiert kolorektalkreft var $1.6 \%(8 / 517)$ etter 20 års oppfølging. Livstidsrisikoen (total life-time risk) for kolorektalkreft før eller etter ulcerøs kolitt diagnosen var 2.3\%. (12/517). Pasienter eldre enn 70 år ved diagnosetidspunktet hadde 15 ganger høyere risiko for kolorektalkreft sammenlignet med pasienter under 40 år, Hazard ratio 15.68 (95\% CI 1.31-187.92). Hverken kjønn, førstegradsslektning med kolorektalkreft, omfanget av kolitt, eller primær skleroserende kolangitt påvirket risikoen for kolorektalkreft. Kromoskopi

Deteksjonsraten for dysplasi var $10.5 \%$ (7/67 patients). Utbytte for påvisning av dysplasi var $20.8 \%$ (10/48) for målrettede biopsier og 3.5\% (11/318) for ikke-målrettede biopsier.

Sensitiviteten og spesifisiteten for korrekt klassifikasjon av lesjoner ved bruk av kromoskopi var 48\% (95\% konfidensinterval (CI): 26-70 \%) og 96\% (95\%CI: 93-98\%), respektivt. De positive og negative prediktive verdiene var 42\% (95\%CI: 27-59\%) og 97\% (95\%CI: 95 98\%), respektivt.

\section{MT-sDNA}

Sensitiviteten for MT-sDNA panelet var 100\% (95\% CI 16-100\%) for kolorektalkreft og $33 \%$ (95\% CI 13-61\%) for lesjoner med lavgradig dysplasi<1 cm, med spesifisitet på $87 \%$ (95\% CI 81-91\%) og 93\% (95\% CI 88-96\%), respektivt. Estimert antall pasienter som må screenes for å avdekke en enkel kolorektalkreft var 96 (95\% CI 93-99\%) og 28 (95\% CI 2234\%) for å avdekke kolorektal neoplasi.

Konklusjon

Pasientene med ulcerøs kolitt i populasjonskohorten i denne studien ble ikke fulgt regelmessig med koloskopi surveillance. Til tross for dette var risikoen for kolitt-assosiert kolorektalkreft lav og sammenlignbar med risikoen for sporadisk kolorektalkreft.

Kromoskopi fremsto som et anvendbart verktøy for neoplasisurveillance på et lokalt sykehus. Nytten av ikke målrettede biopsier var neglisjerbar.

MT-sDNA panelet avdekket kolitt-assosiert kolorektalkreft. Sensitiviteten for neoplastiske lesjoner mindre enn en centimer, var lik den observert i en populasjon uten IBD. 


\section{Introduction}

\section{Inflammatory bowel disease}

Ulcerative colitis (UC) and Crohn's disease (CD) are the two main forms of Inflammatory Bowel Disease (IBD). The diseases are characterized by chronic relapsing inflammation which primarily affects the intestines but may also involve extra-intestinal organs. The exact etiology of IBD remains unclear, however a complex interaction between genetic and environmental factors seems to lead to an inappropriate activation of the immune system of the intestinal mucosa. ${ }^{1-7}$ Symptoms related to involvement of the gut include abdominal pain, blood in stool and weight loss in severe cases.

In UC, the inflammation is limited to the colon and spreads from the rectum to the cecum in a continuous pattern. The disease is classified according to the extent of the inflammation, proctitis, left-sided colitis and extensive colitis. ${ }^{8}$ Although approximately one third of patients present in each subgroup at diagnosis, up to half may experience a proximal extension_during course of the disease. ${ }^{910}$ Therapeutic management is determined by the extent and severity of inflammation which may subside spontaneously in some cases.

Crohn's disease may occur in any part of the alimentary tract, from the mouth to the anus. The inflammation varies in extent, is transmural and clearly demarcated segmentally (skip lesions) in a patchy distribution. The disease is restricted to the colon in one third, the ileum and colon and the terminal ileum, in one third of the patients. Around 5-10\% present with localized disease of the small intestine proximal to the terminal ileum. The ongoing inflammation may lead to strictures, abscesses and fistulae.

IBD seems to be on the increase worldwide. A recent review of population based cohorts described an overall increase of UC and CD in Europe from 6.0 per 100,000 person-years in UC and 1.0 per 100,000 person-years in CD in 1962 to 9.8 per 100,000 person-years and 6.3 per 100,000 person-years in 2010, respectively. ${ }^{11}$ Norway has among the highest incidence rates of UC in the world, ranging from $13.6 / 10^{5}$ in South-Eastern Norway, to $14.8 / 10^{5}$ in western Norway. ${ }^{12}$ The annual incidence of Crohn's disease was found to range from 5.3/10 in western Norway to $5.8 / 10^{5}$ in South-Eastern Norway. ${ }^{12}$ 


\section{Colorectal Cancer in inflammatory bowel disease}

The association between UC and colorectal cancer (CRC) was first described in 1925 by Crohn and Rosenberg. ${ }^{13}$ IBD is one of the main risk factors for CRC and CRC is the most common malignancy in patients with IBD. ${ }^{14}$

CA-CRC patients are younger, more frequently have multiple cancerous lesions, and an invasive pattern of spread, including mucinous or signet ring cell carcinomas, compared with sporadic CRC. The advanced stage at presentation causes less favorable outcome of CA-CRC than non CA-CRC. ${ }^{15} 16$

\section{Risk of CRC in IBD}

At the turn of the century, a meta-analysis including 116 studies described a risk of CRC as high as $18 \%$ after 30 years of diagnosis of IBD. ${ }^{16}$ Subsequent studies have found a declining prevalence of CRC in IBD. In 2009, a Swedish population based cohort of 7607 IBD patients found a SIR ( standardized incidence ratio ) of 2.7 for CRC in IBD compared to the non-IBD population ${ }^{17}$. Also, a twofold increased risk of CRC for both $\mathrm{UC}$ and $\mathrm{CD}$, and a sevenfold risk for UC patients with longstanding extensive colitis, was described in the prospective observational cohort, the CESAME study. ${ }^{18}$ In 2014 an Australian study including 504 UC patients with varying extent of colitis, reported a cumulative incidence of $1 \%$ at 10 years, $3 \%$ at 20 years, and $7 \%$ at 30 years, after 30 years of UC. ${ }^{19}$ More recently, a Norwegian population-based inception cohort, The IBSEN study, found a 2 fold overall risk of CRC after 20 years of UC in males, but no increase in risk for female UC patients, compared to the background population. ${ }^{20}$ The decrease in reported risk has been attributed to improved inflammatory control and the introduction and advances in endoscopic surveillance in the late 1990s. A significant number of patients, however, develop interval cancer, indicating the need of more sensitive tools for risk assessment. ${ }^{21-23}$ Also, the prognosis of CRC-IBD remains poorer than non IBD-CRC, with a recent study describing an increased risk of death (hazard ratio 1.45 ; 95\% CI 1.29-1.63), in CRC-IBD compared to sporadic CRC, with a particularly worse 5-year survival for IBD patients younger than 50 years of age and in CACRC with multifocal neoplasia. ${ }^{24} 25$

Less is known about the risk of CRC in CD. In 2006, a meta-analysis of heterogeneous CD populations described a relative risk of $2.5 \%$ and a cumulative risk of $2.9 \%, 5.6 \%$ and $8.3 \%$ 
at 10, 20 and 30 years, respectively, with $\mathrm{CD}$ with affection at any site. For $\mathrm{CD}$ restricted to the colon, the relative risk was $4.5 \%{ }^{26}$

Risk and protective factors

Several risk factors have been established and include cumulative inflammatory damage, severe and extensive inflammation, previous neoplasia in the colon, coexistence of primary sclerosing cholangitis (PSC), a history of first-degree relatives with CRC and male sex. ${ }^{27-34}$ Anti-inflammatory medication, including 5-ASA, immunomodulators and anti-tumour necrosis factor (anti-TNF) seem to be protective. ${ }^{283536}$

Colonoscopic surveillance appears to protect against CRC by detection and subsequent endoscopic or surgical removal of early neoplastic lesions, however, the effect on survival is not established. ${ }^{37}$ 


\section{Colonic Dysplasia}

The classification of dysplastic lesions of the colonic mucosa is of clinical importance as they carry a varying risk of neoplastic transformation. Traditionally, the dysplasia in IBD has been categorized as follows: indefinite dysplasia (IND), low grade-dysplasia (LGD), high-grade dysplasia (HGD), dysplasia-associated lesion or mass (DALM), adenoma-like mass (ALM), and adenoma-like DALM. IND has not been described to carry a significant risk of progressing to CRC. The implication of detecting LGD remains controversial as reported risk of synchronous CRC is reported to be between 0 and $19 \%$ whilst the risk of malignant transformation varies between $0.5 \%$ and $54 \% .{ }^{38} \mathrm{HGD}$ has a high potential for malignant transformation and, as for prevention of regular adenocarcinoma, represents an indication for proctocolectomy, due to a high risk of synchronous lesions.

Early dysplastic lesions appear to occur in flat mucosa as they spread more frequently to deeper layers of the mucosa in IBD-CRC. These lesions may be small and may arise either uni- or multifocally. Following advances in endoscopic management of lesions, the SCENIC (Surveillance for Colorectal Endoscopic Neoplasia Detection and Management of Inflammatory Bowel Disease) Consensus Statement proposes a modified Paris classification for describing lesions according to their resectability and to abandon the DALM terminology. 39

\section{Molecular alterations in carcinogenesis}

The longstanding chronic inflammation in IBD involves a complex interaction between the accumulation of free radicals and cytokines, alterations of the epithelial barrier of the colonic mucosa and the microbiome, and inappropriate activation of the mucosal immune system. ${ }^{40}$ ${ }^{41}$ The combination of these mechanisms are thought to result in genetic and epigenetic alterations, the accumulation of which may result in the progressive transformation of nonneoplastic inflammatory epithelium to dysplasia to carcinoma. ${ }^{42} 4344$ However, carcinogenesis has also been found to develop directly from any level of dysplasia. ${ }^{45}$ Although some of the molecular changes are similar, differences in the timing and frequency may explain differences in the biology, morphology and distribution between CA-CRC and non-CA-CRC, which is thought to develop through the adenoma-carcinoma sequence. ${ }^{46} 47$ Genetic modifications include nucleotide mutations, chromosomal changes and microsatellite instability. Mutation of TP 53 typically occurs early in CA-CRC and may be detected in non- 
neoplastic mucosa as well as in early dysplastic mucosa. ${ }^{48} 4950$ p53 mutations are however rare in non CA-CRC. ${ }^{51}$ DNA aneuploidy has been detected in non-dysplastic mucosa in both UC and Crohn's disease, indicating that chromosomal instability occurs early in CA-CRC. ${ }^{52}$ ${ }^{53} \mathrm{APC}$ and $\mathrm{K}$-ras mutations are found less frequently in CA-CRC than in non CA-CRC. ${ }^{54}$ However, loss of APC function has been reported as frequently as $50-100 \%$ in lesions with HGD. 5556

Epigenetic alterations are non-heritable changes in gene expression that are not accompanied by changes in DNA sequence. Oxidative stress related to the longstanding inflammation in IBD may lead to genomic instability by hypo- and hypermethylation promoter regions of oncogenes and tumour suppressor genes. These changes occur before dysplasia or CRC can be detected. The ensuing inactivation of the DNA mismatch repair (MMR) system, leads to widespread somatic mutations at microsatellite loci leading to microsatellite instable (MSI) tumours. Also, shortening of telomeres, a normal feature of ageing tissue, has been found to be accelerated in the colon of UC patients. ${ }^{57}$

Preneoplastic cells thus acquire the molecular alterations necessary to allow them to fully escape growth control check points and ultimately invade surrounding tissues. Cancer cells have been estimated to accumulate about half of their mutational load before tumour development. Both synchronous (simultaneous) and metachronous (consecutive) dysplasia and carcinomas occur more frequently in IBD patients than in sporadic CRC. This is explained by a 'field effect' of molecular changes in which a significant proportion of cancer evolution may occur before the development of histological abnormalities in apparently normal colonic mucosa. ${ }^{58}$ 


\section{Surveillance}

\section{Colonoscopy}

Gastroenterologic societies recommend regular review of symptoms and laboratory tests for patients with UC extending proximal to the rectum. In addition, interval colonoscopy is recommended as early neoplastic lesions may thus be removed endoscopically. Patients with unresectable lesions can be referred for colectomy. Although colonoscopic surveillance is effective for the detection of CRC, firm evidence for improving survival has not been established. The most appropriate surveillance technique, the optimal interval and the true efficacy of surveillance colonoscopy remains debated. 59

Clinical guidelines recommend first surveillance colonoscopy 6-10 years after diagnosis of UC with ensuing annual or biannual colonoscopies in UC patients with extensive or left-sided colitis or concurrent PSC. The frequency of surveillance is further determined by the presence of additional clinical features. ${ }^{14}$ 60-62

Endoscopic visualization of early dysplastic lesions in UC represents a challenge, as they may be diminutive, flat or concealed in inflammatory changes and/or pseudopolyps. ${ }^{286364}$ Traditional standard definition white-light endoscopy (SD WLE) relies on random 4-quadrant biopsies taken every $10 \mathrm{~cm}$ and is a laborious and costly method. Under-sampling is common and even when the recommended 30-40 biopsies are harvested, only a fraction of the mucosal surface of the colon is examined. In consequence, high rates of $\mathrm{CRC}$ between scheduled visits have been observed. ${ }^{22} 65$ More recently, advances in optical technology allow improved endoscopic identification of dysplasia and indicate that most dysplasia in IBD is in fact visible. ${ }^{66}$ The diagnostic yield of dysplasia using CE with targeted biopsies has been found to be superior to WLE when using SD colonoscopes. ${ }^{636467-70}$ When applying topical dye during chromoendoscopy (CE), mucosal abnormalities are highlighted, allowing for more precise biopsies. ${ }^{64}$ The Scenic meta-analysis study including eight randomized controlled trials (RCTs) using SD colonoscopies, found that CE with targeted biopsy had 1.8 higher rate of dysplasia detection compared with WLE with random biopsies. ${ }^{71}$ Based on this meta-analysis, non-RCTs demonstrate a benefit of chromoendoscopy over SD WLE and HD WLE, whereas RCTs only show a small benefit of chromoendoscopy over SD WLE, but not over HD WLE. ${ }^{72}$ Furthermore, targeted biopsies are considered superior to random biopsies of apparently unaffected mucosa which are of negligible additional value as they have a poor diagnostic yield. ${ }^{73}$ Assuming that fewer biopsies are required in CE renders the technique more time and cost efficient than standard WLE. ${ }^{6364775}$ Most clinical guidelines now cite 
$\mathrm{CE}$ as the preferred surveillance tool when available. These strategies are however based on studies from tertiary health centres and CE is not widely implemented in routine clinical practice. A study including 92 endoscopists in the US found that only $34 \%$ used CE with targeted biopsies in IBD dysplasia surveillance. ${ }^{76}$

\section{Molecular markers}

Genetic and epigenetic alterations which accumulate during CA-CRC tumorigenesis, are attractive candidates for tumour markers. Altered DNA from neoplastic cells of the colon are shed into the gut lumen and may be recovered in stool samples (sDNA). Technical advances in DNA stabilization, recovery and quantification have enabled the development of assays with high analytical sensitivity and specificity. Pilot case-control study observations suggest that sDNA may be feasible for the detection of CRC in IBD patients. ${ }^{77}$ Also, the use of sDNA for CRC surveillance in UC has found to be cost efficient. ${ }^{78}$ The MT-sDNA panel containing a combination of mutant $K R A S$, aberrantly methylated bone morphogenetic protein 3 (BMP3), N-Myc downstream-regulated gene 4 (NDRG4) and a fecal immunochemical test (FIT) for human haemoglobin, detects CRC and screening relevant adenomas with good discrimination in individuals with average risk of developing non CACRC. ${ }^{79}$ This panel is available for the screening of non CA-CRC in the United States. MTsDNA may serve as a non-invasive supplement to colonoscopic surveillance in UC. 


\section{Aims of the study}

The primary aim of the present study was to investigate the frequency of CA-CRN in longstanding IBD in Norway, by current surveillance practice.

The secondary objectives were:

1. To evaluate the risk of selected clinical risk factors associated with CA-CRC, in longstanding UC, in a prospective population cohort in Norway. (Article I)

2. To describe the outcome of $\mathrm{CE}$, when implemented for the surveillance of patients with longstanding $\mathrm{UC}$, in routine clinical practice in a community hospital in Norway. (Article II)

3. To assess the use of non-invasive stool tumour markers for the detection of colonic neoplasia in IBD patients. (Article III) 


\section{Material and methods}

\section{Research design}

A population-based inception cohort of IBD patients and a single centre surveillance cohort of UC patients from a community hospital were included in this prospective observational study.

The International Classification of Diseases (ICD-10) is the standard diagnostic tool for epidemiology, clinical diagnosis and health management. All cases of malignant neoplasms of the colon, malignant neoplasms of the recto-sigmoidal junction and malignant neoplasms of the rectum (C18-20), recorded until January 2015 in the Cancer Registry of Norway, were used in this study.

\section{Study population}

Population based cohort, The IBSEN-study

All patients $(\mathrm{n}=843)$ diagnosed with IBD or possible IBD from January 1, 1990, until December 31, 1993 in the counties of Oslo, Østfold, Telemark and Aust-Agder in southeastern Norway were prospectively followed. Clinical data including gender, maximum extent of colitis at any time, duration of disease, age at diagnosis of UC, coexisting PSC, as well as first-degree relatives with CRC, were recorded from the time of enrollment, and at 1-, 10- and 20- years of follow-up. The organization of the cohort, diagnostic criteria for IBD and clinical follow-up protocol, have been described in detail elsewhere. ${ }^{80} 81$ All visits included a clinical examination, a structured interview and laboratory tests. Surveillance colonoscopies were performed at local and referral hospitals, according to guidelines in patients with PSC, history of CRC in first degree relatives, or pseudopolyps. Colonoscopies were otherwise performed when indicated clinically, unless the patients objected. Patients were followed closely, and thus received adequate anti-inflammatory treatment. All data were updated from digital medical journals at inclusion, in the present study.

A total of 517 patients were diagnosed with UC; half were males (51\%), and median age at inclusion was 37.4 years (range 4 to 88 ). A total of ten UC patients were lost to follow-up during the study period of 20 years. A total of 57 UC patients underwent colectomy, 26/347 UC patients with left-sided colitis and a total of $31 / 170$ UC patients with extensive colitis. ${ }^{81} 82$ 
Lovisenberg prospective surveillance cohort

All cases of UC (K 51) registered in the database of Lovisenberg Hospital from 1999-2013, were invited to participate in the present study if they had 1) extensive UC, documented by endoscopy at any time during the course of disease and 2) disease duration of eight years or more. A total of 67 UC patients were included.

Exclusion criteria included death or colectomy at any time during follow up.

Demographic and clinical data were extracted from digital medical journals and by structured interview of each patients. 


\section{Data management and validation}

Population based cohort, The IBSEN-study

Both a nurse and a physician interviewed and examined the patients at the 20 years' visit. The physician filled in a standardized form and the patients a comprehensive questionnaire, assisted by the nurse when necessary. All data were monitored by a project coordinator and subsequently, manually entered into a central database. The proportion of incorrect data was monitored by comparing ten percent of transferred records, and found to be less than $0.5 \%$.

\section{Lovisenberg prospective surveillance cohort}

All demographic and clinical data as well as results from blood tests, stool samples, colonoscopy and biopsies, were transferred into a database by the primary investigator. The proportion of incorrect data was monitored by comparing ten percent of transferred records and found to be less than $0.5 \%$.

\section{Cancer Registry of Norway}

All medical doctors in Norway are, by law, obliged to report new and suspected cancers to the Cancer Registry which contains detailed information on each case of cancer, thus ensuring a completeness of approximately $99 \%$. Cases of dysplasia are not recorded in the Cancer Registry of Norway.

All cases of malignant neoplasms of the colon, malignant neoplasms of the recto-sigmoidal junction and malignant neoplasms of the rectum (C18-20), recorded until January 2015 in the Cancer Registry of Norway, were used in this study.

The interpretation and reporting of these data are the sole responsibility of the authors, and no endorsement by the Cancer Registry of Norway is intended, nor should it be inferred. 


\section{Methods}

\section{Chromoendoscopy}

All CE were conducted during routine everyday practice between January 2012 and August 2013. Prior to the study, the endoscopists underwent specific CE training at the Endoscopic unit of St Gjoran Hospital, Gothenburg, Sweden. One may expect a sequential increase in accurate identification and discrimination of lesions as the endoscopists gained experience by each successive CE.

All patients in the Lovisenberg prospective surveillance cohort underwent CE with standard definition endoscopes Olympus CF190, when the quality of bowel preparation was adequate $(n=67 / 68)$.

The colonoscope was advanced to the ileum. Each examined segment was then examined during extubation after topical application of blue dye (indigo-carmine 0,3\%), using a spraycatheter.

Endoscopic degree of inflammation was classified according to the Mayo endoscopic score for UC. Extensive colitis was defined as endoscopic inflammation proximal to the splenic flexure.

Images were taken of all target lesions which were described according to terminology adapted from the Scenic Consensus. ${ }^{71}$ The lesions were then either removed or biopsied according to standard clinical practice. If more than one lesion was present, the largest was marked as the index lesion

Also, a minimum of one random biopsy was taken from each of the six segments (cecum, ascending, transverse and descending colon, sigmoid and rectum) to determine the extent of disease and grade of inflammation.

Independent and blind analyses of formalin-fixed paraffin embedded biopsies were performed by two expert gastropathologists blinded to clinical data.

Histologic degree of inflammation was recorded according to the Mayo and Geboes indexes. ${ }^{83}$ Mucosal biopsies were classified as either negative for dysplasia, indefinite for dysplasia, positive for low-grade dysplasia (LGD), high-grade dysplasia (HGD) or adenocarcinoma. ${ }^{84}$ The final result for each patient was based on the histopathological evaluation. Neoplasia was considered proximal when occurring proximal to and distal when occurring distal to the splenic flexure. 
Stool tumour markers, MT-sDNA

A total of 205 IBD patients were included from the prospective IBSEN ( $n=142)$ populationbased and Lovisenberg $(n=63)$ surveillance cohorts. After informed consent, they were then provided with equipment for convenient collection of stool samples. 192 patients submitted a stool sample for MT-sDNA analysis

Stool samples were collected before $(n=130(68 \%))$ or at least one week after $(n=62(32 \%))$ bowel preparation and colonoscopy as both may affect cell desquamation from the gut wall. To avoid DNA degradation, patients added $250 \mathrm{ml}$ Progene stabilizing buffer (EpiGen laboratory, Department of Clinical Molecular Biology, Akershus University Hospital, Lørenskog, Norway) promptly after collection in the provided container. Samples were then homogenized, separated into aliquots in $50 \mathrm{ml}$ Falcon tubes and frozen to $-80^{\circ} \mathrm{C}$. Frozen aliquots were subsequently sent to Exact Sciences (Madison, WI, USA) for blinded quantitative molecular assays for methylated $B M P 3$, methylated $N D R G 4$, mutant $K R A S$ and $\beta$-actin (a reference gene for human DNA recovery). Due to association with inflammatory disease activity, fecal immunochemical testing was not performed. ${ }^{85}$ Mt-sDNA analysis was possible in all returned samples. As no preparation nor restriction of diet or medication were required, the test was considered to be patient friendly. According to protocol, stool samples were to be delivered at the Unger-Vetlesen laboratory within 24 hours. The time from sample collection and homogenization exceeded 24 hours in approximately $1 / 6$ of the stool samples. Neither the delay nor the variable character of the stool samples appeared to affect the DNA extraction.

Assay methodology for the multi-target stool DNA ( MT-sDNA) test has been previously published. ${ }^{79}$ Briefly, targeted DNA sequences were hybrid captured from fecal supernatants, bisulfite treated, and assayed by multiplex quantitative allele-specific real-time target and signal amplification (QuARTS) assays. Samples in which $\beta$-actin amplified to more than 200 copies indicated sufficient DNA recovery. The resulting quantitative measurements of each marker were then incorporated into a validated logistic-regression algorithm which generates a composite score which is positive when above a predefined threshold. ${ }^{8687} \mathrm{~A}$ value of zero was entered for the fecal immunochemical hemoglobin test variable in the algorithm; results for each sample were reported as positive or negative. All technicians performing stool assays were blinded to clinical data thus avoiding bias.

Data regarding colonoscopy was extracted for included patients in whom stool samples MTsDNA analysis was completed. Patients included from the prospective surveillance cohort 
$(n=63)$ underwent CE as described previously. In the prospective population cohort, $(n=33)$ patients underwent either dye-enhanced chromoendoscopy (CE) or $(n=92)$ standard definition white-light colonoscopy (WLE); procedure type data was missing in four patients. 


\section{Data analysis and statistical methods}

All variables included in the statistical analyses were recorded at inclusion, and at scheduled follow-up interview, colonoscopy and upon result of bioptic or MT-sDNA analyses. Data were summarized as a median (interquartile range) for continuous variables and as a percentage of subgroup totals for categorical variables. Sensitivity and specificity were estimated with corresponding $95 \%$ confidence intervals (CI) calculated using the exact binomial distribution. All tests were two-sided and p-values $<0.05$ were considered statistically significant. Statistical analysis was performed with SPSS version 22-26.

In the IBSEN 20 cohort, the age used in the analysis was age in years at the 20 years follow up presentation. Patients who developed CRC prior to UC diagnosis were not included in the statistical analysis. Follow up time was defined as time from the date of diagnosis of UC to the date of CRC diagnosis, date of death, colectomy or end of follow-up which ever came first. The event was defined as occurrence of CRC. The risk of having CRC was adjusted for colectomy. The risk of having CRC was modelled using Cox proportional hazard regression and the results are expressed as Hazard ratios (HR) with 95\% confidence intervals ( $95 \% \mathrm{CIs}$ ). Variables tested in the univariate Cox models were gender, maximum extent of colitis at any time, duration and age at diagnosis of UC, coexisting PSC, and first-degree relative with CRC. Grade of mucosal healing was not analyzed as case data were incomplete.

In chromoendoscopy, dysplasia detection yield was defined as the proportion of bioptic sites containing dysplasia or invasive $\mathrm{CRC}$ in relation to the total number of biopsies.

The dysplasia detection rate was defined as the proportion of UC patients in whom neoplasia was detected in relation to the total number of UC patients.

The number of patients needed to be screened with MT-sDNA to detect one single IBD-CRC or IBD-CRN was estimated as 1/ (disease prevalence $\mathrm{x}$ test sensitivity). The corresponding 95\% CIs were calculated assuming the prevalence of disease as a known fixed quantity. ${ }^{88}$ The association of IBD-specific risk factors for CRN with MT-sDNA test outcomes and the differences between the cohorts were investigated using the Yates'Correction for Continuity or Fisher exact test for categorical variables and the Mann-Whitney U Test for continuous variables. 
Ethics

The study protocols were approved by the Regional Committee for Medical and Health Research Ethics (REC). Project numbers 2010/1093 and 2010/1540.

The confidentiality of patient identity and records was maintained using the guidelines of the National Health Department.

Written informed consent was collected from all included subjects. 


\section{Results}

Flow charts

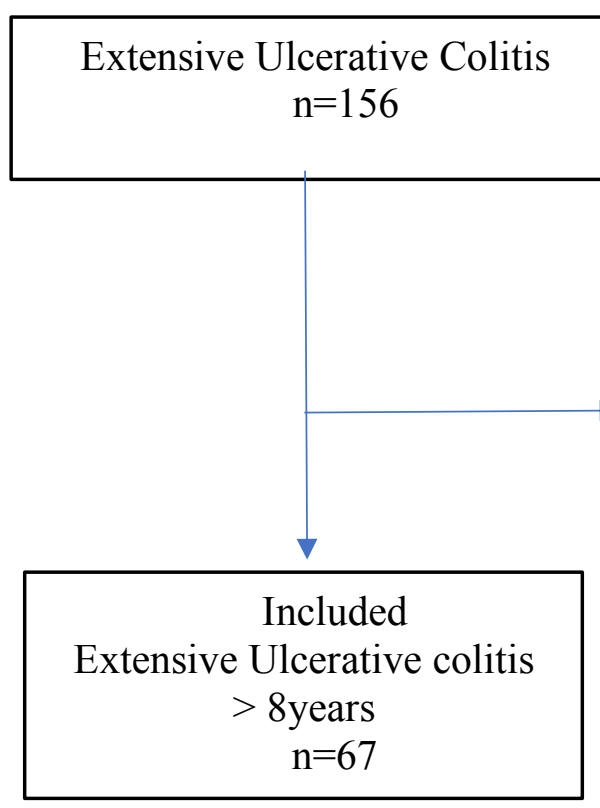

Excluded, $\mathrm{n}=81$

Colectomy due to:

-Refractory colitis, $n=32$

-Colorectal cancer, $\mathrm{n}=5$

-Dysplasia, $\mathrm{n}=1$

Other:

-Metastasized colorectal cancer, $\mathrm{n}=1$

Dead/unavailable, $n=7$

Extensive Colitis $<$ 8years, $n=34$

Inadequate bowel preparation, $\mathrm{n}=1$

\section{Lovisenberg Surveillance Cohort}

756 IBD patients at baseline

$$
519 \text { UC }
$$

$237 \mathrm{CD}$

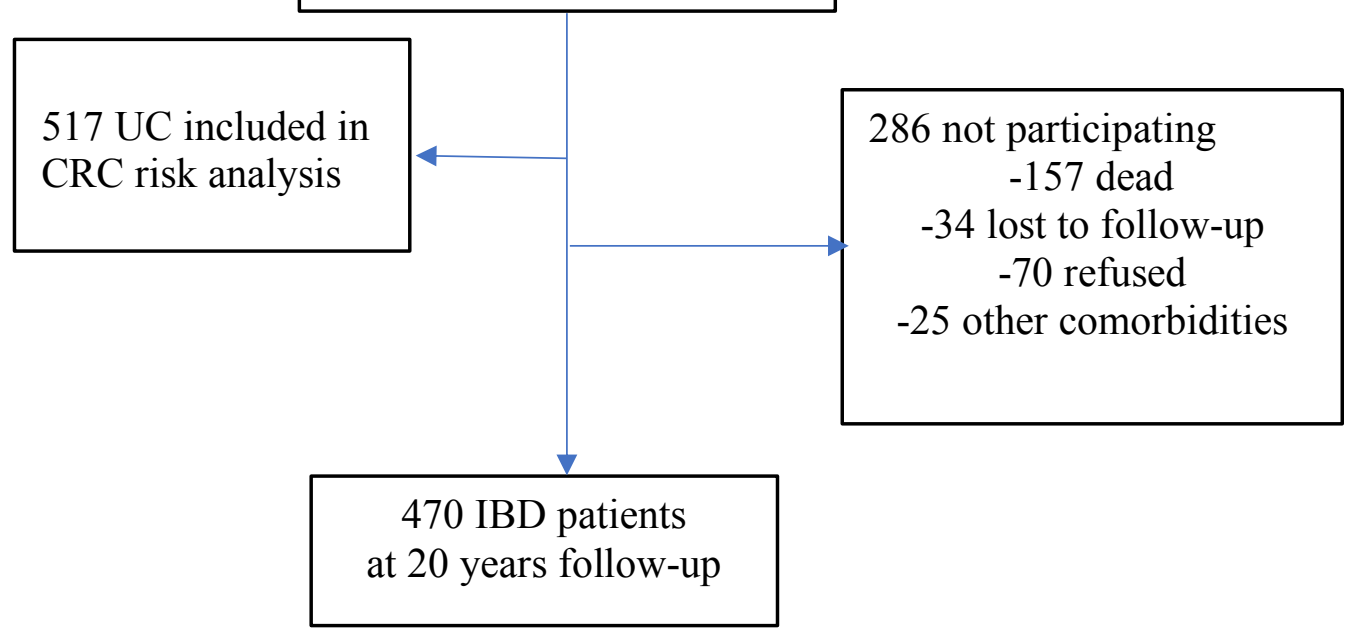


Summary of articles

\section{Article I}

Background

The association between UC and CA-CRC is widely accepted although attenuated risk has been reported in recent years. The magnitude of the risk is related to established clinical factors. In the present study, we evaluated the risk and clinical factors associated with CACRC in a population cohort of UC patients 20 years after diagnosis, the IBSEN study.

Results

A total of 517 patients with UC were included; 264 (51\%) males; median age at inclusion 37.4 years (4 to 88$)$.

The overall incidence of CA-CRC was $1.6 \%$ (8/517) at 20 years-follow up. The total lifetime risk of CRC prior to or after UC diagnosis was 2.3\% . (12/517). Patients older than 70 at diagnosis had a 15-fold higher risk of CRC compared to those diagnosed when younger than 40 years, Hazard ratio 15.68 (95\% CI 1.31-187.92). Neither sex, first degree relative with CRC, extent of colitis nor primary sclerosing cholangitis affected the risk of CA-CRC. Conclusion

The risk of CA-CRC in UC was low and comparable to the risk of CRC in the background population of Norway. 


\section{Article II}

Background

Patients with longstanding and extensive UC carry an increased risk of developing colonic neoplasia and are advised to attend colonoscopic surveillance. At CE, mucosal abnormalities are highlighted, allowing for precise targeted biopsies. The value of additional random biopsies is doubtful, thus fewer biopsies are needed than with WLE. These guidelines are however based on studies performed in advanced endoscopic units and CE is not routinely applied in Norway.

We wished to evaluate the endoscopic and histologic outcome of CE for the surveillance of neoplasia in UC patients in a community hospital of Norway.

Results

Neoplasia was detected in 7/67 patients; with both targeted and non-targeted biopsies in 4/7 patients and in 2/7 patients by non-targeted biopsies alone. In 1/67, adenocarcinoma was diagnosed after colonic resection. The dysplasia yield of non-targeted biopsies was 3\% $(24 / 809)$ and 20\% (10/48) for targeted biopsies. Sensitivity and specificity for diagnosing neoplasia was 43\% (95\% CI 22-66\%) and 93\% (95\% CI 90-96\%), respectively. A total of 19/23 dysplastic lesions were detected in mucosa with past or present inflammation.

\section{Conclusion}

The study suggests that, although novice to $\mathrm{CE}$, the endoscopists accurately evaluated the absence of neoplasia. The yield of non-targeted biopsies with LGD was negligible. LGD appears to be present in mucosa with histologic signs of inflammation. 


\section{Article III}

Background

Colonoscopic surveillance is advised in patients with longstanding IBD as they are at increased risk of CRC. Adherence to recommended guidelines is however suboptimal. Noninvasive tests surveillance may improve access and compliance to surveillance. Multi-target stool DNA (MT-sDNA) has been validated for screening of non CA-CRC but has not been assessed in IBD.

We assessed the performance of a MT-sDNA test panel in a real-life surveillance setting of patients with longstanding IBD enrolled from two prospective cohorts. submitted an EDTA buffered stool sample and underwent chromo- or white light colonoscopy. Stools were assayed for methylated $B M P 3 \& N D R G 4$, mutant $K R A S$ and $\beta$-actin by a laboratory blinded to clinical data.

Results:

The MT-sDNA panel was positive in $2 / 2 \mathrm{CRC}$ and $5 / 15$ low-grade dysplasia $<1 \mathrm{~cm}$ in diameter. Sensitivities were 100\% (95\% CI 16-100 \%) for CRC and 33\% (95\% CI 13-61 \%) for low-grade dysplasia lesions $<1 \mathrm{~cm}$, with specificities of $87 \%$ (95\% CI $81-91 \%)$ and 93\% (95\% CI 88-96\%), respectively. The estimated number of patients needed to screen to detect a single CRC was 96 (95\% CI 93-99) and was 28 (95\% CI 22-34) to detect any colorectal neoplasia.

\section{Conclusion:}

The MT-sDNA panel detected CRC in IBD. Sensitivity for sub-centimeter colorectal neoplasms in IBD patients appears similar to that observed in the general population. The test may be a valuable tool for detection of malignancy during structured surveillance of long term IBD in a first line hospital setting. 


\section{Discussion}

The thesis comprises three papers presenting prospective observational studies of IBD patients recruited from outpatient clinics at gastroenterological hospital departments. In view to more precisely assess individual risk of CA-CRC in UC, we evaluated the risk of CA-CRC and clinical factors associated with CA-CRC 20 years after the diagnosis of UC in a prospective inception population cohort of Norwegian patients. The implementation of dyeenhanced chromoendoscopy in everyday clinical practice in a community hospital was assessed and generated awareness on the real-world challenges of recommended surveillance guidelines. We finally investigated the accuracy of stool tumour markers as noninvasive tools could serve as supplement to current surveillance practices. 


\section{Methodological considerations}

Study population

\section{IBSEN 20 cohort}

In the IBSEN study completeness of data was achieved by a strong collaboration between primary and secondary health care physicians involved in IBD, thus to our knowledge achieving a complete inclusion of the catchment IBD-patients in the early 1990s. All patients had equal and good access to both general practitioners and pediatricians, gastroenterologists and gastrosurgeons. Both diagnostic methods and treatment were similar in the region involved. Five years after inclusion, up-to date clinical information was available for $94 \%$ of the initial cohort. At ten years after inclusion complete data were obtained from $90 \%$ of patients. Finally, at twenty years after inclusion a total of 470/599 live patients were included, resulting in a completeness of $78 \%$. The limited time during which inclusion took place and the dedicated primary and secondary health care physicians responsible for diagnosis of IBD ensured a uniform diagnostic and therapeutic approach.

Quality of data was ensured by scrutiny of digital medical journals at inclusion in the present study.

All Norwegian citizens are assigned a unique digital identification number, which makes it possible to link data from several registries and enables highly reliable epidemiological research.

\section{Lovisenberg surveillance cohort}

As CA-CRN is infrequent in UC, UC patients with extensive colitis were included as they carry an increased risk of developing CA-CRN.

The recruitment may be biased as the study was performed in a single community hospital where patients may display a less severe course UC than those followed in secondary and tertiary institutions and therefore may have a lower risk of CA-CRN. ${ }^{89}$ On the other hand, the prospective design of the study reduced the risk of selection bias. Furthermore, the fraction in whom neoplasia was detected was comparable to studies performed in tertiary referral centres.

To minimize volunteer bias all patients were informed either upon inclusion in the Lovisenberg Surveillance cohort or at scheduled follow-up in the IBSEN population cohort. As CA- CRC is a serious threat, IBD patients would be expected to be motivated to participate in the study. 


\section{Case evaluation}

All medical doctors in Norway are, by law, obliged to report new and suspected cancers to the Cancer Registry which contains detailed information on each case of cancer, thus ensuring a completeness of approximately $99 \%$. Cases of dysplasia are not recorded in the Cancer Registry of Norway.

The interpretation and reporting of these data are the sole responsibility of the authors, and no endorsement by the Cancer Registry of Norway is intended, nor should it be inferred.

Patients underwent structured interview and clinical examination by one primary investigator. Answers were consecutively filed in electronic case report forms. The data was coded accorded to predefined whole numbers enabling acquisition of data from the electronic files Each patient file was handled similarly, limiting data processing errors and bias.

Questions regarding patient history extended up to previous decades. Recall bias was limited through verification by scrutiny of digital medical hospital journal. A complete record of all variables was not possible to achieve but the study has few missing data, thus statistical analyses were not limited.

As CA-CRN is fortunately infrequent, although considerable effort was spent on the inclusion of patients, the sample size was moderate thus limiting the statistical power. Also, the median age at diagnosis of UC was 38, As risk increases with age one may thus expect an extended observation period may reveal an increased number of CRC.

\section{Chromoendoscopy}

Prior to $\mathrm{CE}$, all patients underwent bowel preparation with oral sodium phosphate. Although reports do not recommend the use of oral sodium phosphate in IBD patients as it may cause aphthous ulcers which may be misinterpreted as inflammatory activity, we did not find such changes in the present study. ${ }^{90}$ The endoscopists trained prior to the study, then gained experience by performing CE successively on the study patients. Thus, one may expect a sequential increase in accurately identifying and discriminating lesions.

Colonoscopy was performed when the quality of bowel preparation was deemed adequate. Previous reports have found that only low quality bowel cleansing appears to affect adenoma detection rate (ADR) in non-IBD colonoscopy, whilst intermediate/fair quality of bowel cleansing does not affect ADR. ${ }^{91}{ }^{92}$ A recent study has further shown that poor bowel preparation alongside inflammation were the most frequent factors of an unsuccessful CE. ${ }^{93}$ In IBD as lesions may be difficult to discern, one could expect the requirements of 
appropriate bowel cleaning to be higher. Standardized scales are recommended to minimized interobserver variation. In the present study, although the quality bowel cleansing was described, a standardized scale was not used.

CE was performed using standard definition endoscopes Olympus CF190. Lesions may have been missed as standard definition endoscopes as opposed to high definition colonoscopes were employed. Also, the accuracy of lesion detection is influenced by the duration of withdrawal of the colonoscope. ${ }^{94}$ The duration of the colonoscopy including the withdrawal time was not systematically recorded in the present study. As each segment of the colon was initially examined using WLE and subsequently after application of spray-dye, the detection of mucosal lesions may thus be influenced by the second pass scrutiny of the mucosa. Lengthened procedure time as compared to WLE may lead to reluctance to implement CE in clinical practice. $\mathrm{CE}$ was found to increase the procedure time by an average of 11 minutes in two meta-analyses including mostly studies using a spray catheter for dye application. ${ }^{71} 95$ Recently, a RCT comparing HD CE with HD WLE did not find that CE was more time consuming than WLE. Proposed reasons were the use of an automated water lavage pump for dye application and a lesser number of harvested biopsies. ${ }^{96}$ The adenoma detection rate was not registered in the present study as this parameter is not routinely utilized in Norway. 


\section{Risk of CRC}

In line with previous studies we found an increased risk of CA-CRC in UC patients. The risk and overall incidence of CA-CRC are however the lowest reported so far reflecting the population-based nature of the cohort. The St Mark's tertiary centre cohort study followed patients enrolled in a surveillance program since 1971. The cumulative incidence of CA-CRC was $2.9 \%$ and $10 \%$ in patients with extensive UC at 20 and 40 years follow-up, respectively. ${ }^{97}$ Whilst, a cumulative incidence of $1 \%$ at 10 years, $3 \%$ at 20 years, and $7 \%$ at 30 years for CRC-UC was reported in a cohort of 504 UC patients with varying extent of colitis included from both tertiary and community-based health care centres. ${ }^{19}$

On the other hand, several studies find no increased risk of CRC in IBD. A Danish population cohort study which included about $32000 \mathrm{UC}$ patients and $14000 \mathrm{CD}$ patients from 1979 until 2008 found a comparable risk of CRC between patients with IBD and the general population when adjusted for age and gender. Also, both incidence and mortality of CRC in UC was found to decrease from 1982-1989 and 2000-2010. 9899 Interestingly, the overall risk of CRC in the present UC population cohort was found to be slightly lower than the risk of sporadic CRC in Norway. ${ }^{100}$ The cumulative risk of sporadic $\mathrm{CRC}$ before the age of 75 years is reported to be $2.8 \%$ for females and $3.1 \%$ for males, ranking Norway as the country with fourth highest rate in the world. ${ }^{100}$ The present study supports the decrease in risk of CA-CRC observed in the aforementioned large population and surveillance studies. ${ }^{97} 98$ Reasons for the decrease are probably multifactorial as diagnosis and treatment evolved during the observed time span from the 1960 until around 2015. Systematic neoplasia surveillance was introduced during this time period. Also, technical advances enhanced lesion detection and management and surgery. Finally, the introduction of immunosuppressive medication and anti-TNF agents contributed to a markedly improved inflammatory control. 


\section{Risk factors}

Clinical factors have been acknowledged to influence the risk of CA-CRC.

Gastroenterological societies recommend surveillance programs at intervals determined by individual risk factors. ${ }^{60101-103} 62$ We evaluated the association between established risk factors and UC-CRC in the IBSEN population cohort.

\section{Sex}

We found that UC was equally distributed between men and women as reported in other high incidence areas. ${ }^{104}$ Although males had a two-fold increased risk of CRC after 20 years of $\mathrm{UC}$ when compared to the background population of Norway, the risk of CRC was not different from the females' within the cohort. ${ }^{20}$ Similarly, a nationwide population-based Danish cohort study with 30 years of follow-up from the late 1970s described a similar risk of CRC for males and females ( RR 1.02, 95\% CI, 0.86-1.21 and RR 1.12, 95\% CI, $0.95-$ 1.33, respectively). ${ }^{98}$ Whilst in a retrospective population cohort of IBD patients using data from 1960s until 2004, Søderlund et al found that in patients diagnosed with UC above the age of 45 and with 10 or more years of pancolitis, males had an increased risk of CRC compared to females (RR for males vs females was 1.7 (95\% CI, 1.1-2.8). ${ }^{105}$

\section{Age at CRC diagnosis}

We observed a median age of CRC in UC in line with previous studies including a population-based cohort study from Copenhagen, St Marc's tertiary hospital cohort, a nationwide study from the Netherlands and a Hungarian population study in which the median age at CRC diagnosis was 64, 58 and 51 years, respectively 2910610797108

On the other hand, the median age of patients in whom CRC was diagnosed prior to UC was comparable to reported median age for sporadic CRC (73 years). ${ }^{100}$ Accordingly, UC-CRC has been reported to occur around 17 years earlier than the median age ( 73 years) for sporadic CRC in the non-IBD population of Norway. ${ }^{109}$ However, the actual date of onset of symptoms related to UC are not available, which means that these cases of CRC may in fact be a complication to undiagnosed UC.

We further found that patients older than 70 years at diagnosis had a 15 -fold higher risk of CRC compared to those diagnosed when younger than 40 years. Molecular changes leading to neoplasia accumulate over time, thus old age in itself, rather than either longstanding IBD or elderly onset UC, may have contributed to CRC in these patients. In addition, molecular changes involving the shortening of telomeres have found to be accelerated in the 
colonocytes of UC patients. ${ }^{110}$ Although, few data are available for IBD diagnosed in the elderly, advancing age itself has not been described to increase the risk of CA-CRC. ${ }^{111}$ Nevertheless, a study from 2009 suggested that the interval between colitis and CRC decreases with age, and that higher age at onset of IBD may be related to a more aggressive CRC, suggesting the need of earlier surveillance in older IBD patients. ${ }^{112}$

The incidence of CRC in elderly IBD is, however, low whilst these patients have been found to have a greater need for hospitalization related to surveillance colonoscopy. ${ }^{113}$ Moreover, as comorbidities are more frequent in the elderly, the risk and benefits of surveillance colonoscopy should be considered carefully.

\section{Age at UC diagnosis}

Although the majority of UC patients are diagnosed between the age of 30 and 40 with a second peak described around the age of 60 to 80 , an increase in incidence of UC has been found in all age groups in Northern America and Europe. ${ }^{104} 114$ In the present study, the median age at UC diagnosis was 40 years in the UC-CRC patients and 39 years for all UC patients. Comparatively, in a population-based cohort study from Copenhagen and a nationwide study from the Netherlands, the median age at UC diagnosis in patients who developed CRC was 50 and 46 years, respectively. ${ }^{107}$ In line with the St Marc's cohort, the median duration of UC until the development of CRC was 22 years. ${ }^{97}$ In contrast, the Copenhagen study and the Dutch study, which both described median duration time of colitis to development of CRC, as 12 and 11 years, respectively. ${ }^{107} 108$

\section{Extent of colitis}

We were unable to confirm extensive colitis as a risk factor for UC-CRC, although previously described in several studies. ${ }^{115}$ This may be due to the high standard of follow-up and good compliance to anti-inflammatory medication, but a type-II error in this real-life cohort is not excluded. 


\section{Primary sclerosing cholangitis}

A total of 15 UC patients had PSC of whom $80 \%$ had extensive colitis. As relatively few cases of CA-CRC were observed, we were unable to evaluate the association between CA$\mathrm{CRC}$ and PSC without or in combination with extensive colitis. A case-control study of two large IBD cohorts has shown that the risk of colorectal neoplasm increased 6.9-fold with a concomitant diagnosis of PSC. ${ }^{116}$

\section{First degree relative with $\mathrm{CRC}$}

A family history of CRC in UC patients increases the risk of CRC, irrespectively of the type and extent of IBD, as compared with patients with UC without positive family history for CRC. ${ }^{27}$

The limited statistical power of the present study did not allow us to explore the association between heredity and CA-CRC.

\section{Location of CRC}

In the present study, half of the CA-CRC cases were located in the rectum/distal colon. However, in line with previous studies, the limited number of patients with CA-CRC, did not allow for us to estimate the effect of location on risk of CA-CRC. A retrospective cohort study from 2012 included 700 UC patients with extensive colitis in whom a total of six out of nine of the detected CA-CRCs were located in the rectum. Moreover, $71.2 \%$ of advanced neoplasia was detected in rectum or sigmoid colon. ${ }^{117}$ More recently, the forty year analysis of colonoscopic surveillance in a tertiary referral hospital, the St Marc's cohort, detected CACRC in 72 patients; $57 \%$ were located distal to the splenic flexure. ${ }^{23}$ 


\section{Surveillance}

Clinical guidelines recommend surveillance based on regular review of symptoms and laboratory tests for patients with UC extending proximal to the rectum. In addition, interval surveillance colonoscopy should be performed, as carcinoma in UC is thought to develop through a stepwise progression from inflammation, to LGD to carcinoma. ${ }^{118}{ }^{61} \mathrm{In}$ view to reduce both morbidity and mortality, early neoplastic lesions should be removed endoscopically whilst colectomy is advised in patients with unresectable lesions. However, the approach to endoscopic surveillance in UC patients is not based on robust evidence. Also, up to $30 \%$ of CRC-IBD in surveillance cohorts occur between scheduled colonoscopies "interval cancers". 119

In our surveillance cohort, we found a median time of 24 months (range 0-96) from the prior "pre-study" ( $n=61 / 67)$ until the next scheduled colonoscopy. The wide range in time of scheduled surveillance colonoscopies, underlines that endoscopic surveillance of UC patients according to guidelines is not systematically implemented in Norway. In the IBSEN 20 population study, UC patients with risk factors including PSC, underwent colonoscopy for dysplasia detection, although not at regular defined intervals. However, all patients attended structured clinical follow-up, ensuring optimal anti-inflammatory therapy. Additionally, colonoscopy was performed when clinically indicated, whereby dysplasia may have been resected, thus decreasing the risk of CRC development. Unfortunately, data regarding dysplasia of the colon was not available. No randomized controlled trials have been conducted to demonstrate the most appropriate technique for surveillance, the optimal interval, or that surveillance colonoscopy as truly effective. ${ }^{59} 120$ A reduced odds ratio (OR) for CRC has been demonstrated in retrospective case-control studies. ${ }^{28} 121122$ A subsequent retrospective population-based cohort study found a 5-year CRC-related survival of $100 \%$, in a surveillance group compared with $74 \%$ in a nonsurveillance group $(P=0.042) .{ }^{37}$ Also, in a retrospective cohort study, colonoscopic surveillance within four years was associated with reduced incidence of CRC and lower mortality among those diagnosed with CRC. ${ }^{123}$ Recently the St Marc's study found that neoplasia is detected at an earlier stage in patients enrolled in surveillance programs, thus ensuring a better prognosis. ${ }^{97}$

However, the low observed risk of CRC in UC in present study appears more likely to be attributed to participation in the present study with adequate control of inflammation. Similarly, a nationwide population study following 32911 Danish UC patients for 30 years found that the overall risk of CRC in UC was decreasing and comparable to the general 
population. Surveillance was not routinely implemented in Denmark at the time of the observation period (1979-2008) implying that improved therapeutic control of inflammation as well as colectomy may have contributed to the decline. ${ }^{98}$ In contrast, Singh et al reported low CA-CRN rates in UC and CD patients close to fully adherent to a surveillance scheme at a tertiary IBD centre. ${ }^{124}$

\section{Chromoendoscopy}

Only dysplastic lesions should be removed as they may progress to CRC. Endoscopic surveillance should thus exhibit both a high sensitivity as well as high predictive value for the differentiation between dysplastic and non-dysplastic lesions. ${ }^{125}$ This would imply that all dysplastic lesions are identified endoscopically and that lesions confidently characterized as non-dysplastic can be left in situ without biopsy or resection. Despite CE, endorsed as the gold standard for surveillance in UC, it is not universally used in clinical practice. Reported reasons are lack of equipment, training and expertise, as well as prolonged examination, and thereby a more costly procedure. ${ }^{126} 127$ 128-130 We assessed the implementation of CE for the surveillance of UC patients in a community hospital in which patients may have a less aggressive UC than in advanced units. Neoplasia was detected in 7/67 patients in the present study, lower than the average rate of $14 \%$ found by Mooiweer et al in randomized trials. ${ }^{131}$ In a multicentre RCT, Vleugels et al. detected dysplasia in $19 \%$ of 105 UC patients, of 70.5 $\%$ of whom had pancolitis of similar disease duration as in the present study. In the same study, no targeted biopsies were taken in $34 \%$ of the CE, compared to $76 \%$ in the present study. ${ }^{132}$

The negative predictive value for neoplasia detection was $97 \%$ and sensitivity $43 \%$, similar to previous studies of real-time dysplasia detection, and prediction using CE with sensitivities and NPV in the range of 32-93\% and 88-98\%. 67133134132133 In addition, a recent metaanalysis found a pooled specificity of $93 \%$ and sensitivity of $91 \%$ for CE with indigo carmine dye spray. ${ }^{135}$ Disparity in dysplasia detection may be explained by the use of highdefinition colonoscopes in Vleugel et al study, compared to standard definition colonoscopes, used in the present study. Also, endoscopists underwent a more comprehensive CE training prior to the study. However, Carballal et al found that both $\mathrm{CE}$ novice endoscopists and $\mathrm{CE}$ expert endoscopists evaluated lesions with a high NPV. ${ }^{133}$ Although all lesions were assessed by endoscopists involved in endoscopy research, dysplastic lesions were not reliably identified. This emphasizes the importance of histopathological assessment of all potentially 
dysplastic lesions encountered during surveillance of longterm UC. Moreover, this may have also caused selection bias, as it is unclear how endoscopists would have performed in a nonresearch setting. Although increasingly applied, CE is not widely implemented, nor taught systematically, in endoscopy units in Norway. Also, endoscopists differ regarding the utility and practicality of the technique. As units increasingly focus on efficiency, allocation of time required for acquiring both the basic skill and experience, necessary to perform $\mathrm{CE}$, may represent a challenge.

\section{Field effect and non-targeted biopsies}

In contrast to sporadic $\mathrm{CRC}$, which arises from 1-2 foci of dysplastic changes and follows a recognized adenoma-carcinoma sequence, colitis-associated $\mathrm{CRC}$ results from a field change effect with multi-focal genetic alterations that do not follow the typical adenoma-carcinoma sequence of events. Invisible dysplasia is defined as dysplasia identified on non-targeted biopsies of macroscopically normal mucosa. ${ }^{71}$ In 2/7 patients, low grade dysplasia (LGD) was detected solely by non-targeted biopsies taken during chromoendoscopy described as macroscopically normal. A follow-up with colonoscopies did neither confirm nor reveal any further dysplasia.

In another two patients non-targeted biopsies confirmed a field effect by detecting LGD when dysplastic lesions were identified elsewhere in the colorectum by targeted biopsies. During intensified follow-up colonoscopies, no further dysplasia was detected after 2,5 years follow up (range 2-5) in these patients. Previous reports have found that LGD detected by nontargeted biopsies progresses to CA-CRC in as much as 20-23\%. ${ }^{38} 97136$ More recent data however report a 3-10\% rate of progression to CA-CRC. ${ }^{137-139}$ The decrease in progression may be explained by improved surveillance and detection techniques. The Scenic consensus supports confirmation of dysplasia by two histopathologists and referral to CE or HD-WLE if not already employed. The detection of multifocal dysplasia in non-targeted biopsies has important implications as both AGA and BSG recommend colectomy in such patients. In those unwilling to undergo colectomy, follow-up with CE is advised.

In two of the seven UC patients with colonic neoplasia, non-targeted biopsies confirmed a field effect by detecting LGD when dysplastic lesions were identified elsewhere in the colorectum by targeted biopsies. In another of the seven patients with neoplasia, non-targeted biopsies showed multifocal fields of LGD synchronous with targeted biopsies which showed 
multifocal lesions with HGD and adenocarcinoma. The patient had primary sclerosing cholangitis and procto-colectomy was performed. The Scenic consensus recommends continued surveillance when visible dysplasia is found in the same area as invisible dysplasia and the lesion is resectable. On the other hand if visible dysplasia is not detected individualized follow-up is advised. ${ }^{39}$ The prevalence of synchronous CRC in patients with flat HGD has been found to range from 42-45 \%. ${ }^{97}{ }^{140}$ In a retrospective Dutch study from tertiary IBD centres, the dysplasia yield of non-targeted biopsies was $5 \%(7 / 140$ lesions in 71/196 patients). The dysplastic yield of non-targeted biopsies in the present study was 3\%. Both the high number of biopsies may reflect that the endscopists were novice to $\mathrm{CE}$ and overdiagnosed lesions. Also, as the present study was performed in a community hospital, the patients may have had a milder disease and thus lower risk of neoplasia. In the same study, LGD was detected in the non-targeted biopsies of mucosa surrounding visible lesions. Similar to the present study, a median 37 months follow-up of patients, in whom LGD was detected, non-targeted biopsies taken close to visible lesions did not reveal any progression to CRC. The value of routine non-targeted biopsies in the both the presence or absence of visible dysplasia remains questionable. ${ }^{141}$

\section{Inflammation}

Surveillance colonoscopy should be performed in quiescent IBD as the visualization of subtle or flat early dysplastic lesions may be hampered by active inflammation or chronic changes, such as strictures and pseudopolyps. ${ }^{286364}$ However, in our surveillance cohort, the minimal level of inflammatory changes in the patients, in which dysplasia was diagnosed by nontargeted biopsies only, did not likely impede their detection.

Also, current or previous inflammatory changes were present around all dysplastic lesions, including non-targeted biopsies harbouring lesions with LGD. In patients with longstanding UC, with either left-sided (1/3) or extensive colitis (2/3), Vleugel et al found that $66 \%$ percent of dysplatic lesions were found in a part of the colon that was previously inflamed. ${ }^{132}$ When evaluating interval CRC in IBD patients undergoing endoscopic surveillance, close to $3 / 4$ of CRC were detected in areas with histologic signs of chronic inflammation. ${ }^{142}$ However, although the patients had active inflammation at index colonoscopy, they had a mild course of disease as in the present study. This suggests that although inflammation is considered a precondition for carcinogenesis in IBD, the severity may not be of great importance. 
Watanabe et al suggested that random biopsies might be omitted in the absence of previous or current inflammation. ${ }^{143}$ Conversely, Ullman et al reported a five-year progression rate to HGD or as high as $9 \%$ in biopsies from mucosa with chronic active inflammation. Moreover, distinguishing regeneration and repair from dysplasia may be difficult. ${ }^{38}$ Important advances in endoscopic techniques occurred during the observation period of the IBSEN 20 study. The presence of pseudopolyps, a sign of previous severe inflammation was an indication for surveillance colonoscopy according to guidelines at the initiation of the present study. Recently, pseudopolyps were not found to be a risk factor for CRC and guidelines have been updated accordingly. ${ }^{144}$ 


\section{Molecular markers}

Although health care is universally accessible in Norway, certain patients remain reluctant to undergo colonoscopy. Also, reports indicate that clinicians do not fully adhere to surveillance recommendations. Non-invasive tumour markers have been found to increase compliance in non CA-CRC screening. ${ }^{145}$ They may serve as a supplement to colonoscopy and benefit the surveillance of CA-CRN. Stool samples would be familiar to many UC patients as these are used for monitoring inflammation of the colonic mucosa by quantification of calprotectin. ${ }^{146}$ In the present study, a multitarget panel of tumour markers was evaluated in stool samples of patients with longterm UC. While the sensitivity for the detection of CRN was moderate, the detection rates for CRC was in line with the detection of sporadic CRC found both in crosssectional high-risk and large multicenter average risk population studies. ${ }^{79} 88$ MT-sDNA test was positive in $1 / 3$ of IBD patients with LGD lesions $<1 \mathrm{~cm}$. The presence of LGD is of minor clinical relevance in the general population, the management of LGD in IBD remains debated as rates of progression to HGD or CRC vary from $14 \%$ to more than $50 \%{ }^{38147-149}$. The presence of macroscopically invisible, flat non-polypoid lesions, $\geq 1 \mathrm{~cm}$ with LGD and previously identified indefinite dysplasia predict an increased risk of development to HGD or CRC. ${ }^{97}$ In an average risk cohort, Imperiale et al. found that although MT-sDNA accurately detected larger advanced neoplasms, sensitivity dropped to $30 \%$ and below for small nonadvanced lesions. ${ }^{79}$ These results suggest that non-invasive detection of IBD-LGD may depend on lesion size, however minute serrated and adenomatous precursor lesions appear to exfoliate mutant and methylated s-DNA markers into stool. ${ }^{150}$ MT-sDNA has been found to be false positive in up to $13 \%$ in previous studies. ${ }^{79}$ Similarly, the present study detected MT-sDNA in close to $12 \%$ of patients where neoplastic lesions were neither described at colonoscopy nor in biopsies. Sporadic colorectal neoplasms may be overlooked in $2-6 \%$ of white-light colonoscopies. 128151 Thus, small non-dysplastic lesions which are more likely to have been missed at colonoscopy could have led to the presence of target DNA markers in our samples. Screening tools need to achieve acceptable specificity as well as sensitivity as false positive tests still remain a concern as how to approach them clinically. Clinicians would need to know how to handle false positive sDNA results in face of negative repeat colonoscopy. Also, the burden of a false positive result on patients must be avoided to avoid unnecessary anxiety.

In stool testing, mucosal inflammation in patients with IBD increases the amount of background human DNA, as measured by $\beta$-actin. ${ }^{150}$ MT-sDNA was equally positive in the 
presence and absence of inflammation further suggesting that inflammation has little impact on the outcome of the stool test, consistent with prior observations. ${ }^{77}$ Methylated BMP3 \& NDRG4 and mutant KRAS have been isolated from cancers of the respiratory system and upper gastro-intestinal tract. Individuals with a history of "aerodigestive" cancers were therefore excluded from the present study. However, in long-term follow-up of average risk patients with positive MT-sDNA after a negative colonoscopy, aerodigestive tract cancer events do not appear to be more common than expected within the general population. ${ }^{152}$

Screening tools need to achieve acceptable specificity as well as sensitivity. The appropriate approach to a positive sDNA in face of negative repeat colonoscopy remains a clinical challenge. Also, false positive results may lead to unnecessary anxiety for patients. In the retrospective DeeP-study Berger et al included around 1000 patients with negative colonoscopy and negative MT-sDNA test and around 200 patients with negative colonoscopy and positive MT-sDNA test. After a median follow-up of 5.3 years, one of the five patients in the false positive group were diagnosed with aerodigestive cancers and 11 patients were diagnosed with CRC in the true negative group. ${ }^{153}$ The results support recommendations to avoid further testing in patients with MT-sDNA followed by high-quality colonscopy. ${ }^{154}$ 


\section{Strengths and limitations of the present study}

The strength of the IBSEN study includes a short inclusion time-interval, the longitudinal follow-up of an unselected and well-defined cohort within a well characterized geographic area. All living patients had the same length of follow-up.

In the Lovisenberg cohort, patient selection bias was minimized by the consecutive inclusion of UC patients undergoing surveillance.

All citizens in Norway are assigned a unique ID number, which enables easy and accurate identification and linkage to medical and death records as well as to the National Cancer Registry. The Norwegian Cancer registry does not have data concerning dysplasia, only CRC. The true risk of CA-CRC in the current study may in fact be higher, as 57 UC patients underwent colectomy. Colectomy would have been performed in any patients in whom HGD was detected in the colonic mucosa. Also, the detection of multifocal LGD in the colonic mucosa or severe and extensive inflammation in the pre-biologic era may have led to colectomy and thus prevented CRC. Data regarding the causes of colectomy was however not available for the present study.

The approach to patient inclusion was rigorous and derived from a large cohort of patients. However, the number of observed cases was low, thus limiting the statistical power. The low rate of CA-CRN is, however, believed to reflect real life scenario in agreement with several recent studies with low observed rates of CA-CRN in both UC and CD. The absence of patients with HGD prevented any observations on detection for these critical targets.

The median age at UC diagnosis was below 40 years in both the Lovisenberg cohort and the IBSEN cohorts. The median duration of UC was around 20 years in both cohorts and the patients were thus still relatively young and extended observation period may therefore reveal further CA-CRN and CRC.

Quality indicators of colonoscopic surveillance which may affect CRN detection were not systematically recorded. These include adenoma detection rate, quality of bowel cleansing and withdrawal time. Also, CE was performed by two experienced gastroenterologists, who were, however, novel to the CE- technique.

Our investigation is however clinically relevant, as data were collected from real life clinical practice and may therefore be generalized to the surveillance of UC patients in secondary health care in Norway. 


\section{Conclusion}

In the present study, we found that UC patients in the area where the investigation was conducted carry a low risk of CA-CRC. The low observed risk does not appear to be related to endoscopic surveillance, but rather to close clinical follow-up and improved therapeutic management of inflammation.

Also, chromoendoscopy appeared to be of value for dysplasia surveillance of UC in a community hospital setting. The yield of non-targeted biopsies was negligible.

Finally, MT-sDNA accurately detected CRC in IBD. The sensitivity for sub-centimeter dysplasia appeared to be similar to that observed in the non-IBD population. This noninvasive test could serve as a non-invasive screening tool in patients unwilling to undergo colonoscopy and may increase the pickup rate of interval carcinomas.

This study reflects the current public health experience in Norway and should inform on surveillance policy also in view of achieving a uniform approach to CA-CRN screening. 


\section{Future perspectives}

Our findings in the IBSEN-20 study mainly reflect the risk of CA-CRC in UC patients on traditional anti-inflammatory treatment as biologics were introduced late in the observation period. In addition, the results are based on patients who did not undergo systematic endoscopic surveillance. Evolving technology and improved optical visualization has altered the therapeutic approach to detected mucosal lesions. Lesions which previously would have warranted colonoscopic follow-up are now resected. A prolonged study period would therefore allow us to assess the risk of CA-CRN based on current IBD therapy, endoscopic surveillance and treatment of CRN.

As the risk of CA-CRC increases with age, a prolonged study may result in more observed cases of CA-CRC. One may thus evaluate the impact of CA-CRC risk factors to more precisely individualize surveillance of UC patients.

Although Mt-sDNA accurately detected CA-CRC, early neoplasia warrants further knowledge about IBD carcinogenesis to establish highly sensitive markers. Combining current with newly developed tumour markers may increase the sensitivity and negative predictive value, also for early neoplastic lesions. These noninvasive markers may thus be applied as a primary health care screening method. Patients with positive tests may thus be referred to invasive endoscopic procedures including dye-based or HD colonoscopy in specialized centres.

One may thus more precisely allocate necessary resources on units already facing an increasing demand for endoscopy for diagnosis and follow-up of flares and complications due the increasing incidence of UC. 


\section{Funding and conflicts of interest}

This study was funded by the Lovisenberg Research fund, the Unger-Vetlesen Research

Institute and MSD Norway AS. None of the funding sources influenced the study design, data collection, data management, data analyses or reporting. 


\section{References}

1. Ellinghaus D, Bethune J, Petersen BS, et al. The genetics of Crohn's disease and ulceratice colitis-status quo and beyond. Scand J Gastroenterol 2015;50(1):13-23.

2. Klement E, Lysy J, Hoshen M, et al. Childhood hygiene is associated with the risk for inflammatory bowel disease: a population based study. Am J Gastroenterol 2008;103(7):1775-82.

3. Ko Y, Kariyawasam V, Karnib M, et al. Inflammatory Bowel Disease Environmental Risk Factors: A Population-Based Case-Control Study of Middle Eastern Migration to Australia. Clin Gastroenterol Hepatol 2015

4. Mahid SS, Minor KS, Soto RE, et al. Smoking and inflammatory bowel disease: a metaanalysis. Mayo Clin Proc 2006;81(11):1462-71.

5. O'Toole A, Korzenik J. Environmental triggers for IBD. Curr Gastroenterol Rep 2014;16(7):396.

6. Vatn M, Sandvik A. Inflammatory bowel disease. Scand J Gastroenterol 2015;50(6):74862.

7. Berry D, Reinisch W. Intestinal microbiota: a source of novel biomarkers in inflammatory bowel diseases? Best Practice \& Research Clinical Gastroenterology 2013;27(1):4758.

8. Satsangi J, Silverberg MS, Vermeire S, et al. The Montreal classification of inflammatory bowel disease: controversies, consensus, and implications. Gut 2006;55(6):749-53. doi: 10.1136/gut.2005.082909

9. Henriksen M, Jahnsen J, Lygren I, et al. Change of diagnosis during the first five years after onset of inflammatory bowel disease: results of a prospective follow-up study (the IBSEN Study). Scand J Gastroenterol 2006;41(9):1037-43.

10. Gower-Rousseau C, Dauchet L, Vernier-Massouille G, et al. The natural history of pediatric ulcerative colitis: a population-based cohort study. Am J Gastroenterol 2009;104(8):2080-8. doi: 10.1038/ajg.2009.177

11. Burisch J, Munkholm P. The epidemiology of inflammatory bowel disease. Scand $J$ Gastroenterol 2015;50(8):942-51. doi: 10.3109/00365521.2015.1014407

12. Moum B, Vatn M, Ekbom A, et al. Incidence of Crohn's disease in four countires in southeastern Norway, 1990-93. A prospective population-based study. The Inflammatory Bowel South-Eastern Norway (IBSEN) Study Group of Gastroenterologists. Scand J Gastroenterol 1996;31(4):355-61.

13. Crohn B, Rosenberg H. The sigmoidoscopic picture of chronic ulcerative colitis (nonspecific). Am J Med Sci 1925;170:220-28.

14. Magro F, Gionchetti P, Eliakim R, et al. Third European Evidence-based Consensus on Diagnosis and Management of Ulcerative Colitis. Part 1: Definitions, Diagnosis, Extra-intestinal Manifestations, Pregnancy, Cancer Surveillance, Surgery, and Ileoanal Pouch Disorders. Journal of Crohn's and Colitis 2017;11(6):649-70. doi: doi: 10.1093/ecco-jcc/jjx008

15. Ou B, Zhao J, Guan S, et al. Survival of Colorectal Cancer in Patients With or Without Inflammatory Bowel Disease: A Meta-Analysis. Dig Dis Sci 2016;61(3):881-9. doi: 10.1007/s10620-015-3940-1

16. Eaden J, Abrams K, Mayberry J. The risk of colorectal cancer in ulcerative colitis: a meta-analysis. Gut 2001;48(4):526-35.

17. Söderlund S, Brandt L, Lapidus A, et al. Decreasing time-trends of colorectal cancer in a large cohort of patients with inflammatory bowel disease. Gastroenterology 2009; 136:1561-67. 
18. Beaugerie L, Svrcek M, Seksik P, et al. Risk of colorectal high-grade dysplasia and cancer in a prospective observational cohort of patients with inflammatory bowel disease. Gastroenterology 2013;145(1):166-75.e8. doi: 10.1053/j.gastro.2013.03.044

19. Selinger C, Andrews J, Titman A, et al. Long-term follow-up reveals low incidence of colorectal cancer, but frequent need for resection, among Australian patients with inflammatory bowel disease. Clin Gastroenterol Hepatol 2014;12(4):644-50.

20. Hovde $\varnothing$, Høivik ML, Henriksen M, et al. Malignancies in patients with inflammatory bowel disease: Results from 20 years of follow-up in the IBSEN study. Journal of Crohn's and Colitis 2017;11(5):571-77.

21. Singh S, Singh P, Murad M, et al. Prevalence, risk factors, and outcomes of interval colorectal cancers: a systematic review and meta-analysis. Am J Gastroenterol 2014; 109:1375-89.

22. Mooiweer E, van der Meulen-de Jong A, Ponsioen C, et al. Incidence of interval colorectal cancer among inflammatory bowel disease patients undergoing regular colonoscopic surveillance. Clin Gastroenterology and Hepatology 2015;13:1656-61.

23. Choi C, Rutter M, Askari A, et al. Forty-year analysis of colonoscopic surveillance program for neoplasia in ulcerative colitis: an updated over- view. Am J Gastroenterol 2015;110:1022-34.

24. Bogach J, Pond G, Esckicioglu C, et al. Age-Related Survival Differences in Patients With Inflammatory Bowel Disease-Associated Colorectal Cancer: A PopulationBased Cohort Study. Inflamm Bowel Dis 2019; [Epub ahead of print]

25. Brackmann S, Aamodt G, Andersen S, et al. Widespread but not localized neoplasia in inflammatory bowel disease worsens the prognosis of colorectal cancer. . Inflamm Bowel Dis. , 2010:474-81.

26. Canavan C, Abrams K, Mayberry J. Meta-analysis: colorectal and small bowel cancer risk in patients with Crohn's disease. Aliment Pharmacol Ther 2006;23(8):1097-104. doi: 10.1111/j.1365-2036.2006.02854.x

27. Askling J, Dickman P, Karlen P, et al. Family history as a risk factor for colorectal cancer in inflammatory bowel disease. Gastroenterol 2001;120:1356-62.

28. Velayos FS, Loftus Jr EV, Jess T, et al. Predictive and protective factors associated with colorectal cancer in ulcerative colitis: A case-control study. Gastroenterol 2006;130(7):1941-49. doi: doi: 10.1053/j.gastro.2006.03.028

29. Lakatos L, Mester G, Erdelyi Z, et al. Risk Factors for Ulcerative Colitis Associated Colorectal Cancer in a Hungarian Cohort of Patients With Ulcerative Colitis: Results of a Population-based Study. Inflamm Bowel Dis 2006;12(3):205-11.

30. Shah SC, Ten Hove JR, Castaneda D, et al. High Risk of Advanced Colorectal Neoplasia in Patients With Primary Sclerosing Cholangitis Associated With Inflammatory Bowel Disease. Clin Gastroenterol Hepatol 2018;Epub ahead of print doi: 10.1016/j.cgh.2018.01.023

31. Fumery M, Dulai PS, Gupta S, et al. Incidence, Risk Factors, and Outcomes of Colorectal Cancer in Patients With Ulcerative Colitis With Low-Grade Dysplasia: A Systematic Review and Meta-analysis. Clin Gastroenterol Hepatol 2017;15(5):665-74.

32. Rutter M, Saunders B, Wilkinson K, et al. Severity of Inflammation Is a Risk Factor for Colorectal Neoplasia in Ulcerative Colitis. Gastroenterol 2004;126:451-59.

33. Rubin D, Huo D, Kinnucan J, et al. Inflammation is an independent risk factor for colonic neoplasia in patients with ulcerative colitis: a case-control study. Clin Gastroenterol Hepatol 2013;11(12):1601-8. doi: doi: 10.1016/j.cgh.2013.06.023

34. Choi C, Al-Bakir I, Ding N, et al. Cumulative burden of inflammation predicts colorectal neoplasia risk in ulcerative colitis: a large single-centre study. Gut 2017;0:1-9. 
35. Gupta RB, Harpaz N, Itzkowitz S, et al. Histologic inflammation is a risk factor for progression to colorectal neoplasia in ulcerative colitis: a cohort study. Gastroenterol 2007;133:1099-105. doi: doi: 10.1053/j.gastro.2007.08.001

36. Axelrad J, Lichtiger S, Yajnik V. Inflammatory bowel disease and cancer: The role of inflammation, immunosuppression, and cancer treatment. World journal of gastroenterology : WJG 2016;22(20):4794-801. doi: 10.3748/wjg.v22.i20.4794

37. Lutgens M, Oldenburg B, Siersema P, et al. Colonoscopic Surveillance Improves Survival After Colorectal Cancer Diagnosis in Inflammatory Bowel Disease: Br J Cancer, 2009:1671-5.

38. Ullman T, Croog V, Harpaz N, et al. Progression of flat low grade dysplasia to advanced neoplasia in patients with ulcerative colitis. Gastroenterology 2003;125:1311-139.

39. Laine L, Kaltenbach T, Barkun A, et al. SCENIC international consensus statement on surveillance and management of dysplasia in inflammatory bowel disease. Gastrointest Endosc 2015;81(3):489-501. doi: doi: 10.1016/j.gie.2014.12.009

40. Grivennikov S, Greten F, Karin M. Immunity, inflammation, and cancer. Cell ., 2010:883-99.

41. Payne C, Bernstein C, Dvorak K, et al. Hydrophobic bile acids, genomic instability, Darwinian selection, and colon carcinogenesis . Clin Exp Gastroenterol, 2008:19-47.

42. Grivennikov S. Inflammation and colorectal cancer: colitis-associated neoplasia. Semin Immunopathol 2013;35(2):229-44. doi: 10.1007/s00281-012-0352-6

43. Chiba T, Marusawa H, Ushijima T. Inflammation-associated cancer development in digestive organs: mechanisms and roles for genetic and epigenetic modulation. . Gastroenterology, 2012:550-63.

44. Hussain S, Hofseth L, Harris C. Radical causes of cancer. Nat Rev Cancer, 2003:276-85.

45. Ekbom A, Helmick C, Zack M, et al. Increased risk of large-bowel cancer in Crohn's disease with colonic involvement. . Lancet 1990;336:357-9.

46. Vogelstein B, Fearon E, Hamilton S, et al. Genetic alterations during colorectal-tumor development. N Engl J Med 1988;319(9):525-32.

47. Powell S, Zilz N, Beazer-Barclay Y, et al. Apc mutations occur early during colorectal tumorigenesis. Nature 1992;359(6392):235-37.

48. Yin J, Harpaz N, Tong Y, et al. p53 point mutations in dysplastic and cancerous ulcerative colitis lesions. Gastroenterol 1993;104(6):1633-9.

49. Brentnall T, Crispin D, Rabinovitch P, et al. Mutations in the $\mathrm{p} 53$ gene: an early marker of neoplastic progression in ulcerative colitis. Gastroenterol 1994;107(2):369-78.

50. Galandiuk S, Rodriguez-Justo M, Jeffery R, et al. Field cancerization in the intestinal epithelium of patients with Crohn's ileocolitis. Gastroenterol 2012;142(4)::855-64.

51. Fearon E, Vogelstein B. A genetic model for colorectal tumorigenesis. Cell 1990;61:75967.

52. Söderlund S, Tribukait B, Öst $\AA$, et al. Colitis-associated DNA aneuploidy and dysplasia in Crohn's disease and risk of colorectal cancer. Inflamm Bowel Dis 2011;17(5):11017.

53. Rubin C, Haggitt R, Burmer G, et al. DNA aneuploidy in colonic biopsies predicts future development of dysplasia in ulcerative colitis. Gastroenterology, 1992:1611-20.

54. Tarmin L, Yin J, Harpaz N, et al. Adenomatous polyposis coli gene mutations in ulcerative colitis-associated dysplasias and cancers versus sporadic colon neoplasms. Cancer Res 1995;55(10):2035-8.

55. Rogler G. Chronic ulcerative colitis and colorectal cancer. Cancer Lett 2013;345(2):23541. doi: 10.1016/j.canlet.2013.07.032 
56. Fogt F, Vortmeyer A, Goldman H, et al. Comparison of genetic alterations in colonic adenoma and ulcerative colitis-associated dysplasia and carcinoma. . Hum Pathol . 1998:131-36.

57. Risques R, Lai L, Himmetoglu C, et al. Ulcerative colitis-associated colorectal cancer arises in a field of short telomeres, senescence, and inflammation . 2011:1669-79.

58. Baker KT, Salk JJ, Brentnall TA, et al. Precancer in Ulcerative Colitis: The Role of the Field Effect and its Clinical Implications. Carcinogenesis 2017; ahead of print

59. Farraye F, Odze RD, Eaden J, et al. AGA Technical Review on the Diagnosis and Management of Colorectal Neoplasia in Inflammatory Bowel Disease. Gastroenterology, 2010:746-74.

60. Lamb C, Kennedy N, Raine T, et al. British Society of Gastroenterology consensus guidelines on the management of inflammatory bowel disease in adults. Gut 2019([Epub ahead of print])

61. Magro F, Gionchetti P, Eliakim R, et al. Third European Evidence-based Consensus on Diagnosis and Management of Ulcerative Colitis. Part 1: Definitions, Diagnosis, Extra-intestinal Manifestations, Pregnancy, Cancer Surveillance, Surgery, and Ileoanal Pouch Disorders. Journal of Crohn's and Colitis 2017;11(6):649-70. doi: doi: 10.1093/ecco-jcc/jjx008

62. American Society for Gastrointestinal Endoscopy, Standards of Practice Committee, Shergill A, et al. The role of endoscopy in inflammatory bowel disease. Gastrointest Endosc 2015;81(5):1101-21. doi: 10.1016/j.gie.2014.10.030

63. Matsumoto T, Nakamura S, Jo Y, et al. Chromoscopy might improve diagnostic accuracy in cancer surveillance for ulcerative colitis. American Journal of Gastroenterology 2003;98(8):1827-33. doi: doi: 10.1111/j.1572-0241.2003.07580.x

64. Rutter M D, Saunders B P, Schofield G, et al. Pancolonic indigo carmine dye spraying for the detection of dysplasia in ulcerative colitis. Gut 2004;53(2):256-60. doi: doi: 10.1136/gut.2003.016386

65. Rutter MD, Saunders BP, Wilkinson KH, et al. Thirty-year analysis of a colonoscopic surveillance program for neoplasia in ulcerative colitis. Gastroenterology 2006;130(4):1030-8.

66. Rutter M, Saunders B, Wilkinson K, et al. Most dysplasia in ulcerative colitis is visible at colonoscopy. Gastrointest Endosc 2004;60(3):334-39.

67. Kiesslich R, Fritsch J, Holtmann M, et al. Methylene blue-aided chromoendoscopy for the detection of intraepithelial neoplasia and colon cancer in ulcerative colitis. Gastroenterol 2003;124(4):880-88.

68. Kiesslich R, Goetz M, Lammersdorf K, et al. Chromoscopy-guided endomicroscopy increases the diagnostic yield of intraepithelial neoplasia in ulcerative colitis. Gastroenterol 2007;132:874-82.

69. Marion J, Waye J, Present DH, et al. Chromoendoscopy-targeted biopsies are superior to standard colonoscopic surveillance for detecting dysplasia in inflammatory bowel disease patients: a prospective endoscopic trial. Am J Gastroenterol 2008;103(9):2342-9. doi: doi: 10.1111/j.1572-0241.2008.01934.x.

70. Hlavaty T, Huorka M, Koller T, et al. Colorectal cancer screening in patients with ulcerative and Crohn's colitis with use of colonoscopy, chromoendoscopy and confocal endomicroscopy. Eur J Gastroenterol Hepatol 2011;23(8):680-9.

71. Laine L, Kaltenbach T, Barkun A, et al. SCENIC international consensus statement on surveillance and management of dysplasia in inflammatory bowel disease. Gastrointest Endosc 2015;81(3):489-501.

72. Feuerstein J, Rakowsky S, Sattler L, et al. Meta-analysis of dye-based chromoendoscopy compared with standard- and high-definition white-light endoscopy in patients with 
inflammatory bowel disease at increased risk of colon cancer. Gastrointest Endosc., 2019:186-95.

73. Van den Broek FJ, Stokkers PC, Reitsma JB, et al. Random biopsies taken during colonoscopic surveillance of patients with long- standing ulcerative colitis: low yield and absence of clinical consequences. Am J Gastroenterol 2014;109(5):715-22. doi: doi: 10.1038/ajg.2011.93

74. Marion J F, Waye J D, Israel Y, et al. Chromoendoscopy Is More Effective Than Standard Colonoscopy in Detecting Dysplasia During Long-term Surveillance of Patients With Colitis. Clin Gastroenterol Hepatol 2016;14(5):713-19. doi: doi: 10.1016/j.cgh.2015.11.011

75. Konijeti G, Shrime M, Ananthakrishnan A, et al. Cost-effectiveness analysis of chromoendoscopy for colorectal cancer surveillance in patients with ulcerative colitis. Gastrointest Endosc 2014;79(3):455-65. doi: doi: 10.1016/j.gie.2013.10.026

76. Kaltenbach TR, Soetikno RM, DeVivo R, et al. Optimizing the Quality of Endoscopy in Inflammatory Bowel Disease: Focus on Surveillance and Management of Colorectal Dysplasia Using Interactive Image- And Video-Based Teaching. Gastrointestinal Endoscopy, 2017:1107-17.

77. Kisiel JB, Yab TC, Nazer Hussain FT, et al. Stool DNA Testing for the Detection of Colorectal Neoplasia in Patients with Inflammatory Bowel Disease. Aliment Pharmacol Ther 2013;37(5))

78. Kisiel J, Konijeti G, Piscitello A, et al. Stool DNA Analysis is Cost-Effective for Colorectal Cancer Surveillance in Patients With Ulcerative Colitis. Clin Gastroenterol Hepatol 2016;14(12):1778-87.

79. Imperiale TF, Ransohoff DF, Itzkowitz SH, et al. Multitarget stool DNA testing for colorectal-cancer screening. N Engl J Med 2014;370(14):1287-97.

80. Moum B, Vatn MH, Ekbom A, et al. Incidence of inflammatory bowel disease in southeastern Norway: evaluation of methods after 1 year of registration. Southeastern Norway IBD Study Group of Gastroenterologists. Digestion 1995;56(5):377-81.

81. Solberg I, Lygren I, Jahnsen J, et al. Clinical course during the first 10 years of ulcerative colitis: results from a population-based inception cohort (IBSEN Study). Scand $J$ Gastroenterol 2009;44(4):431-40.

82. Hovde Ø, Smastuen M, Høivik M, et al. Mortality and Causes of Death in Ulcerative Colitis: Results from 20 Years of Follow-up in the IBSEN Study. Inflamm Bowel Dis 2016;22(1):141-45.

83. Geboes K, Riddell R, Öst A, et al. A reproducible grading scale for histological assessment of inflammation in ulcerative colitis. Gut 2000;47:404-09.

84. Riddell RH, Goldman H, Ransohoff DF, et al. Dysplasia in inflammatory bowel disease: standardized classification with provisional clinical applications. Human Pathol 1983;14(11):931-68. doi: doi: 10.1016/S0046-8177(83)80175-0

85. Hiraoka S, Kato J, Nakarai A, et al. Consecutive Measurements by Faecal Immunochemical Test in Quiescent Ulcerative Colitis Patients Can Detect Clinical Relapse. Journal of Crohn's and Colitis 2016;10(6):687-94.

86. Lidgard GP, Domanico MJ, Bruinsma JJ, et al. Clinical performance of an automated stool DNA assay for detection of colorectal neoplasia. Clin Gastroenterol Hepatol 2013;11(10):1313-8.

87. Imperiale TF, Ransohoff DF, Itzkowitz SH, et al. Multitarget Stool DNA Testing for Colorectal Cancer Screening. Supplementary Index. N Engl J Med 2014;370:1287-97.

88. Redwood DG, Asay ED, Blake ID, et al. Stool DNA Testing for Screening Detection of Colorectal Neoplasia in Alaska Native People. Mayo Clin Proc 2016;91(1):61-70. 
89. Mooiweer E, Baars J, Lutgens M, et al. Disease severity does not affect the interval between IBD diagnosis and the development of CRC: results from two large, Dutch case series. J Crohns Colitis 2012;6:435-40.

90. Parra-Blanco A, Ruiz A, Alvarez-Lobos M, et al.

Achieving the best bowel preparation for colonoscopy. World J Gastroenterol., 2014:17709-26.

91. Clark B, Rustagi T, Laine L. What level of bowel prep quality requires early repeat colonoscopy: systematic review and meta-analysis of the impact of preparation quality on adenoma detection rate. Am J Gastroenterol 2014;109(11):1714-23.

92. Froehlich F, Wietlisbach V, Gonvers J, et al. Impact of colonic cleansing on quality and diagnostic yield of colonoscopy: the European Panel of Appropriateness of Gastrointestinal Endoscopy European multicenter study. Gastrointest Endosc 2005;61(3):378-84.

93. Megna B, Weiss J, Ley D, et al. Clear Liquid Diet Before Bowel Preparation Predicts Successful Chromoendoscopy in Patients With Inflammatory Bowel Disease. Gastrointestinal Endoscopy, 2019:373-79.

94. Benson M, Reichelderfer M, Said A, et al. Variation in colonoscopic technique and adenoma detection rates at an academic gastroenterology unit. Dig Dis Sci 2010;55(1):166-71.

95. Subramanian V, Mannath J, Ragunath K, et al. Meta-analysis: the diagnostic yield of chromoendoscopy for detecting dysplasia in patients with colonic inflammatory bowel disease. Aliment Pharmacol Ther 2011;33(3):304-12.

96. Yang D, Park S, Kim H, et al. High - Definition Chromoendoscopy Versus High Definition White Light Colonoscopy for Neoplasia Surveillance in Ulcerative Colitis: A Randomized Controlled Trial. Am J Gastroenterol. , 2019:1642-48.

97. Choi C, Rutter M, Askari A, et al. Forty-year analysis of colonoscopic surveillance program for neoplasia in ulcerative colitis: an updated overview. Am J Gastroenterol 2015;110:1022-34.

98. Jess T, Simonsen J, Jørgensen K, et al. Decreasing risk of colorectal cancer in patients with inflammatory bowel disease over 30 years. Gastroenterology 2012;143:375-81. doi: $10.1053 /$ j.gastro.2012.04.016

99. Jess T, Horváth-Puhó E, Fallingborg J, et al. Cancer risk in inflammatory bowel disease according to patient phenotype and treatment: a Danish population-based cohort study. Am J Gastroenterol 2013;108(12):1869-76. doi: 10.1038/ajg.2013.249

100. National Cancer Registry of Norway. Cancer in Norway 2017. 2018:26, 86, 96.

101. Annese V, Beaugerie L, Egan L, et al. European Evidence-based Consensus: Inflammatory Bowel Disease and Malignancies. Journal of Crohn's and Colitis 2015:945-65. doi: doi: 10.1093/ecco-jcc/jjv141

102. National Institute for Health and Clinical Excellence London. Colonoscopic Surveillance for Prevention of Colorectal Cancer in People with

Ulcerative Colitis, Crohn's Disease or Adenomas . . NICE Clinical Guidelines, 2011:https:// www.ncbi.nlm.nih.gov/pubmedhealth/PMH0033569/pdf/PubMedHealth_PMH69.pdf.

103. Cancer Council Australia Sydney. Cancer Council Australia Surveillance Colonoscopy Guidelines Working Party.

Clinical Practice Guidelines for Surveillance Colonoscopy

. [https://wiki.cancer.org.au/australia/

Guidelines:Colorectal_cancer/Colonoscopy_surveillance, 2018. 
104. Bernstein C, Wajda A, Svenson L, et al. The epidemiology of inflammatory bowel disease in Canada: a population-based study. Am J Gastroenterol 2006;101(7):155968.

105. Söderlund S, Granath F, Broström O, et al. Inflammatory bowel disease confers a lower risk of colorectal cancer to females than to males. Gastroenterol 2010;138(5):1697703. doi: $10.1053 /$ j.gastro.2010.02.007.

106. Cohen-Mekelburg S, Schneider Y, Gold S, et al. Risk of Early Colorectal Cancers Needs to Be Considered in Inflammatory Bowel Disease Care. Dig Dis Sci 2019;Epub ahead of print] doi: 10.1007/s10620-019-05554-1

107. Winther K, Jess T, Langholz E, et al. Long-term risk of cancer in ulcerative colitis: a population-based cohort study from Copenhagen County. Clin Gastroenterol Hepatol 2004;2(12):1088-95.

108. Baars J, Kuipers E, van Haastert M, et al. Age at diagnosis of inflammatory bowel disease early development of colorectal cancer in inflammatory bowel disease patients: a nationwide, long-term survey. Gastroenterol 2012;47:1308-22.

109. Cho Y, Kim D, Cha J, et al. Patients' Preferences for Primary Colorectal Cancer Screening: A Survey of the National Colorectal Cancer Screening Program in Korea. Gut Liver 2017;11(6):821-27.

110. Risques RA, Lai LA, Brentnall TA, et al. Ulcerative Colitis Is a Disease of Accelerated Colon Aging: Evidence From Telomere Attrition and DNA Damage. Gastroenterology, 2008:410-8.

111. Lutgens MW, van Oijen MG, van der Heijden GJ, et al. Declining risk of colorectal cancer in inflammatory bowel disease: an updated meta-analysis of population-based cohort studies. Inflamm Bowel Dis 2013;19:789-99. doi: 10.1097/MIB.0b013e31828029c0

112. Brackmann S, Andersen S, Aamodt G, et al. Relationship between clinical parameters and the colitis-colorectal caner interval in a cohort of patients with colorectal cancer in inflammatory bowel disease. Scand J Gastroenterol 2009;44:46-55.

113. Tran A, Man Ngor E, Wu B. Surveillance colonoscopy in elderly patients: A retrospective cohort study. Jama 2014;174:1675-82.

114. Cosnes J, Gower-Rousseau C, Seksik P, et al. Epidemiology and natural history of inflammatory bowel diseases. Gastroenterology 2011;140(6):1785-94.

115. Jess T, Riis L, Vind I, et al. Changes in clinical characteristics, course, and prognosis of inflammatory bowel disease during the last 5 decades: a population-based study from Copenhagen, Denmark. Inflamm Bowel Dis 2007;13(4):481-9.

116. Jess T, Loftus EJ, Velayos F, et al. Risk factors for colorectal neoplasia in inflammatory bowel disease: a nested case-control study from Copenhagen county, Denmark and Olmsted county, Minnesota. Am J Gastroenterol 2007;102(4):829-36. [published Online First: 2007 Jan 11]

117. Goldstone R, Itzkowiitz S, Harpaz N, et al. Dysplasia is more common in the distal than proximal colon in ulcerative colitis surveillance. Inflamm Bowel Dis 2012;18(5):8327. doi: 10.1002/ibd.21809

118. Ullman T A, Itkowitz S H. Intestinal inflammation and cancer. Gastroenterol 2011;140(6):1807-16. doi: doi: 10.1053/j.gastro.2011.01.057

119. Mooiweer E, van der Meulen-de Jong A, Ponsioen C, et al. Incidence of interval colorectal cancer among inflammatory bowel disease patients undergoing regular colonoscopic surveillance. Clin Gastroenterology and Hepatology 2015;13:1656-61.

120. Collins P. Strategies for Detecting Colon Cancer and Dysplasia in Patients with Inflammatory Bowel Disease 2013:860-63. 
121. Karlén P, Kornfeld D, Broström O, et al. Is Colonoscopic Surveillance Reducing Colorectal Cancer Mortality in Ulcerative Colitis? A Population Based Case Control Study: Gut, 1998:711-4.

122. Eaden J, Abrams K, Ekbom A, et al. Colorectal cancer prevention in ulcerative colitis: a case-control study. Aliment Pharmacol Ther 2000;14(2):145-53.

123. Ananthakrishnan AN, Cagan A, Cai T, et al. Colonoscopy is associated with a reduced risk for colon cancer and mortality in patients with inflammatory bowel diseases. Clin Gastroenterol Hepatol 2015;13(2):322-29.

124. Singh K, Al Khoury A, Kurti Z, et al. High Adherence to Surveillance Guidelines in Inflammatory Bowel Disease Patients Results in Low Colorectal Cancer and Dysplasia Rates, While Rates of Dysplasia are Low Before the Suggested Onset of Surveillance. J Crohns Colitis, 2019:1343-50.

125. East J, Suzuki N, von Herbay A, et al. Narrow band imaging with magnification for dysplasia detection and pit pattern assessment in ulcerative colitis surveillance: a case with multiple dysplasia associated lesions or masses . Gut, 2006:1432 - 5.

126. Ananthakrishnan A. Chromoendoscopy Is Better: So Why Am I Not (yet) Using it for Routine Inflammatory Bowel Disease Surveillance? Clinical Gastroenterology and Hepatology 2016;14(5):720-22. doi: 10.1016/j.cgh.2015.09.016

127. Hammad H, Kaltenbach T, Soetikno R. Surveillance for dysplasia in inflammatory bowel disease: it is time to move forward. Endoscopy, 2017:110-12.

128. van Rijn A, Fockens P, Siersema PD, et al. Adherence to surveillance guidelines for dysplasia and colorectal carcinoma in ulcerative and Crohn's colitis patients in the Netherlands. World journal of gastroenterology : WJG 2009;15(2):226-30.

129. Velayos F, Liu L, Lewis J, et al. Prevalence of colorectal cancer surveillance for ulcerative colitis in an integrated health care delivery system. Gastroenterology 2010;139:1511-8.

130. Shinozaki M, Kobayashi K, Kunisaki R, et al. Surveillance for dysplasia in patients with ulcerative colitis: Discrepancy between guidelines and practice. Dig Endosc 2017;29(5):584-93.

131. Mooiweer E, van der Meulen-de Jong AE, Ponsioen CY, et al. Chromoendoscopy for Surveillance in Inflammatory Bowel Disease Does Not Increase Neoplasia Detection Compared With Conventional Colonoscopy With Random Biopsies: Results From a Large Retrospective Study. Am J Gastroenterol 2015;110(7):1014-21. doi: doi: 10.1038/ajg.2015.63

132. Vleugels JLA, Rutter MD, Ragunath K, et al. Diagnostic Accuracy of Endoscopic Trimodal Imaging and Chromoendoscopy for Lesion Characterization in Ulcerative Colitis. Journal of Crohn's and Colitis, 2018:1438-47.

133. Carballal S, Maisterra S, López-Serrano A, et al. Real-life chromoendoscopy for neoplasia detection and characterisation in long-standing IBD. Gut 2018;67(1):70-78. doi: doi: 10.1136/gutjnl-2016-312332

134. Iacucci M, Kaplan G, Panaccione R, et al. A Randomized Trial Comparing High Definition Colonoscopy Alone With High Definition Dye Spraying and Electronic Virtual Chromoendoscopy for Detection of Colonic Neoplastic Lesions During IBD Surveillance Colonoscopy. Am J Gastroenterol 2018;113(2):225-34. doi: 10.1038/ajg.2017.417

135. Wu L, Li P, Wu J, et al. The diagnostic accuracy of chromoendoscopy for dysplasia in ulcerative colitis: meta-analysis of six randomized controlled trials. Colorectal dis 2012;14(4):416-20. doi: doi: 10.1111/j.1463-1318.2010.02505.x.

136. Thomas T, Abrams KA, Robinson RJ, et al. Meta-analysis: cancer risk of low-grade dysplasia in chronic ulcerative colitis. Aliment Pharmacol Ther 2007;25(6):657-69. 
137. Lim C, Dixon M, Vail A, et al. Ten year follow up of ulcerative colitis patients with and without low grade dysplasia. Gut 2003;52(8):1127-32.

138. Befrits R, Ljung T, Jaramillo E, et al. Low-grade dysplasia in extensive, long-standing inflammatory bowel disease : a follow-up study. Dis Colon Rectum, 2002:615-20.

139. Hata K, Watanabe T, Kazama S, et al. Earlier surveillance colonoscopy programme improves survival in patients with ulcerative colitis associated colorectal cancer : results of a 23-year surveillance programme in the Japanese population.: Br J Cancer, 2003:1232-36.

140. Bernstein C, Blanchard J, Kliewer E, et al. Cancer risk in patients with inflammatory bowel disease: a population-based study. Cancer 2001;91(4):854-62.

141. ten Hove JR, Mooiweer E, van der Meulen-de Jong AE, et al. Clinical implications of low grade dysplasia found during inflammatory bowel disease surveillance: a retrospective study comparing chromoendoscopy and white-light endoscopy. Endoscopy 2017;49(2):161-68.

142. Burke K, Nayor J, Campbell E, et al. Interval Colorectal Cancer in Inflammatory Bowel Disease: The Role of Guideline Adherence. Dig Dis Sci 2019;[Epub ahead of print]

143. Watanabe T, Ajioka Y, Mitsuyama K, et al. Comparison of Targeted vs Random Biopsies for Surveillance of Ulcerative Colitis-Associated Colorectal Cancer. Gastroenterol 2016;151(6):1122-30. doi: doi: 10.1053/j.gastro.2016.08.002

144. Mahmoud R, Shah S, Ten H, JR, et al. No Association Between Pseudopolyps and Colorectal Neoplasia in Patients With Inflammatory Bowel Diseases. Gastroenterology, 2019:1333-44.e3.

145. Prince M, Lester L, Chiniwala R, et al. Multitarget stool DNA tests increases colorectal cancer screening among previously noncompliant Medicare patients. World journal of gastroenterology, 2017.

146. Johne B, Fagerhol M, Lyberg T, et al. Functional and clinical aspects of the myelomonocyte protein calprotectin. Mol Path, 1997:113-23.

147. Navaneethan U, Jegadeesan R, Gutierrez NG, et al. Progression of low-grade dysplasia to advanced neoplasia based on the location and morphology of dysplasia in ulcerative colitis patients with extensive colitis under colonoscopic surveillance. $J$ Crohns Colitis 2013;7(12):684-91.

148. Venkatesh PG, Jegadeesan R, Gutierrez NG, et al. Natural history of low grade dysplasia in patients with primary sclerosing cholangitis and ulcerative colitis. $J$ Crohns Colitis 2013;7(12):968-73.

149. Goldstone R, Itzkowitz S, Harpaz N, et al. Progression of low-grade dysplasia in ulcerative colitis: effect of colonic location. Gastrointest Endosc 2011;74:1087-93.

150. Johnson D, Taylor W, Aboelsoud M, et al. DNA Methylation and Mutation of Small Colonic Neoplasms in Ulcerative Colitis and Crohn's Colitis: Implications for Surveillance. Inflamm Bowel Dis 2016;22(7):1559-67.

151. Xiang L, Zhan Q, Zhao XH, et al. Risk factors associated with missed colorectal flat adenoma: a multicenter retrospective tandem colonoscopy study. World journal of gastroenterology : WJG 2014;20:10927-37.

152. Cotter TG, Burger KN, Devens ME, et al. Long-Term Follow-up of Patients Having False Positive Multi-target Stool DNA Tests after Negative Screening Colonoscopy: The LONG-HAUL Cohort Study. Cancer Epidemiol Biomarkers Prev 2017;26(4):614-21.

153. Berger B, Kisiel J, Imperiale T, et al. Low Incidence of Aerodigestive Cancers in Patients With Negative Results From Colonoscopies, Regardless of Findings From Multitarget Stool DNA Tests. Clin Gastroenterol Hepatol 2019; [Epub ahead of print] 
154. Cooper G, Markowitz S, Chen Z, et al. Evaluation of Patients with an Apparent False Positive Stool DNA Test: The Role of Repeat Stool DNA Testing. Dig Dis Sci 2018;63(6):1449-53. 
Original articles I-III 

I 

Cvancarova $M$, et al. Risk of colorectal cancer in a population-based study 20 years after diagnosis of ulcerative colitis results from the IBSEN study. BMJ Open Gastro 20e0;7:e000361. doi:10.1136 bmjgast-2019-000361

Received 15 December 2019 Revised 17 February 2020 Accepted 21 February 2020

\title{
Risk of colorectal cancer in a population-based study 20 years after diagnosis of ulcerative colitis: results from the IBSEN study
}

\author{
Pasquale Klepp $\odot{ }^{1,2}$ Stephan Brackmann, ${ }^{3,4}$ Milada Cvancarova, ${ }^{2,4}$ \\ Marte Lie Hoivik, ${ }^{2,4}$ 'Øistein Hovde, ${ }^{4,5}$ Magne Henriksen, ${ }^{6}$ Gert Huppertz-Hauss, ${ }^{7}$ \\ Tomm Bernklev, ${ }^{4,8}$ Ole Hoie, ${ }^{9}$ Iril Kempski-Monstad $\odot,{ }^{10}$ Inger Camilla Solberg, ${ }^{2}$ \\ Njaal Stray, ${ }^{11}$ Jorgen Jahnsen, ${ }^{3,4}$ Morten H Vatn, ${ }^{4}$ Bjorn Moum ${ }^{2,4}$
}

\section{ABSTRACT}

Objective The association between ulcerative colitis (UC) and colorectal cancer (CRC) is widely accepted, although attenuated risk has been reported in recent years.

Colonoscopic surveillance is recommended with intervals based on established dinical risk factors. Nevertheless, a significant number of patients develop interval

cancers, indicating the need of improved individualised assessment. In the present study, we evaluated clinical risk factors associated with CRC during a prescheduled follow-up 20 years after diagnosis, the IBSEN study. Design A population-based inception cohort of patients diagnosed with inflammatory bowel disease from 1 January 1990 until 31 December 1993, prospectively followed at 1, 5, 10 and 20 years after diagnosis. A total of 517 patients with UC were included; 264 (51\%) men; median age at inclusion 37.4 years (4-88). Results The overall incidence of CRC was $1.6 \%(8 / 517)$ at a 20-year follow-up. The total lifetime risk of CRC prior to or after UC diagnosis was 2.3\%. (12/517). Patients older than 70 years at diagnosis had a 15 -fold higher risk of CRC compared with those diagnosed when younger than 40 years, with HR 15.68 (95\% Cl: 1.31 to 187.92). Neither sex, first-degree relative with CRC, extent of colitis nor primary sderosing cholangitis affected the risk of CRC. Conclusion The risk of CRC in UC was low and comparable with the risk of CRC in the background population of Norway.

\section{INTRODUCTION}

The association between ulcerative colitis (UC) and colorectal cancer (CRC) is widely accepted although the magnitude of the risk seems to have decreased, according to recent studies. ${ }^{12}$ In 2014, an Australian study described a cumulative incidence of $1 \%$ at 10 years, $3 \%$ at 20 years and $7 \%$ at 30 years for CRC-UC. ${ }^{3}$ More recently, a populationbased inception cohort study, the IBSEN study, described a twofold increased risk after 20 years for male patients with UC but no

\section{Summary box}

What is already known about this subject?

Ulcerative colitis (UC) is associated with colorectal cancer (CRC).

- The risk of CRC appears to have decreased in magnitude.

- Clinical risk factors influence the risk and determine the frequency of surveillance.

What are the new findings?

- The overall incidence of CRC was $1.6 \%$ in a prospective cohort at a 20 -year follow-up of UC, the IBSEN 20 cohort.

The total lifetime risk of CRC was similar to the risk in the background population of Norway.

How might it impact on clinical practice in the foreseeable future?

The present study provides real-world knowledge on the risk of CRC in UC allowing us to update and improve surveillance strategies.

increase in risk for female patients with UC, compared with the background population. ${ }^{4}$ Several risk factors have been established and include cumulative inflammatory damage, severe and extensive inflammation, previous neoplasia in the colon, coexistence of primary sclerosing cholangitis (PSC), a history of first-degree relatives with CRC and male sex. ${ }^{5-12}$ In contrast, anti-inflammatory medication seems to be protective, probably as chronic inflammation contributes to the development of CRC. ${ }^{6} 1 \mathrm{1} 14$ Colonoscopic surveillance is effective for the detection of CRC in UC patients with UC; however, the effect on survival is not established. Moreover, although decreasing in incidence in parallel with technical advances in endoscopy a significant number of patients develop interval 


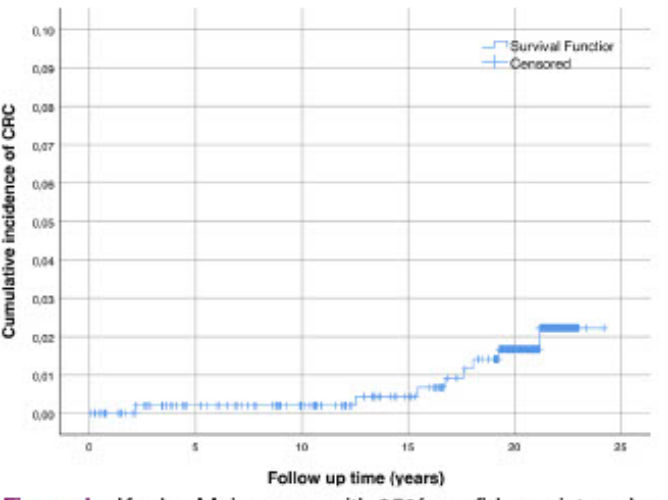

Figure 1 Kaplan Meier curve with $95 \%$ confidence intervals showing the cumulative incidence of $\mathrm{CRC}$ by calendar period of follow-up

cancer, indicating the need for more sensitive tools for risk assessment. ${ }^{15-17}$ This need is further emphasised by the rising incidence of $\mathrm{UC}$, with the need for endoscopic surveillance due to disease flares or complications. ${ }^{18} 19$ More detailed knowledge on the specific effect of each risk factor could enable more precise and personalised surveillance.

Thus, the aim of the present study was to assess the association between selected clinical risk factors and CRC in a prospective population-based cohort of UC patients.

\section{MATERIAL AND METHODS}

\section{Study population}

A population-based inception cohort of patients with inflammatory bowel disease (IBD), the IBSEN cohort, diagnosed with IBD from 1 January 1990 until 31 December 1993, has been prospectively followed at 1,5 , 10 and 20 years after diagnosis. The organisation of the cohort, diagnostic criteria for IBD and clinical follow-up protocol have been described in detail elsewhere. ${ }^{20}{ }^{21} \mathrm{Al}$ visits included a clinical examination, a structured interview and laboratory tests. Surveillance colonoscopies were performed according to guidelines in patients with PSC, history of CRC in first-degree relative or pseudopolyps. Colonoscopies were otherwise performed at loca and referral hospitals when indicated clinically. Surveillance colonoscopy was not performed in the remaining patients as surveillance has not been found to be costeffective and newer modalities time-consuming. Patients were followed closely and thus received adequate antiinflammatory treatment.

A total of 517 patients were diagnosed with UC; half were men $(51 \%)$ and the median age at inclusion was 37.4years (range: 4-88). A total of 10 patients were lost to follow-up during 20years of follow-up. A total of 26 of 347 patients with left-sided colitis and a total of 31 of 170 patients with extensive colitis underwent colectomy. ${ }^{21} 22$

\section{Data collection}

All Norwegian citizens are assigned a unique digital identification number, which makes it possible to link data from several registries and enables highly reliable epidemiological research. All medical doctors in Norway are, by law, obliged to report new and suspected cancers to the Cancer Registry which contains detailed information on each case of cancer, thus ensuring completeness of approximately $99 \%$. Cases of dysplasia are not recorded in the Cancer Registry of Norway.

The International Classification of Diseases, 10th Revision (ICD-10) is the standard diagnostic tool for epidemiology, clinical diagnosis and health management. All cases of malignant neoplasms of the colon, malignant neoplasms of the rectosigmoidal junction and malignant neoplasms of the rectum (C18-C20) recorded until January 2015 in the Cancer Registry of Norway were used in this study.

The interpretation and reporting of these data are the sole responsibility of the authors, and no endorsement by the Cancer Registry of Norway is intended, nor should it be inferred.

Data in this study were extracted from the enrolment, 1-year, 10-year and 20-year follow-up time points.

\section{Ethics}

The regional ethics committees and the Norwegian Data Inspectorate approved the study. Patient identity and record confidentiality were maintained according to guidelines from the Norwegian Ministry of Health. All patients signed an informed consent form. This study was conducted in accordance with the Declaration of Helsinki.

Patient and public involvement (PPI) statement Indirect PPI

We did not directly include PPI in this study, but the database used in the study was developed with PPI and is updated by a committee that includes patient representatives.

\section{Statistical analyses}

Data were described with medians and ranges for continuous variables and counts with percentages for categorical variables. The age used in the analysis was age in years at the 20-year follow-up presentation.

Patients who developed CRC prior to UC diagnosis were not included in the statistical analysis.

Follow-up time was defined as the time from the date of diagnosis of UC to the date of CRC diagnosis, date of death, colectomy or end of follow-up which ever came first. The event was defined as the occurrence of CRC. The risk of having CRC was modelled using Cox proportional hazard regression and the results are expressed as $\mathrm{HRs}$ with $95 \%$ CIs. Variables tested in the univariate Cox models were gender, maximum extent of colitis at any time, duration and age at diagnosis of UC, coexisting PSC and first-degree relative with CRC. All tests were 


\begin{tabular}{|c|c|c|c|c|}
\hline & $\begin{array}{l}\text { UC no CRC } \\
(n=505)\end{array}$ & $\begin{array}{l}\text { CRC after UC } \\
\text { diagnosis }(n=8)\end{array}$ & $\begin{array}{l}\text { CRC prior to UC } \\
\text { diagnosis }(n=4)\end{array}$ & $\begin{array}{l}\text { Total } \\
(n=517)\end{array}$ \\
\hline Male & 255 & 5 & 4 & $264(51 \%)$ \\
\hline Age at UC diagnosis (years) & 37 (4 to 88$)$ & 40 (25 to 62$)$ & 79 (74 to 82$)$ & \\
\hline Age at CRC diagnosis (years) & & 56 (39 to 88$)$ & $69(64$ to 79$)$ & \\
\hline Time from UC diagnosis to CRC (years) & & 22 (1 to 23$)$ & $-6.5(-18$ to -2$)$ & \\
\hline CRC location & & & missing $n=2$ & \\
\hline Rectum & & 3 & 1 & \\
\hline Left colon (excluding rectum) & & 1 & 1 & \\
\hline Right colon & & 4 & & \\
\hline \multicolumn{5}{|l|}{ Maximum extent of UC at any time } \\
\hline Proctitis & 168 & 1 & & $169(33 \%)$ \\
\hline Left sided & 174 & 1 & 3 & $178(34 \%)$ \\
\hline Extensive & 163 & 6 & 1 & $170(33 \%)$ \\
\hline Primary sclerosing cholangitis & 14 & 1 & 0 & $15(3 \%)$ \\
\hline First-degree relative with $\mathrm{CRC}$ (missing $n=70$ ) & 37 & 1 & 0 & $38(7.6 \%)$ \\
\hline
\end{tabular}

$\mathrm{CRC}$, colorectal cancer, UC, ulcerative colitis.

two-sided and $p$ values $<0.05$ were considered statistically significant. All analyses were performed using SPSS V.24.

\section{RESULTS}

Incidence of CRC at a 20-year follow-up

A total of 517 patients with UC were included in the study. The median time of follow-up in years was $20.4(95 \% \mathrm{CI}$ 0.1 to 24.2 ) and IQR was 2.53 .

The cumulative incidence of developing CRC was $1.6 \%$ $(8 / 517)$ at a 20-year follow-up from the diagnosis of UC. The total lifetime risk of developing CRC either before or after the UC diagnosis was 2.3\% (12/517) (figure 1).

CRC was diagnosed $\geq 1$ year after the UC diagnosis in a total of 8 of 517 patients $(5 / 8 \mathrm{men})$, and the median age at CRC diagnosis was 56 (range: $39-88$ ).

CRC was diagnosed prior to UC diagnosis in a total of 4 of 517 patients, all men with the median age at CRC diagnosis being 69years (range: 64-79). These patients were not included in the risk analysis.

The clinical characteristics of all patients with UC are summarised in table 1 .

Variables associated with risk of CRC

Only patients diagnosed with CRC after their UC diagnosis were included in the analyses presented below.

Older age at UC diagnosis was associated with higher risk of CRC. Patients aged above 70 at UC diagnosis had a 15-fold higher risk of CRC compared with those diagnosed aged below 40 years, HR 15.68 (95\% CI: 1.31 to 187.92).

Neither sex, extent of colitis at any time nor concomitant PSC was associated with the risk of CRC.

Details concerning the selected risk factors and clinical characteristics of patients with CRC are summarised in tables 2 and 3 .

\section{DISCUSSION}

In the present inception cohort study prospectively following 517 patients with UC, the overall cumulative incidence of developing CRC was $1.6 \%$ at a 20 -year follow-up from the diagnosis of UC. The total lifetime risk of developing CRC either before or after the UC diagnosis was $2.3 \%$. The present study is the first to prospectively follow an unselected cohort of patients with UC for 20 years and thus provide real-world data about the magnitude of CRC in UC. The overall incidence of CRC in UC is, to our knowledge, the lowest reported so far reflecting the population-based nature of the cohort. The St Mark's surveillance tertiary centre cohort study found a cumulative incidence of $2.9 \%$ and $10 \%$ in patients with extensive UC at 20-year and 40-year follow-up, respectively. ${ }^{17}$ However, a cumulative incidence of $1 \%$ at 10 years, $3 \%$ at 20 years and $7 \%$ at 30 years for CRC-UC was reported in a cohort of 504 patients with UC with varying extent of colitis included from both tertiary and community-based healthcare centres. ${ }^{3}$

Interestingly, the overall risk of CRC in the present UC cohort was found to be slightly lower than the risk of sporadic CRC in Norway. ${ }^{23}$ The cumulative risk of CRC before the age of 75 years is reported to be $2.8 \%$ for women and $3.1 \%$ for men, ranking Norway as the country with fourth-highest rate in the world. ${ }^{23}$

The decrease in risk of CRC for patients with UC has been attributed to improved control of colonic inflammation by medication, appropriate follow-up with regular colonoscopies and technical advances with improved detection of early neoplastic lesions. At the time of the initiation of the present study, standard treatment strategies for UC were 5-ASA as maintenance therapy and prednisolone in cases of disease flares. However, treatment for steroid-refractory severe colitis was colectomy in this 


\begin{tabular}{|c|c|c|c|c|}
\hline & $\begin{array}{l}\text { Total } \\
n=8\end{array}$ & HR & $95 \% \mathrm{Cl}$ & P value \\
\hline \multicolumn{5}{|l|}{ Age (years) } \\
\hline$\leq 0$ (reference) & 2 & 1 & & \\
\hline $41-50$ & 2 & 1.03 & 0.25 to 39.52 & 0.97 \\
\hline $51-70$ & 1 & 1.97 & 0.06 to 6.21 & 0.54 \\
\hline$>70$ & 3 & 15.68 & 1.31 to 187.92 & 0.03 \\
\hline Female (reference) & 3 & 1 & 0.39 to 6.98 & 0.48 \\
\hline Male & 5 & 1.67 & & \\
\hline \multicolumn{5}{|c|}{ Extent of colitis at any time } \\
\hline $\begin{array}{l}\text { Proctitis and left } \\
\text { sided (reference) }\end{array}$ & 2 & 1 & 0.90 to 15.84 & 0.07 \\
\hline Extensive & 6 & 3.78 & & \\
\hline $\begin{array}{l}\text { Primary sclerosing } \\
\text { cholangitis }\end{array}$ & 1 & 3.70 & 0.45 to 30.16 & 0.22 \\
\hline
\end{tabular}

'pre-biologic' era. ${ }^{24}$ Patients without PSC, history of CRC in first-degree relative or pseudopolyps did not undergo surveillance colonoscopy as surveillance is not systematically implemented in Norway and was thus not included in the protocol. All patients included in the study attended regular clinical follow-up including colonoscopy when indicated and optimisation of anti-inflammatory therapy. Thus, the low observed risk of CRC in the present study appears more likely to be attributed to participation in the present study with adequate control of inflammation than improved surveillance techniques. Similarly, a nationwide population study following 32911 Danish patients with UC for 30 years found that the overall risk of CRC in UC was decreasing and comparable with the general population. Surveillance was not routinely implemented in Denmark at the time of the observation period (1979-2008) implying that the decline could not be attributed to superior surveillance procedures ${ }^{1}$

Although the association between pseudopolyps and CRC remains debated, patients with a history of pseudopolyps underwent surveillance colonoscopy according to guidelines at the time of the study. ${ }^{25}$

Patients who had undergone colectomy were not included in the risk analysis. Colectomy was performed due to severe and extensive inflammation unresponsive to available medical treatment. Also, patients in whom high-grade dysplasia or multifocal neoplastic lesions were detected underwent colectomy. As previously described, colectomy may therefore be viewed as a 'protective' factor against CRC. ${ }^{26}$ Although younger patients are less prone to accept stoma than older patients, colectomy could be expected to be more frequent in younger persons due to more extensive and aggressive inflammation. In contrast, operators may be less willing to perform colectomy in older patients due to an increased risk of intraoperative and postoperative complications. However, the power of the study did not allow for the evaluation of competing risk so that the true risk of CRC may be underestimated.

All patients included in the study were referred to colonoscopy when indicated at scheduled clinical follow-up but did not undergo a systematic surveillance scheme. Colonoscopies were performed at local and referral hospitals and therefore recorded in records of several hospitals. Also, the Norwegian Cancer Registry does not include dysplasia. Thus, despite a rigorous approach, data regarding dysplasia are incomplete.

Based on the assumption that inflammation in UC is a prerequisite for the development of CRC, patients in whom CRC was diagnosed prior to UC were not included in the risk analyses. These cases may due to previously undiagnosed UC or due to differential diagnostic challenges by

\begin{tabular}{|c|c|c|c|c|c|c|c|}
\hline Sex & $\begin{array}{l}\text { Time between } \\
\text { UC diagnosis } \\
\text { and CRC (years) }\end{array}$ & $\begin{array}{l}\text { Age at UC } \\
\text { diagnosis } \\
\text { (years) }\end{array}$ & $\begin{array}{l}\text { Age at CRC } \\
\text { diagnosis } \\
\text { (years) }\end{array}$ & $\begin{array}{l}\text { CRC } \\
\text { location }\end{array}$ & $\begin{array}{l}\text { Maximum } \\
\text { historical extent } \\
\text { of colitis }\end{array}$ & $\begin{array}{l}\text { First-degree } \\
\text { relative with } \\
\text { CRC }\end{array}$ & PSC \\
\hline $\mathrm{F}$ & 1 & 38 & 39 & Sigmoid colon & Proctitis & No & No \\
\hline M & 12 & 61 & 74 & Cecum & Extensive & No & No \\
\hline $\mathrm{F}$ & 15 & 25 & 40 & Rectum & Extensive & Missing & No \\
\hline $\mathrm{F}$ & 15 & 57 & 72 & Cecum & Extensive & No & No \\
\hline M & 18 & 30 & 48 & Ascending colon & Extensive & 0 & Yes \\
\hline M & 18 & 26 & 44 & Transverse colon & Extensive & No & No \\
\hline M & 20 & 43 & 64 & Rectum & Left sided & No & No \\
\hline M & 23 & 65 & 88 & Rectum & Extensive & No & No \\
\hline M & -18 & 82 & 64 & Sigmoid colon & Left sided & No & Missing \\
\hline M & -9 & 76 & 67 & Unknown & Left sided & No & No \\
\hline M & -3 & 74 & 71 & Unknown & Left sided & No & No \\
\hline M & -2 & 81 & 79 & Rectum & Extensive & No & No \\
\hline
\end{tabular}

CRC, colorectal cancer, PSC, primary sclerosing cholangitis; UC, ulcerative colitis . 
which the diagnosis of UC was delayed due to the presence of CRC.

Previous studies have similarly excluded CRC diagnosed within 1 year of IBD. ${ }^{1}$

In the present study, the observed median age of CRC in patients with CRC diagnosed after UC (56 years (39-88)) was in line with previous reports for CRC-UC ${ }^{727}$ However, the median age of the four patients in whom CRC was diagnosed prior to UC was comparable with the reported median age for sporadic CRC (73 years) ${ }^{29}$ These cases of CRC may in fact be a complication of undiagnosed UC. Accordingly, UC-CRC has been reported to occur around 17 years earlier than the median age ( 73 years) for sporadic CRC in the non-IBD population of Norway. ${ }^{28}$

We further observed that patients older than 70 years at diagnosis had a 15-fold higher risk of CRC compared with those diagnosed when younger than 40 years. However, the $\mathrm{CI}$ is wide so that these results must be considered with caution. Increasing age is in itself a risk factor for dysplasia and CRC, thus old age in itself rather than either longstanding IBD or elderly onset UC may have contributed to CRC in the patients in the present study. Although, little data are available for IBD diagnosed in the elderly, advancing age itself has not been found to increase the risk of IBD-CRC. ${ }^{29}$ Nevertheless, a study from 2009 suggested that the interval between colitis and CRC decreases with age and that higher age at onset of IBD may be related to a more aggressive CRC suggesting the need for earlier surveillance in elderly patients with IBD. ${ }^{30}$ The incidence of CRC in elderly patients with IBD is however low although these patients have been found to have a greater need for hospitalisation related to surveillance colonoscopy. One might consider individualised surveillance strategies in elderly patients.

The median duration of UC until the development of CRC was 22 (1-23) years, which is longer than previously described $^{31} \mathrm{~A}$ majority of the CRC cases in the present study occurred later than 8-10 years after diagnosis of the recommended surveillance colonoscopy thus supporting current practice. $^{92} 9 \mathrm{~s}$

In the present cohort, males with UC were found to have a twofold increased risk of CRC when compared with the background population of Norway. ${ }^{4}$ In the present study, men did not appear to have a different risk of CRC 20 years after the diagnosis of UC compared with women with UC of the same duration.

A total of 15 UC patients with UC had PSC of whom $80 \%$ had extensive colitis ${ }^{34}$ Although relatively few cases of CRC were observed, the high proportion of extensive colitis, both without and in combination with PSC, supported the previously reported increased risk of CRC. A case-contro study of two lange IBD cohorts has shown that the risk of colorectal neoplasm increased 6.9-fold with a concomitant diagnosis of PSC. ${ }^{95}$

In contrast to other studies, in our cohort, extensive colitis was not confirmed as a risk factor for UC-CRC. ${ }^{36}$ This could be due to a type-II error in this real-life cohort, but also to other factors such as high standard of follow-up and good compliance with anti-inflammatory medication.

A retrospective cohort study from 2012 included 700 patients with UC with extensive colitis in whom a total of six out of nine of the detected CRCs were located in the rectum. Moreover, $71.2 \%$ of advanced neoplasia was detected in rectum or sigmoid colon. ${ }^{97}$ In the present study, four out of the eight CRC cases detected after the diagnosis of UC were located in the rectum/distal colon. The limited number of patients with CRC, however, did not allow us to estimate the effect of location on the risk of CRC.

The use of the Norwegian National Cancer Registry to accurately detect CRC cases, and the prospective and longitudinal follow-up of a population-based inception cohort, are major strengths of the present study. Although the number of patients included was high, the occurrence of CRC was low, limiting the statistical power of analysis of risk factors for UC-CRC. Risk factors were therefore evaluated one by one in univariate analyses as the limited number of CRC cases did not allow any multiple regression modelling. In conclusion, in this population-based inception cohort study, the risk of CRC after 20 years of UC was low and comparable with the risk of CRC in the background population of Norway. The patients in the present study did not undergo systematic colonoscopic surveillance but close clinical follow-up ensuring adequate anti-inflammatory therapy. Fortunately, the number of observed CRC cases was low. Thus, although CRC remains a significant concern in patients with UC, the present study supports the reported decrease of CRC in UC. The power of the study did not allow us to conclusively evaluate the association between CRC and previously established risk factors. However, we anticipate the number of CRC cases to increase with an even longer follow-up, thus allowing for a more precise estimation of the possible risk factors.

\section{Author affiliations}

'Unger-Vettesen Institute, Lovisenberg Diakonale Hospital, Oslo, Norway ${ }^{2}$ Department of Gastroenterology, Oslo Unive rsity Hospital, Oslo, Norway ${ }^{3}$ Department of Gastroenterology, Akershus University Hospital, Lorenskog, Norway 'Faculty of Medicine, Institute for Clinical Medicine, University of 0 slo, 0 sla, Norway 5 Deparment of Gastroenterology Inlandet Hospital Trust Gipik, Oppland, Nonvay Jepartion ${ }^{7}$ Department of Gastroenterology, Telemark Hospital, Ulefossveien, Skien, Norway ${ }^{8}$ R\&D Department, Vestfold Hospital Trust, Tonsberg, Norway 'Department of Internal Medicine, Serlandet Hospital, Sykehusveien, Arendal, Norway

${ }^{10}$ Department of Internal Medicine, Lowisenberg Diakonale Hospital, Oslo, Norway

${ }^{11}$ Department of Internal Medicine, Diakonhjemmet Hospital, Oslo, Norway

Acknowledgements The authors thank all members of the Inflammatory Bowel South-East Norway (IBSEN) Study Group for participating in the study.

Contributors PK: acquisition of data, analysis and interpretation of data, drafting of the manuscript, revision of the manuscript SB: critical revision of the manuscript for important intellectual content, study supervision. MC: statistical anabysis, critical revision of the manuscript for important intellectual content MLH, MH, GH-H, TB, OH, IK-M, ICS, NS, لJ: acquisition of data, critical revision of the manuscript for important intellectual content. ØH: acquisition of data, including data form Statistics Norway, Norwegian Causes of Death Registry and the Cancer Registry of Norway, critical revision of the manuscript for important intellectual content IK-M: Acquisition of data, critical revision of the manuscript for important intellectual Acquisition of data, critical revision of the manuscript for important intellectug
content. MHV: critical revision of the manuscript for important intellectual 
Open access

content, study supervision. BAM: study concept and design, critical revision of the manuscript for important intellectual content, study supervision.

Funding PK is employed and funded by the Lovisenberg Diaconal Hospital. Competing interests None declared.

Patient consent for publication Not required.

Provenance and peer review Not commissioned; externally peer reviewed. Data availability statement Data are available upon reasonable request. Deidentified participant data is available from https://orcid. org/0000-0002-58844543.

Open access This is an open access article distributed in accordance with the Creative Commons Attribution Non Commercial (CC BY-NC 4.0) license, which permits others to distribute, remix, adapt, build upon this work non-commercially, and license their derivative works on different terms, provided the criginal work is property cited, appropriate credit is given, any changes made indicated, and the use is non-commercial. See: http:///creativecommons.org/icenses/by-nc/4.0/.

ORCID iDs

Pasquale Klepp http://orcid.org/0000-0002-0477-691X

lril Kempski-Monstad http://orcid.org/0000-0002-0803-9603

\section{REFERENCES}

1 Jees T, Simonsen J, Jergensen $\mathrm{KT}$, et al. Decreasing risk of colorectal cancer in patients with inflammatory bowel disesse over 30 years. Gastroenterology 2012;143:375-81.

2 Söderlund S, Brandt L, Lapidus A, et al. Decreasing time-trends of colorectal cancer in a large cohort of patients with inflammatory of colorectal cancer in a large cohort of patients with in 3 Selinger CP, Andrews JM, Titman A, et al. Long-term follow-up resection, among Australian patients with inflammatory bowel disease. Clin Gestroenterol Hepatol 2014;12:644-50.

4 Hovde Øistein, Heivik ML, Henriksen M, et al. Malignancies in patients with inflammatory bowel diseese: results from 20 years of follow-up in the IBSEN study. J Crohns Colitis 2017;11:571-7.

5 Askling J, Dickman PW, Karlén P, et al. Family history as a risk factor for colorectal cancer in inflammatory bowel disease Gestroenterology 2001; 120:1356-62.

6 Velayos FS, Loftus EV, Jess T, et al. Predictive and protective factors associated with colorectal cancer in ulcerative colitis: a case-control study. Gastroentevology 2006;130:1941-9.

7 Lakatos L, Mester G, Erdelyi Z, et al. Risk factors for ulcerative colitis-associated colorectal cancer in a Hungarian cohort of patients with ulcerative colitis: results of a population-based study. Infigmm Bowel Dis 2006;12:205-11.

8 Shah SC, Ten Hove JR, Castaneda D, et al. High risk of advanced colorectal neoplasia in patients with primary sclerosing cholangitis associated with inflammatory bowel disease. Clin Gestroenterol Hepatol 201 8; 16:1106-13.

9 Fumery M, Dulai PS, Gupta S, et al. Incidence, risk factors, and outcomes of colorectal cancer in patients with ulcerative colitis with low-grade dysplasia: a systematic review and meta-analysis. Clin Gestroenterol Hepatol 2017:15:665-74.

10 Rutter M, Saunders B, Wilkinson K, et al. Severity of inflammation is a risk factor for colorectal neoplasia in ulcerative colitis. Gestroenteralogy 2004;126:451-9.

11 Rubin DT, Huo D, Kinnucan JA, et al. Inflammation is an independent risk factor for colonic neoplasia in patients with ulcerative colitis: case-control study. Clin Gastroenterol Hepatol 2013;11:1601-8.

12 Choi C-HR, Al Bakir I, Ding N-SJ, et el. Cumulative burden of inflammation predicts colorectal neoplasia risk in ulcerative colitis: a large single-centre study. Gut 2017;0:1-9.

13 Gupta RB, Harpaz N, Itzkowitz S, et al. Histologic inflammation is a risk factor for progression to colorectal neoplasia in ulcerative colitis a cohort study. Gestroenterology 2007;133:1099-105.

14 Axelrad JE, Lichtiger S, Yajnik V. Inflammatory bowel disease and cancer: the role of inflammation, immunosuppression, and cancer treetment. World J Gastroentevol 2016;22:4794-801.

15 Singh S, Singh PP, Murad MH, et al. Prevalence, risk factors, and outcomes of interval colorectal cancers: a systematic review and meta-analysis. Am J Gestroenterol 2014;109:1375-89.
16 Mooiweer $\mathrm{E}$, van der Meulen-de Jong $\mathrm{AE}$, Ponsioen $\mathrm{CY}$, et al. Incidence of interval colorectal cancer among inflammatory bowel disease patients undergoing regular colonoscopic surveillance. Clin (1)

17 Choi C-HR, Rutter MD, Askari A, et al. Forty-Year analysis of colonoscopic surveillance program for neoplasia in ulcerative colitis: an updated overview. Am J Gastroenterol 2015;110:1022-34.

18 Ghione $\mathrm{S}$, Sarter $\mathrm{H}$, Fumery $\mathrm{M}$, et al. Dramatic increase in incidence of ulcerative colitis and Crohn's disease (1988-2011): $a$ population-based study of French addescents. Am J Gestroenterol 2018;113:265-72.

19 van den Heuvel TRA, Jeuring SFG, Zeegers MP, et al. A 20-year temporal change analysis in incidence, presenting phenotype and mortality, in the Dutch IBDSL Cohort-Can diagnostic factors explain the increase in IBD incidence? J Crohns Colitis 2017;11:1169-7

20 Moum B, Vatn MH, Ekbom A, et al. Incidence of inflammatory 1 year of registration. southeastern Norway IBD Study group of 1 year of registration. southeastern Norway IBD

21 Solberg IC, Lygren I, Jahnsen J, et al. Clinical course during the first 10 years of ulcerative colitis: results from a populationbesed inception cohort (IBSEN study). Scand J Gestroenterol 2009;44:431-40.

22 Hovde Øistein, Smảstuen MC, Høivik ML, et al. Mortality and causes of death in ulcerative colitis: results from 20 years of follow-up in the IBSEN study. Infiamm Bowel Dis 2016;22:141-5.

23 National Cancer Registry of Norway. Cancer in Norway 2017. 2018: 26, 86, 96.

24 Moum B, Ekbom A, Vatn MH, et al. Clinical course during the 1st year after diagnoeis in ulcerative colitis and Crohn's disease. Results of a large, prospective population-besed study in southeasten Norway, 1990-93. Scand J Gastroenterol 1997;32:1005-12.

25 Mahmoud R, Shah SC, Ten Hove JR, et al. No association between Pseudopolyps and colorectal neoplasia in patients with inflammatory bowel diseases. Gestroenterology 2019;156:1333-44.

26 Winther KV, Jess T, Langholz E, et al. Long-term risk of cancer in ulcerative colitis: a population-based cohort study from Copenhagen County. Clin Gastroenterol Hepatol 2004;2:1088-95.

27 Cohen-Mekelburg S, Schneider Y, Gold S, et al. Risk of early colorectal cancers needs to be considered in inflammatory bowel disease care. Dig Dis Sci 2019;64:2273-9.

28 Cho Y-H, Kim DH, Cha JM, et al. Patients' preferences for primary colorectal cancer screening: a survey of the National colorecter cancer screening program in Korea. Gut Liver 2017; 11: 821-7.

Den MMM, van Ojen MGH, van der Heijden GJMG, et al. Declining risk of colorectal cancer in inflammatory bowel disease: an updated meta-analysis of population-besed cohort studies. Inflamm

30 Brackmann S, Andersen SN, Aamodt G, et al. Relationship between clinical parameters and the colitis-colorectal cancer interval in a cohort of patients with colorectal cancer in inflammatory bowel disease. Scand J Gestroenterol 2009;44:46-55.

31 Eaden JA, Abrams KR, Mayberry JF. The risk of colorectal cancer in ulcerative colitis: a meta-analysis. Gut 2001;48:526-35.

32 American Society for Gastrointestinal Endoscopy Standards of Practice Committee, Shergill AK, Lightdale JR, et $a$. The role of endoecopy in inflammetory bowel disease Gestrointest Endose 2015;81:1101-21.

з3 Magro F, Gionchetti P, Eiakim R, et al. Third European evidencebased consensus on diagnoeis and management of ulcerative colitis. Part 1: definitions, diagnosis, extra-intestinal manifestations, pregnancy, cancer surveillance, surgery, and ileo-anal pouch disorders. J Crohns Colitis 2017;11:649-70.

34 Lunder AK, Hov JR, Borthne A, et al. Prevalence of sclercsing cholangitis detected by magnetic resonance cholangiography in petients with long-term inflammatory bowel disease. Gestroenterology 201 6;151:660-9.

35 Jess T, Loftus EV, Velayos FS, et al. Risk factors for colorectal neoplasia in inflammatory bowel disease: a nested case-control study from Copenhagen County, Denmark and Olmsted County, Minnesota. Am J Gestroenterol 2007;102:829-36.

36 Jess T, Riis L, Vind I, et al. Changes in clinical characteristics, course, and prognosis of inflammatory bowel disease during the last 5 decades: a population-based study from Copenhagen, Denmark. Inflearm Bowel Dis 2007;13:481-9.

37 Goldstone R, Itzkowitz S, Harpez N, et al. Dysplasia is more common in the distal than proximal colon in ulcerative colitis surveillance. Inflemm Bowel Dis 2012;18:832-7. 


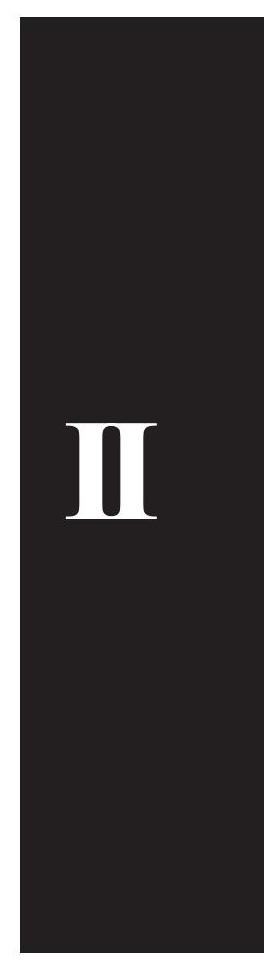





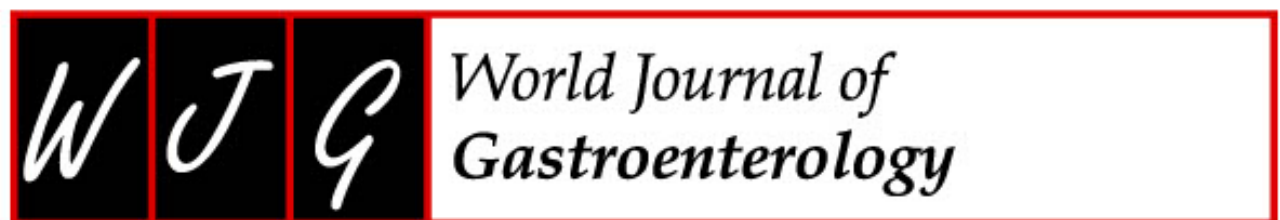

\section{Real-life chromoendoscopy for dysplasia surveillance in ulcerative colitis}

Pasquale Klepp, Anita Tollisen, Arne Røseth, Milada Cvancarova Småstuen, Solveig N Andersen, Morten Vatn, Bjørn A Moum, Stephan Brackmann

Pasquale Klepp, Anita Tollisen, Arne Røseth, Unger-Vetlesen Institute, Department of Intemal Medicine, Lovisenberg Diaconal Hospital, Oslo 0456, Norway

Pasquale Klepp, Milada Cvancarova Småstuen, Morten Vatn, Bjørn A Moum, Stephan Brackmann, Institute of Clinical Medicine, University of Oslo, Oslo 0317, Norway

Solveig N Andersen, Department of Pathology, Akershus University Hospital, Lorenskog 1474, Norway

Bjørn A Moum, Department of Gastroenterology, Oslo University Hospital, Oslo 0450, Norway

Stephan Brackmann, Department of Gastroenterology, Akershus University Hospital, Lorenskog 1474, Norway

ORCID number: Pasquale Klepp (0000-0002-0477-691X); Anita Tollisen (0000-0002-4776-9808); Ame Roseth (0000-0003-0916 -5111); Milada Cvancarova Småstuen (0000-0001-8947-8649); Solveig N Andersen (0000-0002-4814-8894); Morten Vatn (0000-0002-1179-4550); Bjorn A Moum (0000-0002-5884-4543); Stephan Brackmann (0000-0001-6434-0571).

Author contributions: Klepp P contributed to acquisition, analysis and interpretation of the data, and drafting and revision of the manuscript; Tollisen A contributed to planning and collection of the data; Roseth A contributed to conception and design of the study, and performed critical revision of the manuscript for important intellectual content; Cvancarova Småstuen M contributed to the statistical analysis and critical revision of the manuscript for important intellectual content; Andersen SN provided technical support and contributed to revision of the histopathological material; Vatn M provided critical revision of the mamuscript for important intellectual content and performed study supervision; Moum BA and Brackmann S contributed to conception and design of the study, and performed critical revision of the mamuscript for important intellectual content and study supervision; all authors have approved the final draft.

Supported by the Unger-Vetlesen Institute, Department of Intemal Medicine, Lovisenberg Hospital
Institutional review board statement: The study protocol was designed according to the combined knowledge and expertise of Assistant Professor Stephan Brackmann (Akershus University Hospital), Professor Bjom A Moum (Oslo University Hospital) and Professor Morten Vatn (University of Oslo). The study protocol was approved by the Regional Committee for Medical and Health Research Ethics (REC Project NO. 2010/1093).

Informed consent statement: Written informed consent was collected from subjects prior to study inclusion.

Conflict-of-interest statement: The authors have no conflicts of interest.

Data sharing statement: No additional data are available.

STROBE statement: The authors have read the STROBE Statement, and the manuscript was prepared and revised according to the STROBE Statement.

Open-Access: This article is an open-access article which was selected by an in-house editor and fully peer-reviewed by extemal reviewers. It is distributed in accordance with the Creative Commons Attribution Non Commercial (CC BY-NC 4.0) license, which permits others to distribute, remix, adapt, build upon this work non-commercially, and license their derivative works on different terms, provided the original work is properly cited and the use is non-commercial. See: http://creativecommons.org/ licenses/by-nc/4.0/

Manuscript source: Unsolicited manuscript

Correspondence to: Pasquale Klepp, MD, Attending Doctor, Department of Internal Medicine, Lovisenberg Hospital, Lovisenberggt.17, Oslo 0456, Norway. pasklepp $\alpha$ gmail.com Telephone: $+47-23225000$

Received: May 30, 2018

Peer-review started: May 30, 2018

First decision: July 4, 2018

Revised: August 6, 2018

Accepted: August 24, 2018 
Klepp P et al. Chromoendoscopy for surveillance in UC

Article in press: August 24, 2018

Published online: September 21, 2018

\begin{abstract}
AIM

To evaluate the use of chromoendoscopy for surveillance of ulcerative colitis in a real-life community hospital setting.

\section{METHODS}

Patients with extensive ulcerative colitis, having disease duration of more than $\mathbf{8}$ years and who presented between the years of 1999 to 2013, were offered enrolment in this single cohort prospective study. All participants underwent standard bowel preparation with sodium phosphate and chromoendoscopy. Two expert endoscopists, novice to chromoendoscopy, evaluated each segment of the colon with standarddefinition colonoscopes after spray application of $0.4 \%$ indigo carmine. All observed lesions were recorded and evaluated before being removed and/or biopsied. In addition, nontargeted biopsies were taken from each segment of the colon. The dysplasia detection rate and dysplasia detection yield were ascertained.
\end{abstract}

\section{RESULTS}

A total of 21 neoplastic lesions (2 carcinomas, 4 of high-grade dysplasia and 15 of low-grade dysplasia) and 27 nondysplastic lesions were detected in 16 of the total 67 patients ( $70 \%$ male; median disease duration: 17 years; median age at diagnosis: 25 years; $92 \%$ aminosalicylate-treated). The dysplasia detection rate was $10.5 \%$ ( $7 / 67$ patients). The dysplasia detection yield was $20.8 \%$ (10/48) for targeted biopsies and $3.5 \%$ $(11 / 318)$ for nontargeted biopsies. The sensitivity and specificity for the macroscopic evaluation of neoplasia using chromoendoscopy were $48 \%$ [ $95 \%$ confidence interval (CI): $26 \%-70 \%$ ] and $96 \%$ (95\%CI: 93\%-98\%), respectively. The positive predictive and negative predictive values were $42 \%$ ( $95 \%$ CI: $27 \%-59 \%$ ) and $97 \%$ ( $95 \%$ CI: $95 \%-98 \%$ ), respectively. A total of $19 / 21$ dysplastic lesions were detected in mucosa with histologic inflammation.

\section{CONCLUSION}

Chromoendoscopy seems to be of value for dysplasia surveillance of ulcerative colitis in a community hospital setting. The yield of non-targeted biopsies is negligible.

Key words: Colorectal cancer; Dysplasia; Ulcerative colitis; Surveillance; Chromoendoscopy

() The Author(s) 2018. Published by Baishideng Publishing Group Inc. All rights reserved.

Core tip: Patients with longstanding and extensive ulcerative colitis are at increased risk of developing colonic neoplasia and are advised to undergo regular colonoscopic surveillance. Current clinical guidelines favour chromoendoscopy with targeted biopsies, as it detects dysplasia more accurately and thus requires fewer biopsies than white-light endoscopy. However, these recommendations are based on studies performed in advanced endoscopic units and chromoendoscopy is not routinely applied in everyday clinical practice. This prospective cohort study suggests that, although novice to chromoendoscopy, endoscopists can accurately evaluate the absence of neoplasia. The yield of nontargeted biopsies was also found to be negligible.

Klepp P, Tollisen A, Røseth A, Cvancarova Småstuen M, Andersen SN, Vatn M, Moum BA, Brackmann S. Real-life chromoendoscopy for dysplasia surveillance in ulcerative colitis. World J Gastroenterol 2018; 24(35): 4069-4076 Available from: URL: http://www.wjgnet.com/1007-9327/full/v24/135/4069.htm DOI: http://dx.doi.org/10.3748/wjg.v24.i35.4069

\section{INTRODUCTION}

Patients with extensive and long-standing ulcerative colitis (UC) carry an increased risk of developing colonic neoplastic lesions ${ }^{[1]}$. Carcinoma in UC is thought to develop through a stepwise progression from inflammation to low-grade dysplasia and finally to carcinoma ${ }^{[2]}$. Patients are therefore advised to undergo periodic colonoscopic surveillance, so as to detect neoplasia at an early stage ${ }^{[3]}$. Visualization of dysplastic lesions in UC represents a challenge as they may be flat or obscured by inflammatory changes and/or pseudopolyps ${ }^{[4]}$. Dysplasia surveillance using white-light endoscopy relies on random 4-quadrant biopsies taken every $10 \mathrm{~cm}$, being a laborious and costly method ${ }^{[5]}$. Under-sampling is common with that technique and even if the recommended 30-40 biopsies are harvested, only a fraction of the entire mucosal surface of the colon is examined ${ }^{[6]}$

Chromoendoscopy (CE), on the other hand, uses a topical dye, which highlights mucosal abnormalities and allows for more precise biopsies ${ }^{[7]}$. Targeted biopsies are considered superior to random biopsies of apparently unaffected mucosa, as the latter are of little additional value since they have poor diagnostic yield ${ }^{[8]}$. Thus, recommendations for surveillance using $\mathrm{CE}$ are based on the assumption that CE requires fewer biopsies and is more cost effective than standard whitelight endoscopy ${ }^{[7,-11]}$. European clinical guidelines recommend CE with targeted biopsies as the favoured technique for dysplasia surveillance $e^{[3]}$. It is important to note that these guidelines are based on studies that were performed in endoscopic units with highly advanced expertise. However, in many countries, such as Norway, CE is not routinely applied for surveillance of UC patients. A retrospective multicentre study conducted over a 14-year period of CE implementation also did not show significant increase in the detection of 


\section{Table 1 Patient demographics and clinical features}

\begin{tabular}{|c|c|}
\hline Feature & Data \\
\hline Study patients & 67 \\
\hline$A_{g e}(y x)$ & $40(27-73)$ \\
\hline Male sex & $46(70)$ \\
\hline Disease duration $(y x)$ & $17(8-51)$ \\
\hline Age at diagnosis (yx) & $25(12-59)$ \\
\hline Colitis activity index score ${ }^{2}$ & $0(0-8)$ \\
\hline Primary scleroaing cholangitis & $3(5)$, missins $n=2$ \\
\hline Colorectal cancer in first degree relative & $3(5)$, nussins $n=5$ \\
\hline Previous dysplasia in colon & $3(5)$, nissins $n=3$ \\
\hline \multicolumn{2}{|l|}{ Treatment } \\
\hline Aninosalicylate' & $58(92)$, missing $n=3$ \\
\hline Steroids ${ }^{1}$ & $12(18)$, missing $n=4$ \\
\hline Arathioprine' & $4(6)$ \\
\hline Antitumour necrosis factor ${ }^{1}$ & $4(6)$, mussins $n=1$ \\
\hline
\end{tabular}

'At time of surveillance colonoscopy and/or during past two years; 'Simple clinical colitis activity index. Data are presented as $n$ (\%) or median (interquartile range).

dysplastic lesions ${ }^{[12]}$.

The aim of this study was to assess the macroscopic and histologic evaluation of CE when implemented in real-life surveillance of patients with long-standing UC in a community hospital in Norway.

\section{MATERIALS AND METHODS}

\section{Ethical considerations}

The study protocol was designed according to the combined knowledge and expertise of Assistant Professor Stephan Brackmann (Akershus University Hospital), Professor Bjørn A Moum (Oslo University Hospital) and Professor Morten Vatn (University of Oslo). The study protocol was approved by the Regional Committee for Medical and Health Research Ethics (Project NO. 2010/1093). Written informed consent was collected from all subjects prior to study inclusion.

\section{Recruitment of participants}

Patients registered in the database of Lovisenberg Hospital from 1999-2013 were invited to participate in the present study if they had (1) extensive UC, documented by endoscopy at any time during the course of disease, and (2) disease duration of 8 years or more. Exclusion criteria included colectomy at any time during follow-up and poor bowel preparation (Figure 1). Demographic and clinical data were extracted from digital medical joumals and by interview of the patients (Table 1).

CE

Patients underwent standard bowel preparation with sodium phosphate. CE was performed with standard definition endoscope (CF190 colonoscope; Olympus, Tokyo, Japan) and only carried out when the quality of bowel preparation was adequate $(n=67 / 68)$. The colonoscope was advanced to the cecum and during the extubation each segment (cecum, ascending colon, transverse colon, descending sigmoid and rectum) was scrutinised for lesions after the spray catheter application of $0.3 \%$ indigo-carmine. Extensive colitis was defined as endoscopic inflammation proximal to the splenic flexure. Endoscopic degree of inflammation was classified according to the Mayo endoscopic score for UC ${ }^{[13]}$.

\section{Biopsies}

The location and size of all lesions identified after spray catheter application of $0.3 \%$ indigo-carmine dye were reported. Also the appearance of the lesions was classified according to terminology adapted from the Scenic Consensus ${ }^{[14]}$ as either nonpolypoid flat or elevated or polypoid pedunculated or nonpedunculated before the lesions were biopsied or removed.

In addition, after spray catheter application of $0.3 \%$ indigo-carmine dye, a minimum of one nontargeted biopsy was taken from each of the six segments (cecum, ascending, transverse and descending colon, sigmoid and rectum) to determine the extent of disease and grade of inflammation.

Independent and blind analyses of the formalinfixed paraffin-embedded biopsies were performed by two expert gastropathologists. The histologic degree of inflammation was graded based on the histological activity index ${ }^{[15]}$. Mucosal biopsies were classified as either negative for neoplasia, indefinite for dysplasia, or positive for low-grade dysplasia (LGD), high-grade dysplasia (HGD) or adenocarcinoma ${ }^{[16]}$. Neoplasia was considered proximal or distal according to its anatomic location to the splenic flexure. The dysplasia detection yield was defined as the proportion of bioptic sites/ lesions containing dysplasia or invasive colorectal cancer (CRC) in relation to the total number of bioptic sites/ lesions. The dysplasia detection rate was defined as the proportion of patients who had at least one dysplastic lesion or invasive CRC in relation to the total number of screened patients.

\section{Statistical analysis}

The statistical methods of this study were reviewed by Milada Cvancarova Småstuen (Institute of Clinical Medicine, University of Oslo, PO Box 1122 Blinderen, 0317 Oslo, Norway). All statistical analyses were carried out with the SPSS software, version 24 (IBM Corp, Armonk, NY, United States). Patient demographic characteristics were summarized as median (interquartile range) for continuous variables and as percentage of subgroup totals for categorical variables. Sensitivity and specificity were estimated with corresponding $95 \%$ confidence intervals (CIs) that were calculated using the exact binomial distribution.

\section{RESULTS}

CE was performed in 67 patients with extensive UC. A 
Klepp P et al. Chromoendoscopy for surveillance in UC

Table 2 Histologic diagnosis of the seven neoplastic lesions detected among the 67 total patients with long-standing and extensive ulcerative colitis

\begin{tabular}{|c|c|c|c|c|c|c|}
\hline \multirow[t]{2}{*}{ Sex } & \multirow[t]{2}{*}{ Age (yr) } & \multicolumn{2}{|c|}{ LGD } & \multirow{2}{*}{$\begin{array}{c}\text { HGD } \\
\text { Targeted biopsy }\end{array}$} & \multirow{2}{*}{$\begin{array}{l}\text { Adenocarcinoma } \\
\text { Targeted bicpoy }\end{array}$} & \multirow[t]{2}{*}{ Total } \\
\hline & & Targeted biopsy & Nontargeted biopsy & & & \\
\hline Male & 34 & 1 & 7 & 4 & $1^{1}$ & 13 \\
\hline Male & 67 & & & & $1^{2}$ & 1 \\
\hline Male & 49 & 1 & 1 & & & 2 \\
\hline Male & 33 & 1 & & & & 1 \\
\hline Female & 36 & 1 & & & & 1 \\
\hline Male & 44 & & 1 & & & 1 \\
\hline Female & 52 & & 2 & & & 2 \\
\hline Total & & 4 & 11 & 4 & 2 & 21 \\
\hline
\end{tabular}

'Adenocarcinoma stage T3N1MO in patient with primary sclerosing cholangitis; ${ }^{2}$ Adenocarcinoma stage T2NOMO. No neoplasia was found in biopsies despite high suspicion of malignancy at endoscopy. Adenocarcinoma was subsequently verified in the resected surgical specimen. LGD: Low-grade dysplasia HGD: High-grade dysplasia.

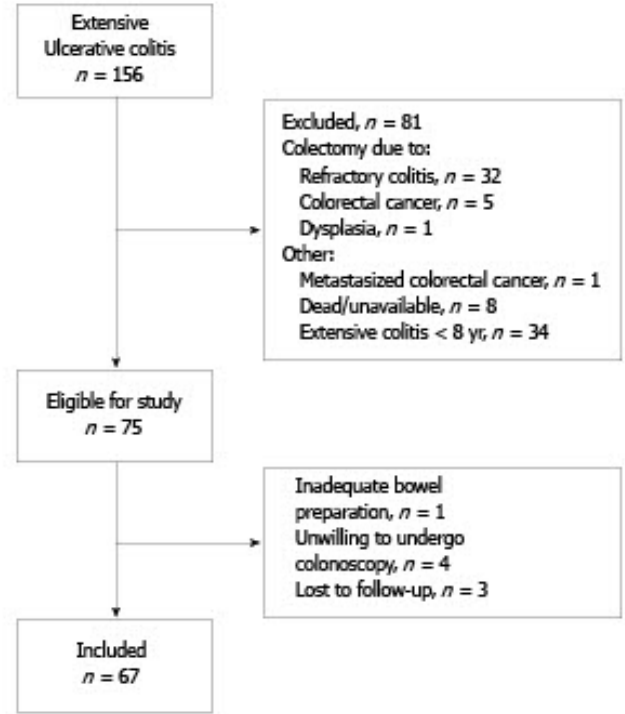

Figure 1 Flowchart of patient inclusion for this atudy.

total of 21 neoplastic lesions were detected in 7 of the 67 patients, including 10 (comprised of 2 CRC, 4 HGD and 4 LGD) identified by targeted biopsies and 11 (all LGD) by nontargeted biopsies.

\section{Dysplasia detection rate}

Neoplasia was detected in 7 of the total 67 patients, giving a dysplasia detection rate of $10.5 \%$. In 4 , neoplasia was detected from both targeted and nontargeted biopsies. In 2, dysplasia was detected by nontargeted biopsies alone. In 1, adenocarcinoma was diagnosed after partial colonic resection.

\section{Dysplasia detection yield}

A total of 48 lesions were visualised in 16 of the total 67 patients. The median number of lesions per patient was 1 (range: 0-6). The distribution and findings from endoscopic and histologic evaluations of the lesions are described in detail in Figure 2 and Tables 2 and 3. Ten of the visualised lesions harboured neoplasia, resulting in a dysplasia detection yield of $20.8 \%$ for targeted biopsies. Among the 318 nontargeted biopsies, 11 harboured LGD, resulting in a dysplasia detection yield of $3.5 \%$ for nontargeted biopsies.

\section{Macroscopic evaluation}

Correct classification by the endoscopists was achieved for 307 of the 345 nondysplastic sites/lesions and 10 of the 21 dysplastic sites/lesions. On the other hand, 11 of the 21 dysplastic lesions were assessed as nondysplasia, whereas 38 of the 345 nondysplastic sites /lesions were assessed as dysplasia. As a result, the sensitivity and specificity for the macroscopic evaluation of neoplasia using CE were $48 \%$ (95\%CI: $26 \%-70 \%$ ) and $96 \%$ (95\% CI: $93 \%-98 \%$ ), respectively. The positive predictive value was $42 \%$ ( $95 \% \mathrm{CI}: 27 \%-59 \%$ ) and the negative predictive value (NPV) was $97 \%$ (95\%CI: 95\%-98\%).

\section{Follow-up of patients with colonic neoplasia}

In 2 of the 7 patients with LGD, the dysplasia was detected solely by nontargeted biopsies taken during a CE described as macroscopically normal. Follow-up with colonoscopy neither confirmed nor revealed any further dysplasia for either patient. In another 2 of the 7 patients, the LGD was detected solely by targeted biopsies. In yet another 2 of the 7 patients, nontargeted biopsies confirmed a field effect by detecting LGD when dysplastic lesions were identified elsewhere in the colorectum by targeted biopsies; during intensified follow-up colonoscopy, no further dysplasia was detected after 2.5 years follow-up (range: $2-5$ years) in these patients.

In 1 of the 7 patients with neoplasia, nontargeted biopsies showed multifocal fields of LGD synchronous with targeted biopsies that showed multifocal lesions with HGD and adenocarcinoma. The patient had primary sclerosing cholangitis and proctocolectomy 
Table 3 Morphology and histology findings for the 16 bioptic sites of the 67 total patients with long-standing and

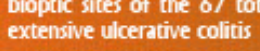

\begin{tabular}{lcc}
\hline Morphology & Histology & $n$ \\
\hline Targeted biopsy & & \\
Nonpolypoid & No neoplasia & 26 \\
Flat lesion & LGD & 2 \\
& HGD & $1^{1}$ \\
& No neoplacia & 10 \\
Supperficial elevated & HGD & $1^{1}$ \\
& Adenocarcinoma & 1 \\
Polypoid & No neoplacia & 1 \\
Pedunculated & LGD & 1 \\
& LGD & 1 \\
Nonpedumculated & HGD & $2^{1}$ \\
Sessile with central ulceration & Adenocarcinoma & $1^{1}$ \\
Sessile & IND & 1 \\
& & \\
Nontargeted biopsy & No neoplasia & 307 \\
& LGD & 11 \\
Total & & 366 \\
\hline
\end{tabular}

'Concomitant primary sclerosing cholangitis. HGD: High-grade dysplasia: IND: Indefinite dysplasia; LGD: Low-grade dysplasia.

was performed. Finally, adenocarcinoma was detected after partial resection of the colon in 1 of the 7 patients for who endoscopy had raised suspicion of malignancy, whereas targeted biopsies of this area were normal on two consecutive colonoscopies. After surgery, no further neoplasia was detected during 3 years of intensified follow-up colonoscopies.

\section{Mucosal inflammation}

No signs of histologic inflammation were recorded in 93 of the 366 bioptic sites. A total of 237 had Mayo grade $0-1$ and 39 had Mayo grade 2-3. The presence of neoplasia in relation to histologic inflammatory changes is described in detail in Table 4.

\section{Schedule of surveillance colonoscopy}

The median time from the prior "prestudy" surveillance colonoscopy ( $n=61 / 67$ ) until the next scheduled colonoscopy was $24 \mathrm{mo}$ (range: 0-96 mo). The median time from the prior "prestudy" surveillance colonoscopy ( $n=66 / 67$ ) until the study CE was 26 mo (range: 1-105 $\mathrm{mo})$.

\section{DISCUSSION}

This prospective cohort study performed in a community hospital suggests that, although novice to $C E$, endoscopists were able to accurately evaluate the absence of neoplasia during real-life surveillance of patients with UC. Neoplasia was detected by targeted biopsies in 5 of the 67 total patients, of whom 2 had a field effect confirmed by nontargeted biopsies. Two additional patients were diagnosed with LGD in the colon by nontargeted biopsies alone. The neoplasia detection rate for the 7 of the 67 total patients in the present study is similar to that found in studies performed in tertiary referral centres $(11.2 \%)$. It is important to note, however, that the present study was conducted in a community hospital in which patients may present with a less aggressive UC than seen in advanced units.

The neoplasia detection yield of the present study was $20.8 \%$, which is lower than the average rate of $14 \%$ found by Mooiweer et $a^{[12]}$ in several prior randomized trials. The endoscopists in our study were able to accurately rule-out neoplasia (NPV $=97 \%$ ); thus, when the endoscopists evaluated the lesion as benign, the probability of dysplasia was minimal (3\%). These results are in line with a recent prospective multicentre cohort study in which both CE novice endoscopists and CE expert endoscopists evaluated lesions, and had a high NPV ${ }^{[1]}$. That same study found a sensitivity of $70 \%$ for $C E$, which is lower than the pooled sensitivity of $91 \%$ reported from a recent metaanalysis $^{[17,18]}$. In the present study, the sensitivity for the detection of LGD by CE was modest, which could be related to the endoscopists' lack of prior CE experience.

Alternatively, these results support the presence of "invisible" dysplasia. In our cohort, "invisible" dysplasia was rare in the absence of dysplastic lesions elsewhere in the colon, similar to findings reported by Matsumoto et $a^{(9.19)}$ and underlining the concept of field cancerization in $U^{[9,19]}$. The results must, however, be evaluated with caution due to the size of the study sample and the low observed rate of cases.

The clinical importance of dysplasia detected through random biopsies is debatable. In the present study, the dysplasia detection yield was $3.5 \%$ for nontargeted biopsies compared to a $20.8 \%$ for targeted biopsies. The nontargeted biopsies were primarily taken not to detect neoplasia but to evaluate the grade of mucosal inflammation. In line with previous studies, the low dysplasia yield of nontargeted biopsies leads to questions about their clinical value ${ }^{[7,8,17,20,21]}$. Also, the follow-up of the patients in which LGD was detected by nontargeted biopsy alone did not reveal any further dysplasia. However, a recent study has suggested that despite a low bioptic neoplasia yield, nontargeted biopsies are advisable in patients with inflammatory bowel disease and related high risk of CRC ${ }^{[21]}$.

Clinical guidelines recommend the first surveillance colonoscopy to be performed between 8-10 years after the diagnosis of UC, with ensuing colonoscopies based on individual risk. In our cohort, the median time until the next scheduled colonoscopy was $24 \mathrm{mo}$, which is in accordance with guidelines ${ }^{[3]}$.

The visualisation of small lesions harbouring dysplasia may have been hampered by inflammation surrounding multifocal lesions. However, the minimal level of inflammatory changes in those patients in who dysplasia was diagnosed by nontargeted biopsies only did not likely impede the detection. 
Klepp P et al. Chromoendoscopy for surveillance in UC

Table 4 Histologic grade of inflammation in the biopsies taken from all 67 patients

\begin{tabular}{|c|c|c|c|c|c|c|}
\hline & \multicolumn{6}{|c|}{ Grade of inflanmation } \\
\hline & Mayo $0^{\prime}$ & Mayo 1 & Mayo 2 & Mayo 3 & $\begin{array}{l}\text { No siggs of previous } \\
\text { inflammmation }\end{array}$ & Tota \\
\hline No dysplasia/IND & 133 & 83 & 33 & 3 & 93 & 345 \\
\hline LGD & 3 & 12 & 0 & 0 & 0 & 15 \\
\hline HGD & 0 & 2 & 2 & 0 & 0 & 4 \\
\hline CRC & 0 & 1 & 1 & 0 & 0 & 2 \\
\hline Total & 136 & 98 & 36 & 3 & 93 & 366 \\
\hline
\end{tabular}

'Inactive colitis: CRC: Colorectal cancer; HGD: High-grade dysplesia; IND: Indefinite dysplasix LGD: Low-grade dysplasiz

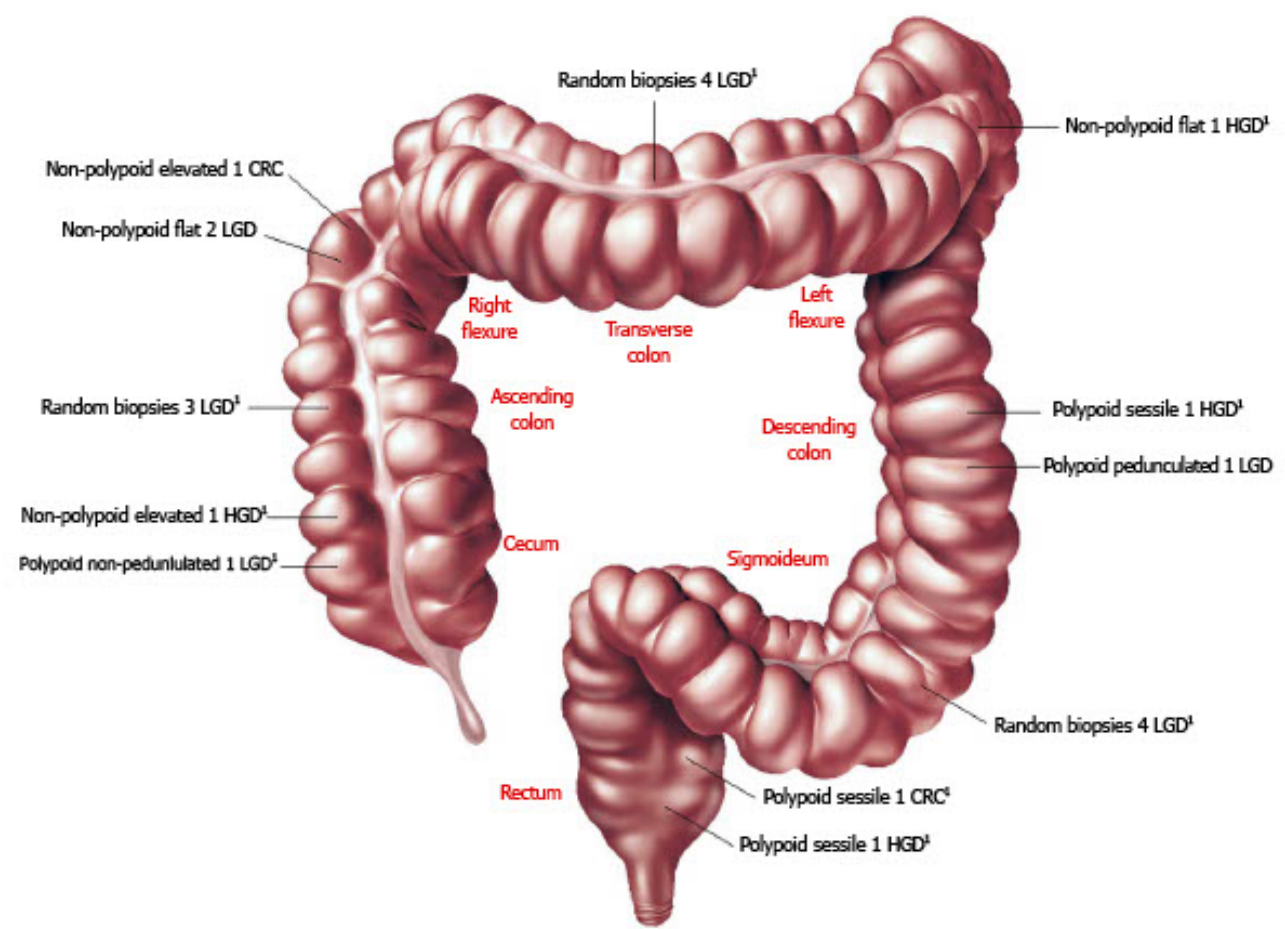

Figure 2 Distribution and findings of endoscopic and histologic evaluation of the 21 total neoplastic lesions found in this study. "Lesions detected in patient with know primary sderosing cholangts.

In the present study, current or previous inflammatory changes were found to be present around all dysplastic lesions, including for nontargeted biopsies harbouring lesions with LGD. These results support the findings of Watanabe et $a^{(22]}$, who suggested that random biopsies may be omitted in the absence of previous or current inflammation.

We recognize that the present study has several limitations. The adenoma detection rate of the endoscopists is not currently implemented in Norway and therefore not available for the endoscopists in the present study. Both endoscopists had however substantial experience in nonCE endoscopy. The present study reflects the everyday clinical world in this location. Each CE was performed with standard and not high-definition endoscopes, which may have affected the detection of lesions. The prospective cohort design of the study minimizes patient selection bias; however, the sample size is moderate, although considerable effort was spent on the inclusion of patients. Patients may have been reluctant to undergo colonoscopy. Low compliance rates for surveillance endoscopy have previously been described, although the reasons remain unclear ${ }^{[23]}$. Additionally, although all the patients in the sample carry an increased risk of colonic neoplasia, the low observed rate of neoplasia resulted in wide CIs around sensitivity estimates for the detection of 
Klepp P et al. Chromoendoscopy for surveillance in UC

dysplastic lesions.

Despite the limitations outlined above, the results of the present study are thought to reflect the real-life scenario of dysplasia surveillance in UC in a communitybased hospital in Norway, which could represent the typical setting in similar hospitals in Europe where CE is not routinely applied.

In conclusion, the present study suggests that, although lacking in previous CE expertise, the endoscopists were able to accurately evaluate the absence of neoplasia. The yield of nontargeted biopsies with LGD was negligible, and LGD appears to be present in mucosa with signs of histologic inflammation. Finally, dysplasia in endoscopically unsuspicious appeaning mucosa seems to occur mostly when visible neoplasia is diagnosed elsewhere in the colon. Although further larger studies are needed, CE seems to be of value for surveillance of neoplasia in UC in a community hospital setting.

\section{ARTICLE HIGHLIGHTS}

\section{Research background}

Patients with longstanding and extensive ulcerafive colitis carry an increased risk of developing colonic neoplasia and are advised to undergo regular colonoscopic surveillance.

\section{Research motivation}

The curent clinical guidelines favour chromoendosoopy with targeted biopsies for dysplasia surveillance of ulcerative colitis. These recommendations, however, are based on studies performed in advanced endoscopic units ans chromoendoscopy is not routinely applied in everyday clinical practice.

\section{Research objectives}

Our aim was to evaluate chromoendoscopy for real-life dysplasia survellance for cases of long-standing ulcerative colitis in a community hospital.

\section{Research methods}

Patients with extensive ulcerative colitis, with disease duration of more than 8 years, were prospectively included in this single cohort study. The chromoendoscopies were performed by two expert endoscopists novice to the method. Lesions were evaluated macroscopically and removed and/or biopsied. Nontangeted biopsies were also taken from each segment of the colon.

\section{Research results}

A total of 21 neoplastic lesions (consisting of 2 carcinomas, 4 high-grade dysplasias and 15 low-grade dysplasias) and 27 nondysplastic lesions were detected in 16 of the 67 total patients included in the study. The dysplasia detection rate was $10.5 \%$ (for 7 of the 67 patients). The dysplasia detection yield was $20.8 \%(10 / 48)$ for targeted biopsies and $3.5 \%$ (11/318) for nontangeted biopsies. The endoscopists accurately evaluated the absence of neoplasia (specificity of $96 \%$, with $95 \%$ confidence interval of $93-98$; and a negative predicive value of $97 \%$, with $95 \%$ confidence interval of $95 \%-98 \%$ ).

\section{Research conclusions}

Although novice to chromoendoscopy, the endoscopists in this Norwegian community hospital accurately evaluated the absence of necplasia. In addition the yield of nontargeted biopsies was negligible.

\section{Research perspectives}

Chromoendoscopy acpears to be of value for dysplasia surveilance for cases of long-standing ulcerative colitis who are treated in a community hospital setting in which endoscopists are novice to the technique.

\section{ACKNOWLEDGMENTS}

The authors thank the staff at the Unger-Vetlesen Research Institute, Lovisenberg Diaconal Hospital and Lars Gustav Lyckander at the Department of Pathology, Akershus University Hospital.

\section{REFERENCES}

1 Rubin DT, Huo D, Kinnucan JA, Sedrak MS, McCullom NB, Bunnag AP, Raun-Royer EP, Cohen RD, Hanauer SB, Hart J, Turner $J R$. Inflanmation is an independent risk factor for colonic neoplasia in patients with ulcerative colitis: a case-control study. Clin Gastroenterol Hepatol 2013; 11: 1601-1608.el-e4 [PMID: 23872237 DOI: 10.1016j.cgh 2013.06.023]

2 Ullman TA, Itzkowitz SH. Intestinal inflammation and cancer Gastroenterology 2011; 140: 1807-1816 [PMID: 21530747 DOI: 10.1053/.gastro.2011.01.057]

3 Magro F, Gionchetti P, Eliakim R, Ardizzone S, Armuzzi A, Barreiro-de Acosta M, Burisch J, Gecse KB, Hart AL, Hindryckx P, Langner C, Limdi JK, Pellino G, Zagórowicz E, Raine T, Harbord M, Rieder F; European Crohn's and Colitis Organisation [BCCO] Third European Evidence-based Consensus on Diagnosis and Third European Evidence-based Consensus on Diagnosis and
Management of Ulcerative Colitis. Part 1: Definitions, Diagnosis, Extra-intestinal Manifestations, Pregnancy, Cancer Surveillance, Surgery, and Ileo-amal Pouch Disorders. J Crohns Colitis 2017; 11 : 649-670 [PMD: 28158501 DOI: 10.1093/ecco-jcc/jjx008]

4 Velayos FS, Loftus EV Jr, Jess T, Harmsen WS, Bida J, Zinsmeister AR, Tremaine WJ, Sandborn WJ. Predictive and protective factors associated with colorectal cancer in ulcerative colitis: A case-control study. Gastroenterology 2006; 130: 1941-1949 [PMD: 16762617 DOI: 10.1053/.j.gastro.2006.03.028]

5 Annese V, Beaugerie L, Egan L, Biancone L, Bolling C, Brandts C, Dierickx D, Dummer R, Fionivo G, Gomet JM, Higgins P, Katsanos KH, Nissen L, Pellino G, Rogler G, Scaldaferri F, Szymanska E, Eliakim R; ECCO. European Evidence-based Consensus: Inflammatory Bowel Disease and Malignancies. J Crohns Colitis 2015; 9: 945-965 [PMID: 26294789 DOI: 10.1093/ecco-jcojjvl41]

6 Eaden JA, Ward BA, Mayberry JF. How gastroenterologists screen for colonic cancer in ulcerative colitis: an analysis of performance. Gastrointest Endosc 2000; 51: 123-128 [PMID: 10650251]

7 Rutter MD, Ssunders BP, Schofield G, Forbes A. Price AB, Talbot IC. Pancolonic indigo carmine dye spraying for the detection of dysplasia in ulcerative colitis. Gut 2004; 53: 256-260 [PMD: 14724160 DOI: 10.1136/gut 2003.016386]

8 van den Broelk FJ, Stokkers PC, Reitsma JB, Boltjes RP, Ponsioen CY, Fockens P, Dekker E. Random biopsies taken during colonoscopic surveillance of patients with longstanding ulcerative colitis: low yield and absence of clinical consequences. Am J Gastroenterol 2014; 109: 715-722 [PMD: 21427710 DOI: 10.1038/ajg.2011.93]

9 Matsumoto T, Nakamura S, Jo Y, Yao T, lida M. Chromoscopy might improve diagnostic accuracy in cancer surveillance for ulcerative colitis. Am J Gastroenterol 2003; 98: 1827-1833 [PMD: 12907339 DOI: $10.1111 /$ j.1572-0241.2003.07580.x]

10 Marion JF, Waye ID, Israel Y, Present DH, Suprun M, Bodian C, Harpaz N, Chapman M, Itzkowitz S, Abreu MT, Ullman TA, McBride RB, Aisenberg J, Mayer L; Chromoendoscopy Study Group at Mount Sinai School of Medicive. Chromoendoscopy Is More Effective Than Standard Colonoscopy in Detecting Dysplasia During Long-term Surveillance of Patients With Colitis. Clin Gastroenternl Hepatal 2016; 14: $713-719$ [PMID: 26656297 DOI: 10.1016/j.cgh.2015.11.011]

11 Konijeti GG, Shrime MG, Ananthakrishnan AN, Chan AT. Costeffectiveness analysis of chromoendoscopy for colorectal cancer surveillance in patients with ulcerative colitis. Gastrointest Endosc 2014; 79: 455-465 [PMID: 24262637 DOI: 10.1016 j.gie.2013.10.026] 
Klepp P et al. Chromoendoscopy for surveillance in UC

12 Mooiweer E, van der Meulen-de Jong AE, Ponsioen CY, Fidder HH, Siersema PD, Dekker E, Oldenburg B. Chromoendoscopy for Surveillance in Inflammatory Bowel Disease Does Not Increase Neoplasia Detection Compared With Conventional Colonoscopy With Random Biopsies: Results From a Large Retrospective Study. Am J Gastroenterol 2015; 110: 1014-1021 [PMID: 25823770 DOI: 10.1038/ajg.2015.63]

13 Schroeder KW, Tremaine WJ, Ilstrup DM. Coated oral 5 -aminosalicylic acid therapy for mildly to moderately active ulcerative colitis. A randomized study. N Engl J Med 1987; 317 1625-1629 [PMID: 3317057 DOI 10.1056NEIM198712243172603]

14 Laine L, Kaltenbach T, Barkun A, McQuaid KR, Subramanian V, Soetikno R; SCBNIC Guideline Development Panel SCENIC international consensus statement on surveillance and management
of dysplasia in inflammatory bowel disease. Gastrointest Endosc 2015; 81: 489-501.e26 [PMID: 25708752 DOI: 10.1016 j.gie.2014.12.009]

15 Gupta RB, Harpaz N, Itzkowitz S, Hossain S, Matula S, Kombluth A, Bodian C, Ullman T. Histologic inflanmation is a risk factor for progression to colorectal neoplasia in ulcerative colitis: a cohor progression to colorectal neoplasia in ulcerative colitis: a cohort
study. Gastroenterology 2007; 133: 1099-1105; quiz 1340-1341 [PMID: 17919486 DOI: 10.1053/j.gastro.2007.08.001]

16 Riddell RH, Goldman H, Ransohoff DF, Appelman HD, Fenoglio CM, Haggitt RC, Ahren C, Correa P, Hamilton SR, Morson BC. Dysplasia in inflanmmatory bowel disease: standardized classification with provisional clinical applications. Hum Pathol 1983; 14 931-968 [PMID: 6629368 DOI: 10.1016/S0046-8177(83)80175-0]

17 Carballal S, Maisterra S, López-Serrano A, Gimeno-García AZ, Vera MI, Marín-Garbriel JC, Diaz-Tasende J, Márquez L, Álvarez MA, Hernández L, De Castro L, Gordillo J, Puig I, Vega P, Bustamante-Balén M, Acevedo J, Peñas B, López-Cerón M, Ricart E, Cuatrecasas M, Jimeno M, Pellisé M; EndoCAR group of the Spanish Gastroenterological Association and Spanish Digestive Endoscopy Society. Real-life chromoendoscopy for neoplasis detection and characterisation in long-standing IBD. Gut 2018; 67: detection and characterisation in long-standing IBD. Gut 2018;

18 Wu L, Li P, Wu J, Cao Y, Gao F. The diagnostic accuracy of chromoendoscopy for dysplasia in ulcerative colitis: meta-analysis of six randomized controlled trials. Coloroctal Dis 2012; 14: 416-420 [PMID: 21073646 DOI 10.1111j.1463-1318.2010.02505.x]
19 Leedham SJ, Graham TA, Oukrif D, McDonald SA, RodriguezJusto M, Harrison RF, Shepherd NA, Novelli MR, Jankowski JA, Wright NA. Clonality, foumder nutations, and field cancerization in human ulcerative colitis-associated neoplasia. Gastraenterolog 2009; 136: 542-550.e6 [PMID: 19103203 DOI: 10.1053 , j.gastro.2008.10.086]

20 Marion JF, Waye ID, Present DH Israel Y Bodian C, Harpaz N, Chapman M, Itzkowitz S, Steinlauf AF, Abreu MT, Ullman TA, Aisenberg J, Mayer L; Chromoendoscopy Study Group at Moumt Sinai School of Medicine. Chromoendoscopy-targeted biopsies are superior to standard colonoscopic surveillance for detecting dysplasia in inflammatory bowel disease patients: a prospective endoscopic trial. Am J Gastroenterol 2008; 103: 2342-2349 [PMID: 18844620 DOI: $10.1111 /$ j. $1572-0241.2008 .01934 . x]$

21 Moussata D, Allez M, Cazals-Hatem D, Treton X, Laharie D, Reimund JM, Bertheau P, Bourreille A, Lavergne-Slove A, Brixi H, Branche J, Gornet IM, Stefanescu C, Moresu J, Marteau P, Pelletier AL, Carbonnel F, Seksik P, Simon M, Fléjou JF, Colombel JF, Charlois AL, Roblin X, Naucey S, Bouhnik Y, Berger F, Flourié B; the GETAID. Are random biopsies still useful for the detection of neoplasia in patients with IRD umdergoing surveillance colonoscopy neoplasia in patients with IBD umdergoing surveillance colonoscopy
with chromoendoscopy? Gut 2018; 67: 616-624 [PMIID: 28115492 with chromoendoscopy? Gut 2018;

22 Watanabe $T$, Ajioka $\mathrm{Y}$, Mitsuyama $\mathrm{K}$, Watanabe $\mathrm{K}$, Hanai $\mathrm{H}$, Nakase H, Kumisaki R, Matsuda $\mathrm{K}$, Iwakin R, Hida N, Tanaka S, Takeuchi Y, Ohtsuka K, Murakami K, Kobayashi K, Iwao Y, Nagahori M, Iizuka B, Hata R, Igarashi M, Hirata I, Kudo SE, Matsumoto T, Ueno F, Watanabe G, Ikegami M, Ito Y, Oba K, Inoue $\mathrm{B}$, Tomotsugu N, Takebayashi T, Sugihara K, Suzuki Y, Watanabe M, Hibi T. Comparison of Targeted vs Random Biopsies for Surveillance of Ulcerative Colitis-Associated Colorectal Cancer. Gastroenterology 2016; 151: 1122-1130 [PMID: 27523980 DOI: 10.1053/.gastro.2016.08.002]

23 Vienne A, Simon T, Cosnes J, Baudry C, Bouhnik Y, Soulé JC, Chaussade S, Marteau P, Jian R, Delchier JC, Coffin B, Admane H, Carrat F, Drouet E, Beaugerie L. Low prevalence of colonoscopic surveillance of inflammatory bowel disease patients with longstanding extensive colitis: a clinical practice survey nested in the CESAME cohort. Aliment Pharmacol Ther 2011; 34: 188-195 [PMID: 21615760 DOI: 10.1111/1.1365-2036.2011.04711]

P- Reviewer: Hiraoka S, Lno H, Tandon RK, Tang ZP S- Editor: Wang XJ L-Editor:A E-Editor: Huang Y

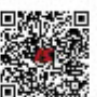

